\title{
Taming of Covid-19: potential and emerging application of mesenchymal stem cells
}

\author{
Nima Najafi-Ghalehlou • Mehryar Habibi Roudkenar • Habib Zayeni Langerodi • \\ Amaneh Mohammadi Roushandeh
}

Received: 26 June 2020/Accepted: 17 February 2021 / Published online: 22 March 2021

(C) The Author(s), under exclusive licence to Springer Nature B.V. 2021

\begin{abstract}
Coronavirus Disease 2019 (COVID-19) caused by the Severe Acute Respiratory Syndrome Coronavirus 2 (SARS-CoV-2) has turned out to cause a pandemic, with a sky scraping mortality. The virus is thought to cause tissue injury by affecting the reninangiotensin system. Also, the role of the overactivated immune system is noteworthy, leading to severe tissue injury via the cytokine storms. Thus it would be feasible to modulate the immune system response in order to attenuate the disease severity, as well as treating the patients. Today different
\end{abstract}

N. Najafi-Ghalehlou

Department of Medical Laboratory Sciences, Faculty of Paramedicine, Tabriz University of Medical Sciences,

Tabriz, Iran

M. H. Roudkenar · A. M. Roushandeh ( $\square)$

Burn and Regenerative Medicine Research Center,

Velayat Hospital, School of Medicine, Guilan University

of Medical Sciences, Rasht, Iran

e-mail: mohammadi_roushandeh@gums.ac.ir

M. H. Roudkenar

Medical Biotechnology Department, Paramedicine Faculty, Guilan University of Medical Sciences, Rasht, Iran

\section{H. Z. Langerodi}

Guilan Rheumatology Research Center (GRRC), Guilan University of Medical Sciences, Rasht, Iran

\section{A. M. Roushandeh}

Anatomical Sciences Department, Medicine Faculty, Guilan University of Medical Sciences, Rasht, Iran medicines are being administered to the patients, but regardless of the efficacy of these treatments, adverse effects are pretty probable. Meanwhile, mesenchymal stem cells (MSCs) prove to be an effective candidate for treating the patients suffering from COVID-19 pneumonia, owing to their immunomodulatory and tissue-regenerative potentials. So far, several experiments have been conducted; transplanting MSCs and results are satisfying with no adverse effects being reported. This paper aims to review the recent findings regarding the novel coronavirus and the conducted experiments to treat patients suffering from COVID19 pneumonia utilizing MSCs.

\section{Keywords SARS-CoV-2 · COVID-19 .}

Mesenchymal stem cells · Renin-angiotensin system · Cytokine storms

\section{Introduction}

Coronaviruses are enclosed pleomorphic viruses, containing the longest genome of all ribonucleic acid (RNA) viruses (Belouzard et al. 2012) which is a positive-sense single stranded RNA viruses with the animals to be the reservoir of these viruses, giving them a zoonotic transmission capability and involving respiratory tract in humans. High rate of mutation and recombination features rapid evolution in these viruses. The novel coronavirus, also known as 
SARS-CoV-2, is the third coronavirus to have raised concerns of a pandemic, with according to the world health organization (WHO) 72.8 million of confirmed cases as of December 16, 2020. The novel coronavirus is supposed to have originated from the horseshoe bat and then transmitted to the humans. SARS-CoV-2induced pneumonia, manifesting like the flue regarding the key symptoms (Gentile et al. 2020d) is diverse in symptoms, varying from the asymptomatic cases to critical and severe cases, with the former requiring intensive care unit (ICU) and the latter being common among the elder people or ones with underlying illnesses such as cardiovascular disease, chronic kidney disease, diabetes mellitus, etc. (Novel 2020) Novel 2020Error! Bookmark not defined. The common symptoms include fever, cough, and difficulty breathing. There are also clinical manifestations, due to the spread of the virus to the other organs and secondary infections, besides from the respiratory tract, such as acute respiratory distress syndrome (ARDS) and acute heart damage (Hamming et al. 2004), sepsis, septic shock, and multiple organ dysfunction syndromes (MODS) (Wang et al. 2020). The main infectious mechanism of the virus is quite dependent on the expression of a specific receptor, referred to as the angiotensin-converting enzyme 2 (ACE2) receptor, as well as the cellular transmembrane protease, serine 2 (TMPRSS2) (Hoffmann et al. 2020), elaborating why the virus involves almost every organ in the body. To precisely report the infection status, reverse-transcription PCR (RT-PCR) is performed, as well as the computerized tomography (CT) of the chest, which could be reliable. To date, there is no cure for the COVID-19, and the most common treatment for severe patients remain to be supportive care, including fluid conservation, (non)invasive supplemental oxygen, and mechanical intubated ventilation support if necessary, along with the administration of vitamins, convalescent plasma, and safety-approved pharmacokinetic medications, including the anti-malarial drug hydroxychloroquine, interleukin 6 (IL-6), receptor inhibitor tocilizumab, Janus kinase (JAK) inhibitor baricitinib, interleukin 1 receptor antagonist (IL1RA) anakinra (Al-Khawaga and Abdelalim 2020), and viral fusion inhibitor camostat mesylate, thus leaving no better choice than to avoid the crowd and stay indoors. Also, frequent usage of detergents and disinfectors would be useful in disease prevention. Besides, given that the cure of
COVID-19 is essentially dependent on the patient's own immune system (Sairam Atluri et al. 2020), some treatment methods have been proposed and several studies are being conducted, among which, transplantation of mesenchymal stem cells can be a reliable solution to treat the patients, owing to their immunomodulatory and tissue-regeneration properties. According to the reports, transplanting MSCs to the patients have also been free of any adverse effects, turning them into a convenient candidate for curing the COVID-19 patients. In this review we are going to highlight the role of MSCs in treatment of COVID-19 patients according to the evidence published in the past and the registered clinical trials worldwide.

\section{Coronaviruses}

Coronaviruses of the Nidovirales order, Coronaviridae family, and Coronavirinae subfamily (Gentile and Sterodimas 2020b), are positive-sense single-stranded (ss)RNA sized 30-32 Kb (Dubey et al. 2020), enveloped, nonsegmented, and pleomorphic viruses, terminology of which is derived from solar corona like appearance of the spikes in electron microscopy. Coronaviruses are subcategorized into four genera; alphacoronavirus, betacoronavirus, deltacoronavirus, and gammacoronavirus, among which SARS-CoV, SARS-CoV-2 and Middle East Respiratory Syndrome Coronavirus (MERS-CoV) belong to the betacoronaviruses, known to be circulating among species). It is likely that all known coronaviruses have an animal reservoir with the zoonotic transmission (Cui et al. 2019), and frequently infect humans by peridomestic animals serving as intermediate hosts (Paules et al. 2020), generally causing cytopathic changes following the replication in the respiratory and enteric epithelial cells, bringing respiratory and gastroenteritis symptoms in human and animal hosts, respectively. The severity of illness ranges from the common cold to severe and fatal disease (Rasmussen et al. 2020). Human coronaviruses are capable of infecting up to one-third of the upper respiratory tract in adults. Of note, 229E, NetherLand 63 (NL63), Organ Culture 43 (OC43), and Hong Kong University 1 (HKU1) are other coronaviruses infecting only the upper respiratory system (Fehr and Perlman 2015) with limited disease severity, as most symptoms in the 
immunocompetent host will not be more severe than the common cold.

Two-thirds of the viral RNA encodes RNA-dependent RNA polymerase (RdRP) enzyme, RNA synthesis components, and two non-structural polyproteins, open reading frame 1 alpha (ORF1a) and ORF1b, with no role in modulating the host response. One-third of the viral genome encodes four structural proteins including spike (S), envelope (E), membrane (M), and nucleocapsid $(\mathrm{N})$, as well as other proteins functioning as helpers (Luk et al. 2019; Sahin et al. 2020). Coronaviruses are characterized by moderate to high rate of mutation ( $\mathrm{Su}$ et al. 2016). The occurrence of nurturing recombination, errors during replication, as well as deletion, substitution and insertion mutations in the genome can be attributed to the discontinuous transcription, as RdRP performs template-switching property and jumps during the replication. This leads to genetic changes in the progeny virus, rapid evolution, altered virulence, resistance to antivirals, and adaptation with a variety of hosts (Drexler et al. 2010; Simon-Loriere and Holmes 2011). Therefore, one of the critical mechanisms of these viruses in evolution can be attributed to gene expression strategy through substitutions in their nucleotides (Lauring and Andino 2010).

\section{The novel coronavirus}

The novel coronavirus, named by the International Committee on Taxonomy of Viruses, SARS-CoV-2, also commonly known as $2019-\mathrm{nCoV}$, is the seventh human coronavirus and fifth betacoronavirus with a diameter of 80-120 nm (Li et al. 2020c) known to be sharing the same family with SARS-CoV, MERS$\mathrm{CoV}$ and rest of the common cold viruses ( $\mathrm{Su}$ et al. 2016). COVID-19 outbroke in December 2019 in Wuhan, China, the capital of Hubei province, which according to the WHO has left, As of December 16, 72.8 million confirmed cases globally, out of which 1.62 million have passed away, and 41.3 patients have recovered. There are various hypotheses regarding how humans are infected with the virus, highlighting the role of the Huanan Seafood Wholesale Market as the point of origin for the illegal sale of wild animals (Wenjie 2019). Thus, the virus is thought to have infected the humans through an intermediate host ( $\mathrm{Lu}$ et al. 2020), such as pangolin (Lam et al. 2020), snake
(Ji et al. 2020), civet cat, mink, or other wild animals (Lam et al. 2020; Lu et al. 2020). However, Rhinoliphus affinis, also known as horseshoe bat, is recognized as the maintenance host for SARS-related coronaviruses. According to Xingguang $\mathrm{Li}$ et al. (2020b) BetaCoV/bat/Yunnan/RaTG13/2013 virus, is more similar to SARS-CoV-2 than pangolin coronavirus, as both belong to the same subgroup and share $70 \%$ of genomic similarity. Peng Zhou et al., (Zhou et al. 2020a) have also reached parallel results, as a short RdRP region in BatCoV RaTG13, a bat coronavirus, is very similar to the genomic sequence of novel Coronavirus (nCoV-2019) and is mentioned as the reservoir of the virus. While based on Tao Zhang et al. (2020b) Pangolin-CoV is $91.02 \%$ and $90.55 \%$ identical to SARS-CoV-2 and BatCoV RaTG13, respectively. Therefore, pangolin is the probable reservoir of the virus, and the virus is transmitted as the consequence of sequential recombination between the precursors of bat SARS-related coronaviruses, then transmitted to the intermediate host, and ultimately to the humans. Studies have also shown that the virus exhibits genetic divergence behavior after infecting each host cell.

Based on genome sequencing data released on January 3, 2020, the novel coronavirus has a genome of $29.9 \mathrm{~kb}$, encoding 29 proteins with $79 \%$ homology with the SARS virus sequence (Rodriguez et al. 2020). In fact, like other beta-coronaviruses, it has a long ORF1ab polyprotein at the $5^{\prime}$ end, followed by four crucial structural proteins; the spike surface protein, small envelope protein, matrix protein and nucleocapsid,) accompanied by three deletion mutations and 42 missense mutations in the genomic sequence of all major structural and nonstructural proteins, including eight substitution mutations in spike surface glycoprotein, one substitution mutation in matrix protein, four substitution mutations in the nucleocapsid protein, two deletion mutations (3 nucleotides and 24 nucleotides) and 29 substitution mutations in the ORF1ab polyprotein, and another deletion mutation (10 nucleotides) at the $3^{\prime}$ end of the genome (Phan 2020). The abovementioned mutations end up to the frequent recombination across the genomes and probably generation of new strains (Gupta et al. 2020). 


\section{Clinical features}

COVID-19 is an emerging resolved acute infection at the animal-human interface, and the patients are classified into mild, moderate, severe, and critical types. The clinical spectrum vary from asymptomatic or paucisymptomatic forms to mild upper respiratory tract symptoms, progressive respiratory syndrome and life-threatening viral pneumonia, or progressive hypoxemia involving both lungs simultaneously in severe stages (Huang et al. 2020b; Wang et al. 2020), leaving the patient in need of mechanical ventilation in the ICU. The disease is studied in four stages, as are early, progressive, peak and absorption (Pan and Ye 2020), and CT findings prove to be useful in determining the severity of the disease, as in most ICU patients developing severe pneumonia (Chen et al. 2020b; Huang et al. 2020b; Wang et al. 2020), bilateral multiple lobular and subsegmental consolidation, and in non-ICU patients, bilateral ground-glass opacity (GGOs) and subsegmental consolidation have been observed (Huang et al. 2020b). It is noteworthy that COVID-19-induced pneumonia should be differentiated from Streptococcus pneumonia, Mycoplasma and Chlamydia-related pneumonia, and other coronavirus infections (de Wit et al. 2016; Malainou and Herold 2019).

The incubation period regarding the incubation period of SARS and MERS viruses, as well as the available traveling data, is approximately 2-14 days (median of 5 days) (Li et al. 2020a) after infection. Studies have also shown that the incubation period of patients with lesser exposure to the infection sources turns out to be longer (Leung 2020), with a maximum of 8 weeks (Backer et al. 2020). However, as the mean interval (3-8 days) shows up earlier than the end of incubation, the carriers are contagious before the presentation of symptoms (Gentile and Sterodimas 2020a).

Symptoms occur after 4-6 days of incubation, including fever, cough, shortness of breath (Chen et al. 2020b), anosmia, bone pain, impaired taste, dyspnea, breathing difficulties, malaise, leukopenia, thrombocytopenia, lymphopenia, along with the elevated levels of neutrophils (Chan et al. 2020), C-reactive protein (CRP), and increased titers of $\mathrm{IgG}$ and IgM antibodies (Zhou et al. 2020a) in the prodromal phase (Chan et al. 2020; Chen et al. 2020b; Huang et al. 2020b). Raised levels of pro- inflammatory and anti-inflammatory cytokines (CKs), such as interleukin-10 (IL-10) have also been reported in plasma, which might be associated with disease severity (Huang et al. 2020b; Wong et al. 2004). Some patients have also developed nausea before the fever, headache or hemoptysis (Guan et al. 2020), sneeze, confusion, chest pain (Rothe et al. 2020; Van Cuong et al. 2020), chills, fatigue or myalgia, several patchy shadows in both lungs based on chest radiography imaging observations (Xu et al. 2020b), elevation in serum levels of either of the aspartate aminotransferase (AST) or alanine aminotransferase (ALT) enzymes (Chen et al. 2020b; Huang et al. 2020b), gastrointestinal symptoms such as diarrhea (Zhu et al. 2019) and upper respiratory symptoms such as rhinorrhea. However, older adults, specially males with a median age of 59 (Chen et al. 2020b), persons with underlying health conditions, such as obesity, hypertension, respiratory disease, endocrine metabolic disease, cardiovascular disease, chronic kidney disease, or diabetes mellitus, as well as persons with compromised immune systems are likely to develop more severe symptoms (Novel 2020). According to WHO, not all COVID-19 patients develop the symptoms as mentioned earlier and roughly 1 out of 6 among the infected develop difficulty breathing, thus approximately $80 \%$ of the infected recover. Newborn babies from the infected mothers may also be subject to the infection. According to two reports of 18 infected mothers in the third trimester, all neonates tested negative for the COVID-19. Still a baby tested positive who was born from a mother suffering from the COVID-19 in London (Chamseddine et al. 2020).

Complications include acute lung injury (ALI), ARDS, characterized by osmotic gradient disruption and impaired alveolar fluid clearance (AFC), interstitial edema, acute heart damage, following the inflammation in the cardiac muscles, resulting in myocardium degeneration, occasional necrosis, and cardiac arrest. Besides, acute renal injury is reported, as proteins or blood is detected in the urine of half of the patients, due to the exudation in the glomerulus leading to kidney failure, and no treatment choice but dialysis or kidney transplantation. Other complications include reduction and damage of spermatogenic cells in testis, brain congestion, pancreatic islet cell degeneration, large necrosis of neutrophil infiltration in hepatocytes (Gentile et al. 2020b), and respiratory failure (Gentile 2019, a, c, d), septic shock (Zhu et al. 
2019), sepsis, multiple organs dysfunction syndrome (MOD) (Del Rio and Malani 2020; Wu and McGoogan 2020), secondary infections, and pneumothorax, that can lead to death, due to multiple organs failure. In some hospitals, patients are given prophylactic antibiotics to prevent secondary infections, in addition to decrease lung inflammation, due to the high levels of cytokines (Huang et al. 2020b).

In addition, ARDS is characterized by diffused pulmonary capillary endothelium and alveolar epithelium damage with osmotic gradient disruption, impaired AFC hyaline membrane formation, proteinrich noncardiogenic pulmonary edema (Force et al. 2012), hemorrhage, and intra-alveolar fibrin deposition, which may be further classified by $\mathrm{PaO}_{2} / \mathrm{FiO}_{2}$ (PF) ratio, as PF ratio of 200-300 indicates mild ARDS, PF ratio of 100-200 indicates moderate ARDS, and PF ratio of $<100$ indicates severe ARDS. At the moment, there is no specific cure for ARDS, but supportive care, including mechanical ventilation, prone positioning ventilation, and fluid management are used (Fan et al. 2018).

The virus can be detected in saliva (To et al. 2020), sputum (Lin and Gong 2020), bronchoalveolar lavage (Zhu et al. 2020a,2020b), throat (Bastola et al. 2020), and nasopharyngeal swabs (To et al. 2020) 1-3 days before the onset of symptoms, and the viral load peaks on the day of symptom onset, but declines steadily over time (Gentile et al. 2017b). Accordingly, the virus transmission, parallel to the influenza, SARS, and MERS is likely to have an airborne route. In other words, the virus is transmitted among individuals through close contact and large respiratory droplets (Perlman and Netland 2009) or secretions of the infected patients. Also the spread of the virus among health care workers might be due to contact of the mucosae with small irresistible respiratory drops (Gentile and Garcovich 2019a; Van Cuong et al. 2020), aerosol, and inoculation via fomite-to-face contact (Guan et al. 2020; Zhou et al. 2020b). Thus, mouth, nose, or eyes are the transmit gates of the disease through infected air droplets, as well as contaminated surfaces and fabrics (Gentile et al. 2019a). Besides, given that the virus is further found in stool specimens, fecal-oral transmission can also be of transmission means (Holshue et al. 2020). However, it's still unknown whether intrauterine can be of the transmission pathways of the virus (Chen et al. 2020a).
Molecular techniques, serology, microbial examination, and virus culture are among the diagnostic strategies used to detect SARS and MERS viruses. RT-PCR or real-time PCR analysis of respiratory fluids is of the molecular methods to detect the positive nucleic acid of the virus. Antibody detection is less sensitive than molecular methods, and the virus culture of respiratory fluids is also time-consuming. Also, utilizing chest CT images can be helpful in early-stage disease detection and estimation of the disease course, as most patients have specific patterns in CT images (Kanne 2020). In fact, the viral activity results in diffuse alveolar damage with cellular fibromyxoid exudates, GGO lesions, and hazy increase in attenuation.

In RT-PCR, which is the standard reference method for virus detection, the target genes include the $\mathrm{N}, \mathrm{S}$, and ORFlab genes (Wong et al. 2020). Samples from the upper respiratory tract such as oropharyngeal swab, sputum, and nasopharyngeal aspirate (Tay et al. 2020), and lower respiratory tract, such as, expectorated sputum, deep tracheal aspirate, and bronchoalveolar lavage can be collected, and PCR would be performed after whole-genome sequencing and cell culture (Murdoch and French 2020). But factors such as sample type regarding the lower /upper respiratory tract sample, sampling error, specimen collection technique, and lack of early RT-PCR assay due to low load prove to be effective in false-negative results and makes it difficult for quick detection of the virus (Chan et al. 2020). In fact, the viral load in the upper respiratory tract is lower than the lower airways, and the peak of viral load in the upper respiratory tract and stool is observed on day 7-10 of the disease (Gentile et al. 2020e). Studies on patients in Singapore also indicate that the higher the virus load is, the lower RTPCR cycle threshold values will be (Wong et al. 2020). It is noteworthy that following a PCR test, chest imaging should be performed and the possibility of common viral and bacterial pneumonia should be ruled out (Huang et al. 2020b). However, for patients with severe respiratory symptoms, antibiotics should be prescribed, like bacterial pneumonia and COVID19 are not often possible to differentiate.

Performing enzyme-linked immunoassay (ELISA) tests to measure the levels of $\operatorname{IgG}, \operatorname{IgA}$, and $\operatorname{IgM}$ antibodies, as well as antigen detection with rapid diagnostic test (RDT) for the immunoglobulins (IgG 
and $\operatorname{IgM}$ ) protein detection reagents can also be considered useful in detecting the viral infection.

\section{Control and prevention}

Based on the experience with different epidemics, the impact of each epidemic depends on the number of the infected individuals, transmission of the infection and severity of its clinical symptoms (Lipsitch et al. 2020). Also, the role of asymptomatic contacts (Rothe et al. 2020) in the continuous transmission is not ignorable, as the carriers developing no symptoms can expose the naïve to the virus (Lipsitch et al. 2020) and account for $1 \%$ of virus transmission during the incubation period (Gentile et al. 2020a). The number of people infected with COVID-19 within a short period is more substantial than SARS and MERS (Rasmussen et al. 2020), and spread of the virus occurs at a time when other coronaviruses cause colds (Dawood et al. 2020), so other infectious pathogens such as influenza can also affect control of the viral infection. To control the spread of the virus, several strategies such as diagnosis, treatment, and quarantine of individual with suspected symptoms including respiratory problems, fever, and sore throat should be designed to prevent further transmission of the virus among individuals and reduce the chance of secondary infection due to close contact. Close contact would be defined as distance of about $2 \mathrm{~m}$ (6 feet) from a person with COVID-19 infection or direct contact with secretions of a confirmed COVID-19 patient (Alhazzani et al. 2020). Individuals at high risk of infection with the virus, such as underlying illness as well as repeated virus testing, also play a crucial role in controlling the spread course. Recommendations provided by the WHO on preventive actions such as staying home, avoiding meetings and crowds, attending virtual classes, reducing office hours and focusing more on teleworking, preventing unprotected contact with live animals, especially animals that are suspected to be the reservoir of the virus, cooking meat and eggs well done, avoiding people with cold symptoms, temperature screening at land, air and sea checkpoints, encouraging the public to use detergents for continuous hand disinfection, and to wear face masks and respirators with an adequate seal and directed movement through the filters (Smith et al. 2016; Tran et al. 2012) can reduce the cumulative mortality rate caused by the virus and be a practical step towards lowering the pandemic peak and developing countermeasures in the field of vaccine design, diagnosis and treatment (Qualls et al. 2017). Besides, assessing the immune response to infection can also be useful in the vaccine design pathway. Various clinical trials are also underway, but it may take weeks or maybe months for the definite results to come out. Various therapeutic strategies, including neutralizing antibodies, passive antibody transfer from convalescent patients' sera, noninvasive and invasive respiratory therapy, blockade of rampant generation of pro-inflammatory mediators, viral capsid protein degradation by PROTACs, and development of blocking agents that bind to the ACE2 receptor (Lu et al. 2020; Zhou et al. 2020b) are also presumed. It is noteworthy that the vaccination and passive antibody transfer from convalescent plasma require stable viral epitopes for their efficacy. For this purpose, transferring viral surface glycoprotein epitopes onto the exosomes surface, including 5 CTL epitopes, 3 sequential B cell epitopes, 5 discontinuous B cell epitopes (Baruah and Bose 2020), 13 major histocompatibility class I (MHC-I), and 3 MHC-II antigenic epitopes would prove to be useful in vaccine development. Administration of chloroquine and hydroxychloroquine has also had positive effects on patients (Yao et al. 2020). Although there is no cure for the COVID-19 patients', several experimental approaches, including human immunodeficiency virus (HIV) antivirals, corticosteroids, old malaria drugs, danoprevir, favipravir, hydroxychloroquine, Interferon-a2b(IFN- $\alpha 2 b)$, chloroquine phosphate, and arbidol (Gentile et al. 2020c), and also coprescription of lopinavir and rotinavir are being tested in patients around the world. It has been shown that, protease inhibitors lopinavir and ritonavir are effective in patients with SARS and ribavirin in patients with MERS. Of note, the abovementioned immunosuppressive medications could not be administered in long term, due to the broad inhibition of the anti-viral immunity (Al-Khawaga and Abdelalim 2020). 


\section{Molecular pathogenesis of COVID-19 by focusing on cytokine storms and renin angiotensin system and crucial role of angiotensin II as a signaling of tissue injuries}

Alveolar epithelium of the lungs consists of a monolayer of alveolar type 1 (AT1) epithelial cells and AT2 cells, connected via the tight junctions to control the flow of alveolar fluid and ions, such as $\mathrm{Na}^{+}$and $\mathrm{Cl}^{-}$ across the epithelial transporters (Ware and Matthay 2001), and the alveolus expansion along with surface tension reduction is further facilitated by the AT2secreted surfactant, covering the alveolar epithelium. AT2 cells along with resident alveolar macrophages are the first cells to be infected by SARS-CoV-2 in the lung and virus entry into the host cell depends on a highly glycosylated homotrimeric S glycoprotein, affinity of which for the cell surface receptor is 10-20 times more than of SARS (Gentile et al. 2019b). The first step for SARS-CoV-2 to infect a cell is the receptor-binding domain (RBD) of the $\mathrm{S} 1$ subunit of the spike bind to the target cell receptor, which is the ACE2, a dimeric type I membrane protein consisting of $\mathrm{N}$-terminal peptidase domain (PD) and C-terminal collection-like domain (CLD) ending with $\sim 40$ residues intercellular segment and forming single transmembrane helix (Gentile et al. 2019c). It can be speculated that the presence or absence of cleavage between the gp120 and gp41 of the S2 subunit of spike can significantly affect host transferability and diversity ( $\mathrm{Li}$ et al. 2020b). Thus, the spike surface glycoprotein plays a vital role in binding to the host cell receptor ( $\mathrm{Lu}$ et al. 2020), and possibly the S protein, present in the envelope, establishes the subsequent junctions between the virus and the host membrane through binding to the ACE2 of host cell and eventually the virus infects the cell (Kirchdoerfer et al. 2016; Xu et al. 2020a), which leads to uncoating, translation of viral components, and suppression of ACE2 expression. Following the formation of structural proteins, nucleocapsids assemble in the cytosol, inward bud into the lumen of the endoplasmic reticulum (ER)-Golgi transitional compartments, and structural proteins are released via exocytosis (Alanagreh et al. 2020). ACE2 is an aminopeptidase membrane enzyme of the renin angiotensin system (RAS) which is expressed in myocardial and pulmonary cell membranes, such as AT2, and has a counter-regulatory effect on the RAS by converting Angiotensin II, a vasoconstrictor, into Angiotensin (1-7), which eventually would cause tissue protection by binding to the Mas receptor, perform anti-inflammatory effects by producing nitric oxide (NO), as well as vasodilation effects, which lowers blood pressure (South et al. 2019). On the other hand, ACE converts Angiotensin I into Angiotensin II, which then binds to the type 1 Angiotensin receptor (AT1R) and cause tissue injury by performing pro-inflammation effects, which results in higher blood pressure, and vasoconstriction effects, followed by increased oxidative stress (Sparks et al. 2014). Hoffmann et al., also highlight the role of TMPRSS2 in proteolytic cleavage of ACE2 and priming the S protein by TMPRSS2 (Hoffmann et al. 2020). Therefore, it can be expected that maintenance of the balance in the function of the ACE and ACE2 would partly contribute in the tissue protection or tissue injury, respectively. Of note, nCoV-2019 wouldn't bind to aminopeptidase $\mathrm{N}$ and dipeptidyl peptidase 4 receptors, unlike the other coronaviruses (Zhou et al. 2020a).

Almost all endothelial cells and smooth muscle cells in bronchial, tracheal and alveolar epithelial cells in the lung, monocyte and macrophage, heart, liver, kidney, testis (Gentile and Garcovich 2019b), lymph nodes, spleen, gallbladder, stomach, duodenum, and small intestine in the digestive tract express the ACE2 receptor, explaining why the virus spreads throughout the body as it finds its way to the bloodstream with the exception of thymus, bone marrow, MSCs, and other immune cells (Hamming et al. 2004). Of note, the intrinsic expression of interferon stimulating genes (ISG) makes pluripotent and multipotent stem cells resistant to viral infections (Zhang et al. 2020a). After the virus entry, genome encoding is performed for facilitating gene expression and synthesis of accessory proteins, as well as determining host tropism and disrupting the expression of neutralizing antibodies (Yu et al. 2020), making the virus capable of adapting to host cell (Sahin et al. 2020). At this point, the viral RNA becomes encapsulated and polyadenylated, and the synthesized polyproteins are affected by proteases that exhibit chymotrypsin-like activity (Lambeir et al. 2003; Sahin et al. 2020). Negative sense mRNAs are also synthesized for transcription, which are shorter than the viral genome. In contrast, negative sense RNA is synthesized similar to the viral genome, serving as a template for the synthesis of the positivesense RNA (Luk et al. 2019; Sahin et al. 2020). For the 
virus to leave the cell, genomic RNA and R protein assemble first, bud from the membrane of the host endoplasmic reticulum, and finally get out of the cell through exocytosis.

The fatality of the virus may be attributable to the severe injury and bleeding in the airways and progressive respiratory failure (Chan et al. 2020; Huang et al. 2020b). Overexpression of T cells, more precisely natural killer (NK) cells, $\mathrm{CD} 4^{+} \mathrm{Th} 1$ and Th17 and high cytotoxicity of $\mathrm{CD}^{+} \mathrm{T}$ cells also play an essential role in the severity of clinical symptoms. In fact, over-activation of immune system in response to the virus, thus an imbalance between pro-inflammatory and anti-inflammatory cytokines leads to severe hemophagocytic lymphohistiocytosis (HLH)like cytokine storms, characterized by the expansion of tissue macrophages and overwhelming localized secretion of pro-inflammatory cytokines into the alveolar spaces by neutrophils and macrophages, such as IL-2, IL-6, IL-7, IL-8, Th2-secreted IL-10, IL-1 $\beta$, Th1-secreted interferon gamma (IFN- $\gamma$, monokine induced gamma interferon (MIG), macrophage inflammatory protein 1 (MIP-1), MIP-2, mononuclear phagocytes cells-1 (MPC-1) (Huang et al. 2020a), CXCL-1, CXCL-2, CXCL-10, TNF- $\beta$, proteases like metalloprotein (MMP)-2, MMP-9 and MMP-12, granulocyte-colony stimulating factor (G-CSF), interferon-gamma-induced protein 10 (IP10), monocyte chemoattractant protein-1 (MCP-1), macrophage inflammatory protein-1 alpha (MIP1A), macrophage inflammatory protein-1 beta (MIP1-B), CRP, and TNF $\alpha$, G-CSF, IP10, MCP-1, MIP1A, MIP1-B (Fig. 1) (Huang et al. 2020b); which subsequently leads to reactive oxygen species (ROS) production, endothelial and epithelial cells damage, intercellular junctions disruption, impaired attachment to the basement membrane, increase permeability of the epithelial cells, migration of inflammatory cells, influx of red blood cells (RBCs) from the capillary, epithelial and interstitial edema (Thompson et al. 2017), accelerate accumulation of extracellular matrix (ECM) factors, formation of an alveolar-capillary barrier, excessive extracellular calcium levels, myocyte, resident and immune cells apoptosis, lymphocytopenia, impaired AFC, cell swelling and death (Al-Khawaga and Abdelalim 2020), fibrin deposition, hyaline membrane formation, carbon dioxide diffusion disorders, air exchange dysfunction, alveolar proteinaceous exudate accumulation, hypoxemic respiratory failure, and ARDS within 8-9 days after symptom onset. The influx of lymphocytes into the airways may correlate with the high neutrophil/lymphocyte ratio, increase Th/regulatory $\mathrm{T}$ cells (Treg cells) ratio, and lymphopenia (Qin et al. 2020). Therefore, prevention the cytokine storms can be a crucial strategy in the treatment of COVID-19 patients. There is no effective treatment for the COVID-19 pneumonia at the moment, especially for severe and critical cases, however conventional treatments for these patients include administration of glucocorticoid, danoprevir, lopinavir + ritonavir, hydroxychloroquine, favipiravir, methylprednisolone, umifenovir, and interferon alpha, but most of these are accompanied by side effects. Another safe candidate is transplanting mesenchymal stem cells for their immunomodulatory properties in attenuating and preventing cytokine storms. As these cells are widely used for treating type II diabetes, autoimmune disease, spinal cord injury, graft versus host disease (GvHD), and systemic lupus erythematosus (SLE) (Kamen et al. 2018), so administration of the MSCs might prove effective in reducing mortality and morbidity in patients (AlKhawaga and Abdelalim 2020; Le Blanc et al. 2004; Rogers et al. 2020).

\section{Mesenchymal stem cell}

Mesenchymal stem cells, also referred to as mesenchymal stromal cells are non-hematopoietic, matrix-derived, spindle-shaped and fibroblast-like progenitor cells with CD73, CD90, CD105, CD29, CD44, CD146 and CD166 surface markers (Gentile et al. 2014b) found in almost all tissues with multiple differentiation capabilities and self-renewal potentials (Pittenger et al. 1999; Rad et al. 2019). Based on their differentiation potential, they are categorized into three groups; pluripotent, multipotent, and unipotent, and can be stimulated to differentiate into mesodermal lineages including adipocytes, osteoblasts, and chondroblasts, as well as myocytes (Bianco 2014), or even transdifferentiate into ectodermal and endodermal cells such as hepatocytes, neurons, and epithelial cells. MSCs can be isolated from different tissues of an adult, including bone marrow, umbilical cord (UC), UC-derived Wharton's jelly, placenta (da Silva Meirelles et al. 2006), adipose tissue, liver, tooth root, hair follicle (Gentile et al. 2019d), perivasculature, 


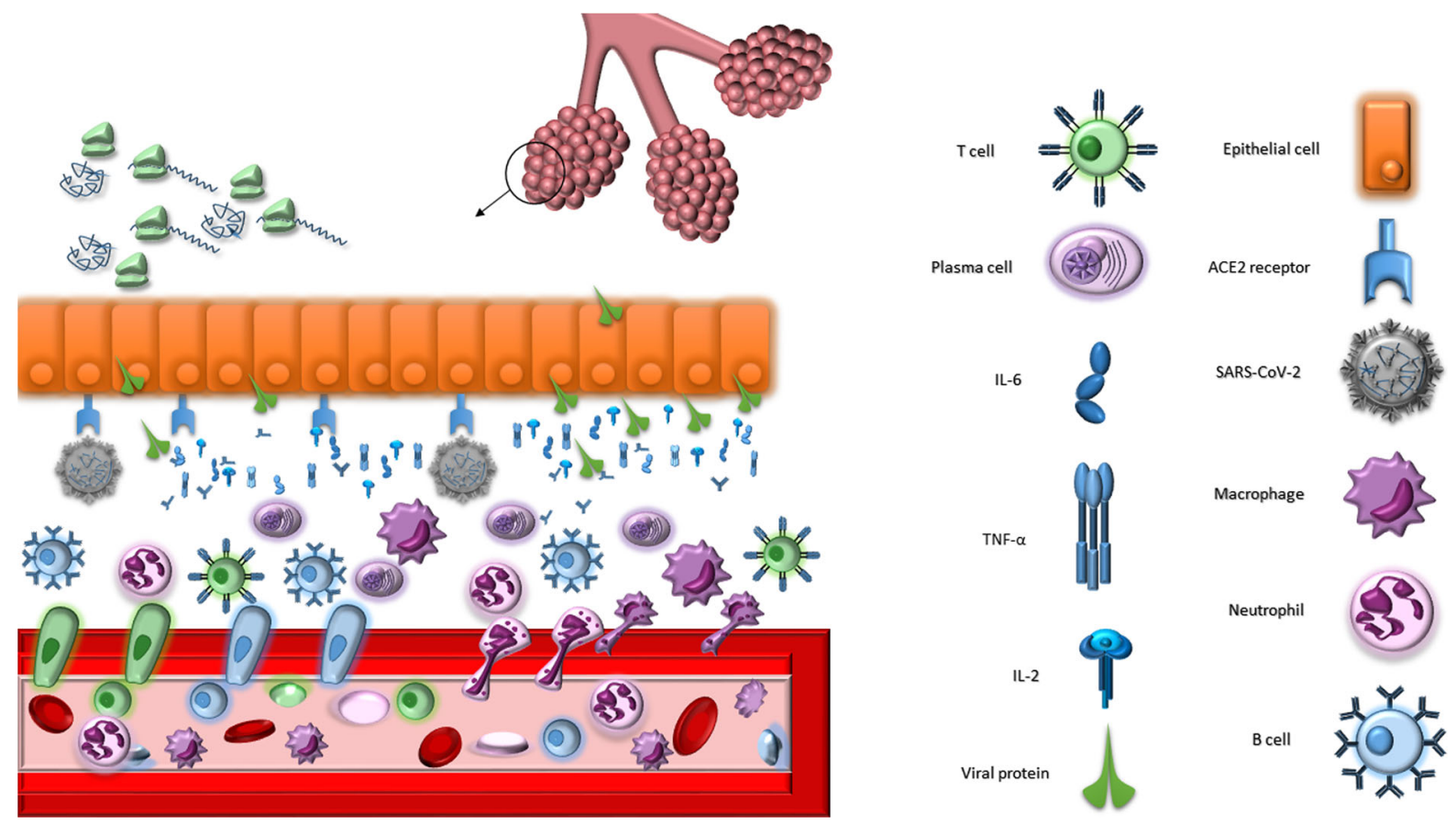

Fig. 1 Shows how the virus exerts its toxicity in cells. As the virus enters the cell after being recognized by the ACE2 receptor, along with the viral replication and transcription to produce viral proteins, the expression of the ACE2 is also suppressed, resulting in pro-inflammatory, vasoconstriction, and finally tissue injury. Furthermore, over-activation of the immune system leads into diapedesis and accumulation of the immune cells, such as T cell, B cell, macrophage, and monocyte in the site of injury, which results in cytokine storms and high

muscle, dermis, menstrual blood, synovial fluid, endometrium, amniotic fluid, cord blood, and even bloodstream (Pollard 2004), but based on preliminary observations, it is likely that MSCs of various sources may prove to be different regarding the immunomodulatory and tissue-protective properties, as well as levels of secretory factors (Melief et al. 2013b; Roushandeh et al. 2017). Additionally, aging is related to cell senescence and stem cells of elderly patients are less potent than fetal stem cells, regarding proliferative, secretory, and differentiation capabilities. However, embryonic stem cells and iPSCs are tumorigenic (Sairam Atluri et al. 2020). Adult stem cells are exempt from ethical restrictions and possess excellent tissue repair capabilities, low immunogenicity and tumorigenicity, thus the usage of adult stem cells has been more popular than embryonic or pluripotent stem cells (Scioli et al. 2017). Ability of migration and homing to sites of inflammation and damaged tissue level of expression of inflammatory cytokines, such as IL-2, IL6 , TNF- $\alpha$, and the secreted antibodies from B cell-derived plasma cells, causing cytotoxic effects on the epithelial cells in the respiratory tract, as well as other organs infected by the virus, such as the heart, liver, and kidney. This in turn would cause clinical manifestations of the disease. ACE2 angiotensinconverting enzyme 2, IL-2 interleukin 2, IL-6 interleukin 6, $T N F-\alpha$ tumor necrosis factor alpha

via the stromal-derived factor-1- chemokine receptor 4 (SDF-1-CXCR4) signaling axis, secreting paracrine factors, such as immunoregulatory, angiogenic, antiapoptotic, and cell migration factors (Xiao et al. 2020), to the site of injury, releasing multiple cell protective, survival and proliferation factors to decrease cell death, clearing alveolar fluid, secreting growth trophic factors, regenerative molecules, extracellular vesicles (EVs), cytokines, chemokines, and anti-microbial peptides, as well as exerting anti-inflammatory, immunomodulatory, and anti-fibrotic functions (AlKhawaga and Abdelalim 2020) by secretion of cytokines, growth factors (GFs), chemokines, antiinflammatory mediators, and extracellular vesicles (EVs) including exosomes and microvesicles (MVs), controlling inflammation by altering adjacent immune cells (Bernardo and Fibbe 2013), and modulating, regulating, and suppressing the immune response are also of features of these cells (Jones and Yang 2011). 
MSC-derived EVs with a maximum diameter of $1000 \mathrm{~nm}$ are heterogeneous biphospholipid encapsulated membrane-packed vesicles, formed by direct budding from the cell membrane, are comprised of exosomes, microvesicles (MVs), and apoptotic bodies, based on their origin and size which function to mediate intercellular communication, decrease the production of pro-inflammatory cytokines and chemokines, and increase the production of antiinflammatory cytokines like IL-10 (Khatri et al. 2018). MSC-EVs may further reduce the risk of tumor formation and pass from the small blood capillaries for being non-proliferative and small size, respectively. Also, EVs can be used for autologous transfusion for the lack of expression of MHC-I and MHC-II (Abraham and Krasnodembskaya 2020). Content delivery of EVs to the target cells, such as mRNA, microRNA, proteins, lipids, and organelles can be accomplished by either binding to the cell surface receptor and merging with the cellular membrane, or forming endocytic vesicles and entering the cytoplasm in a CD44 dependent manner, which finally leads to altering gene expression, modulating the behavior of target cells, and attenuating the inflammatory response (Hao et al. 2019), Mitochondria delivery to the primary human alveolar cells may function to make a shift from M1 to M2 phenotype in response to an increase in the oxidative phosphorylation, enhance their ability to repair lung injuries, and reduce lung edema and endothelial permeability (Monsel et al. 2015). EVs also exert keratinocyte growth factor (KGF) repair facilitation, anti-inflammatory and antiviral properties via transferring RNAs, such as angiopoietin-1 (Ang1) mRNA which reduces lung protein permeability and decreases neutrophil influx and MIP-2 level to reduce the inflammation, protect the endothelial cell, and repair the barrier injury caused by TNF- $\alpha$, IFN- $\gamma$, and IL-1 $\beta$ (Hu et al. 2018). Studies indicate that EVs regardless of their isolation source may be beneficial against lung injury. MSCderived multitargeted biologic agent exosomes with a diameter of less than $200 \mathrm{~nm}$ are hypoimmunogenic (Gattinoni et al. 2020) intracellular multivesicular bodies with a late endosomal origin, harboring a panoply of bioactive molecules, including microRNA (miRNA), transfer RNA (tRNA), long noncoding RNA (lncRNA), GFs, annexins, tetraspanins, heatshock proteins, transcription factors, and genetic materials that can be released in conditions such as serum starvation or hypoxia and function to mediate the crucial therapeutic role of MSCs by infusing from the ECM and bio-fluids (Kowal et al. 2014) to the plasma membrane of the neighboring and distant cells to regulate function, fate, and shapes of target cells, reduce the cytokine storm, promote the release of antiinflammatory factors, reduce the plasma levels of chemokines, suppress apoptosis, induce M2 macrophages, remodel the injured tissue (Bari et al. 2020), reverse the inhibition of host anti-viral defenses, directly inhibit the entry of many RNA viruses and their multiplication, such as influenza, HCV and Coronavirus by altering the expression of the cellular receptors (Cervelli et al. 2013), increase cellular interaction through cell to cell communication, increase the level of anti-inflammatory signaling mediators, permeability and functional aspects of alveolar epithelium to reduce the severity of lung injury (Gentile et al. 2014a), and exhibit pro-angiogenic and anti-fibrotic functions (Taghavi-farahabadi et al. 2020). Exosomes also transfer mitochondria to alveolar cells to increase their survival rate, prevent their apoptosis, and promote cellular regeneration. Of note, the immunomodulatory effects of MSC-Exo depends on the type, maturity, and status of the target immune cells, as well as the type of diseases. The abovementioned features allows the MSC-Exo to be a therapeutic strategy for myocardial infarcts, kidney injury, CNS diseases, liver cirrhosis, diabetic wound, and lung-associated diseases (Baglio et al. 2012). Also, according to a prospective open-label trial, all patients received a single intravenous dose of BMMSC-ExoFlo, which was accompanied by reversal of hypoxia, immune reconstitution, improvement of neutrophilia and lymphopenia, including increased $\mathrm{CD}^{+}, \mathrm{CD}^{+}$, and $\mathrm{CD}^{+}{ }^{+} \mathrm{T}$ lymphocytes, and downregulation of cytokine storm in patients of severe COVID-19 with no adverse effects attributable to the treatment (Sengupta et al. 2020). Due to the abovementioned properties, exosomes are recognized as the primary factors to exert paracrine effects and transfer the genetic material from SCs to the tissue-specific cells in need of regeneration. MVs, also known as shedding vesicles, containing phosphatidylserine-containing proteins, cholesterol, sphingomyelin, ceramide, mRNAs, and microRNAs, function to increase AFC, reduce protein permeability and bacterial load in the injured lung, and reduce neutrophil influx and macrophage inflammatory protein-2 levels in 
bronchoalveolar lavage fluid (BALF) (Zhu et al. 2014). The uptake of MVs is further mediated by CD44 receptors which is essential for the therapeutic effects of MVs. Apoptotic bodies which are DNA and histones rich irregular fragments of death cells with a size of 50-4000 nm, bud during the apoptotic process into the extracellular space (McVey et al. 2012).

Suppression or activation of the inflammatory response is done through the sensor and switcher mechanism, along with sensation of different danger signals using the Toll-like receptors (TLRs) (RomieuMourez et al. 2009), which aggravates inflammation when the immune system is underactive, and as the immune system is overactivated, inhibits the inflammatory response and prevents self over attack (Aggarwal and Pittenger 2005; Bashiri et al. 2018) by inhibiting the proliferation, differentiation and secretory profile of $\mathrm{T}$ cells and other immune cells. Thus, MSCs do not always exhibit immunosuppressive effects, but may also cause pro-inflammatory effects, and for MSCs to be immunosuppressive, a specific level of the inflammatory cytokines and pro-inflammatory cytokines, such as IL- 6 and TNF- $\alpha$ is required. However, in addition to the inflammatory stimuli, the immunomodulatory phenotype of MSCs is also subjected to other environmental factors such as hypoxia. In fact, hypoxia is one of the pathological signs of inflamed tissue microenvironment (Taylor and Colgan 2017) and stimulates MSCs to produce soluble paracrine factors such as transforming growth factorbeta (TGF $\beta$ ), (L-10) IL-6, IL-7, and chemokines (Hosseini et al. 2019; Maffioli et al. 2017). Cytokines are affective in accelerating the immune response, stimulating Treg cells, and preventing lymphocyte activation (Sioud et al. 2010), as IL-6 and IL-7 are crucial for the proliferation, differentiation, and survival of $\mathrm{T}$ cells (Tan et al. 2001). Besides, the immunosuppressive and anti-inflammatory effects of mesenchymal stem cells can be partially mediated by specific cytokines. Studies show that immunomodulatory factors secreted by MSCs include indoleamine 2,3-dioxygenase (IDO), prostaglandin E2 (PGE2), tumor necrosis factor-stimulated gene 6 (TSG6), inducible nitric oxide synthase (iNOS), TGF- $\beta$, IL10 , hepatocyte growth factor (HGF), histocompatibility locus antigen-G (HLA-G), CD39 and CD73, galectin, C-C motif chemokine ligand 2 (CCL2), programmed cell death ligands 1 and 2 (PD-L1 and PD-L2), haem oxygenase 1 (HO-1), interleukin-1 receptor antagonist (IL1RA), and complement system-related factors (Jiang and Xu 2020). Following the modulation of the innate immune cells, MSCs will have indirect regulatory effects on $\mathrm{T}$ and $\mathrm{B}$ cells (Roudkenar et al. 2018; Wang et al. 2014). In general, MSCs can directly or indirectly interact with the innate and acquired immune system components (Fig. 2). The direct interaction is achieved through the cell-tocell contact, via the cell surface molecules and receptors, and results in modulation of downstream pathways, such as effecting cell proliferation, effector production, and cell survival. Indirectly, MSCs upregulate anti-inflammatory factors and secrete a series of immune modulators including growth factors, immunomodulatory factors, soluble immunoregulatory molecules, adhesion molecules (Ren et al. 2010), immunosuppressive molecules, exosome, chemokine, complement components and various metabolites to suppress immune cells' activity in response to alloantigens and mitogens, including $\mathrm{T}$ cell, Treg, $\mathrm{B}$ cell, Breg, dendritic cell (DC), monocyte /macrophage, T helper (Th1), Th2, Th17, NK, neutrophil, innate lymphoid cell (ILC), myeloid-derived suppressor cell (MDSC) and mast cell (Najar et al. 2016), resulting in balancing the immune responses and regulation of the inflammation profile. Undifferentiated MSCs are not immunomodulatory and can lead to immune effector cell suppression, as well as immune suppressor cell activation through a shift from proinflammatory phenotype towards anti-inflammatory phenotype. It is important to note that the variability in the composition and functional status of immune cells during inflammation affects the modulatory ability of MSCs and their role in the course of disease. However, allogeneic MSCs are recognized for being immune evasive and they are poorly immunogenic, which means MSCs are capable of escaping the cytotoxic effects of lymphocytic T cells, B cells, and NK cells, for the low expression of immune-stimulating molecules such as human leucocyte antigen (HLAI) (Nauta and Fibbe 2007), and major histocompatibility class II (MHCII). In addition, co-stimulatory molecules, such as CD40L, CD45, CD31 and CD34, CD14, CD19, $\mathrm{CD} 11 b, \mathrm{CD} 79 \alpha$, and human leucocyte antigen (HLA)DR, CD80, and CD86 are not expressed, which is more dependent on severity, type, and intensity of the received signals ( $\mathrm{Li}$ et al. 2012). Of note, studies indicate the expression of MHC-II by the fetal MSCs, adult BMMSCs, and adipose-derived stem cells 


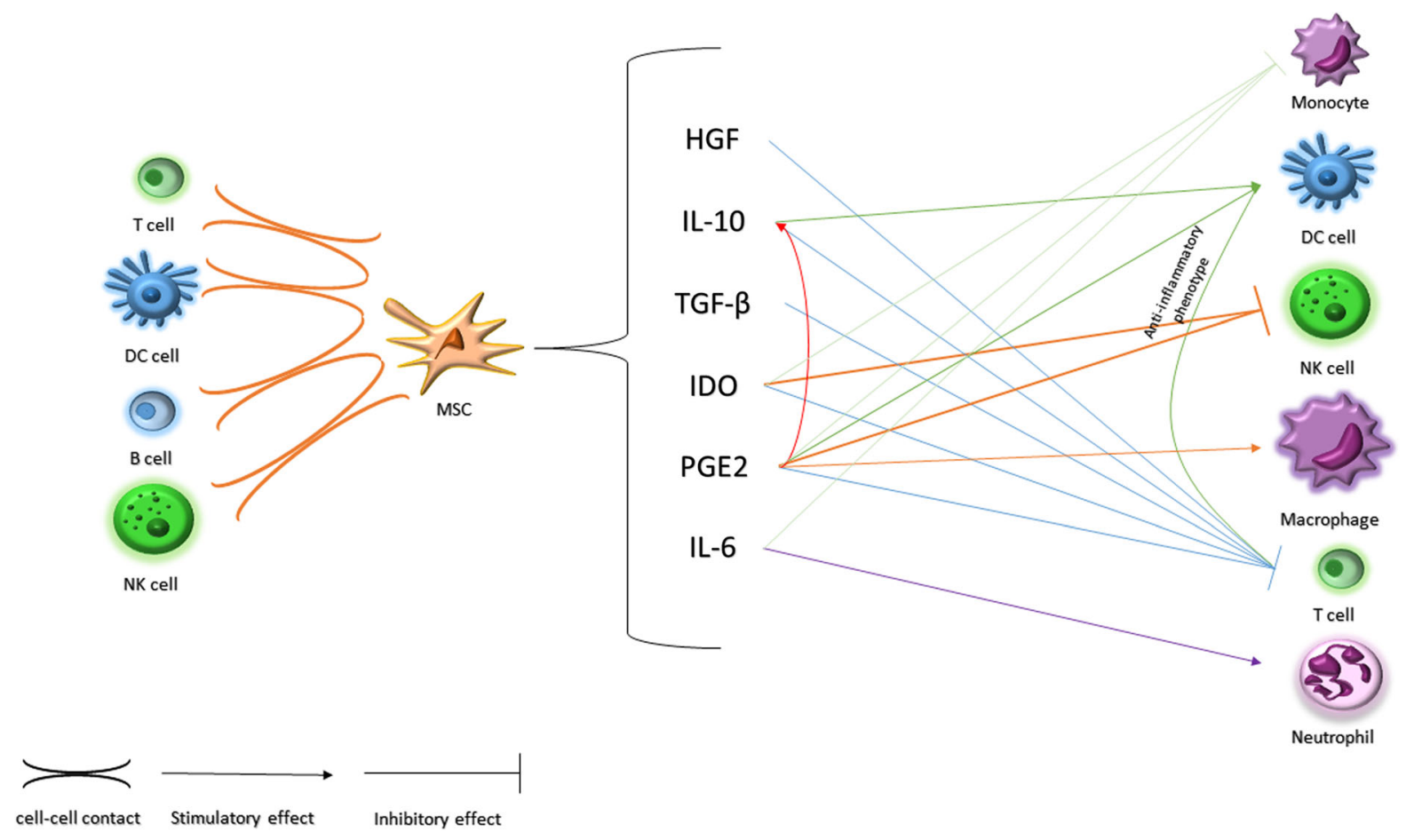

Fig. 2 Immunosuppressive and immunomodulatory properties of MSCs. IL-10 prevents the production of pro-inflammatory cytokines, $\mathrm{T}$ cell proliferation, memory $\mathrm{T}$ cell formation, APC maturation, as well as the expression of MHC and costimulatory factors, which are produced by MSCs in a quiescent state. Its expression is elevated under the influence of TLR ligands and PEG2. PGE2 can suppress inflammation by inducing Foxp $3^{+}$Treg cells production. Also inhibits the proliferation of $\mathrm{T}$ cells by elevating DCs' maturation and exhibit a pro-inflammatory effect, so low levels of this chemokine can cause an inflammatory response. PGE2 can suppress natural killers and inhibit $\mathrm{CD}^{+} \mathrm{T}$ cell activity by stimulating TGF- $\beta$ secretion from monocytes. Also, the expression of PGE2, IL-6, and IDO by MSCs modulates the direct differentiation of monocytes into M2 type macrophages. TGF- $\beta$ is a cytokine that is primarily secreted by MSCs and is

(ASCs) when stimulated by the IFN- $\gamma$, which means that the recently mentioned MSCs exhibit immunogenicity properties, facing the risk of immune rejection (Le Blanc et al. 2003).

MSCs along with parenchymal cells, also play a role in balancing the inflammation, tissue repair, and facilitation in times of disease and trauma, as well as the maintenance of tissue homeostasis (Kfoury and Scadden 2015). Following tissue or cell damage, MSCs facilitate tissue regeneration by suppressing or stimulating the immune system (Keating 2012), in that both exogenous and endogenous mesenchymal stem upregulated by inflammatory factors such as IFN- $\gamma$ and TNF- $\alpha$. This chemokine can inhibit the differentiation of $\mathrm{T}$ cells into Th1 and Th2 and promote the production of Treg and Breg cells, thus disrupting the expression of IL-2, MHC-II and stimulatory cofactors in DCs and T cells. MSCs produce Treg by changing DCs phenotype into the Tolurogenic phenotype. By inducing MSCs-produced IDO, T cell proliferation is inhibited and Treg is stimulated. $I L-10$ interleukin $10, M H C$ major histocompatibility complex, $A P C$ antigen-presenting cell, $M S C$ mesenchymal stem cell, TLR toll-like receptor, PEG2 prostaglandin E2, $D C$ dendritic cell, TGF- $\beta$ transforming growth factor beta, $I L-6$ interleukin 6,IDO indoleamine-pyrrole 2,3-dioxygenase, IFN- $\gamma$ interferon gamma, $T N F-\alpha$ tumor necrosis factor alpha, Th1 T helper cell type 1 , Th2 $\mathrm{T}$ helper cell type 2 , Treg regulatory $\mathrm{T}$ cell, Breg regulatory B cell, $I L-2$ interleukin 2

cells move to the site of inflammation through the interstitium, owing to their chemokine cognate surface receptors such as $\mathrm{C} 3 \mathrm{a}$ and $\mathrm{C} 5 \mathrm{a}$ chemokines (Schraufstatter et al. 2009), contact the endothelial cells in a P-selectin- and VCAM1-dependent manner, promote the homing by probably binding of CD90 to the integrins b3 and b5, stimulate the basal membrane matrix degradation by metalloproteinases, and allow subsequent extravasation (Son et al. 2006). To inhibit the proliferation, activation, and maturation of CD19 ${ }^{+}$ $\mathrm{B}$ cells, $\mathrm{CXCR}^{+}{ }^{+} \mathrm{CD} 4^{+} \mathrm{T}$ cells, $\mathrm{CXCR}^{+}{ }^{+} \mathrm{CD} 8^{+} \mathrm{T}$ cells, $\mathrm{CXCR}^{+} \mathrm{NK}$ cells, monocytes and neutrophils, 
reduce the levels of BALF chemokines and cytokines, and suppress the extracellular release of myeloperoxidase and elastase (Sindrilaru et al. 2011). MSCs release of various types of growth factors, such as hepatocyte growth factor (HGF), vascular endothelial growth factor (VEGF), keratinocyte growth factor (KGF), angiopoietin-1, and fibroblast growth factor (FGF) in the presence of inflammatory cytokines, direct pro-regenerative signaling processes, and activate regenerative potential of tissue-resident stem cells, trigger angiogenesis, remodel the stroma, clear alveolar fluid in the lungs, reconstitute immune microenvironment by regulating the immune response, empower tissue stem/ progenitor cells to differentiate, as well as the other cells, prevent apoptosis, and suppress inflammation. This mechanism is likely accomplished by cell replacement (Tsukamoto et al. 2016). It is noteworthy that this ability of MSCs is also mediated by molecules such as indoleamine 2,3-dioxygenase (IDO), soluble human leukocyte antigen class I molecule G5 (HLA-G5) and CCL2 through specific mechanisms (Su et al. 2014b), secreted by MSCs themselves (Che et al. 2012). Tissue regeneration is closely linked to inflammation, as the immunosuppressive activity of mesenchymal stem cells is also affected by inflammatory cytokines (Pourgholaminejad et al. 2016). In other words, inflammatory cytokines triggering the production of chemokines in MSCs lead to the recall of monocytes, macrophages, and neutrophils, or can lead to suppressive effects on immune cells by producing IDOs in MSCs. Further protection of the lung endothelial barrier is guaranteed by inhibiting the pulmonary vascular endothelial cell apoptosis, enhancing the recovery of VE-cadherin, reducing proinflammatory factors, and directly differentiating into AT2 cells via the wnt/ $\beta$-catenin signaling pathway (Zhang et al. 2019). MSCs exhibit anti-apoptotic properties by salvaging dying host cells through transferring their mitochondria, cell fusion, or transferring mRNA through exosomes, and by secreting growth factors (Sairam Atluri et al. 2020). Also, antimicrobial properties may be accomplished by indirectly influencing the role of host immune response against pathogens or increasing the phagocytic activity of macrophages and monocytes via promoting mitochondrial transfer, and directly by secreting antimicrobial peptides and proteins (AMPs), including cathelicidin LL-37, human-beta defensin-2 (hBD-2), hepcidin, lipocalin-2 (Lcn2) (Sutton et al. 2016), and KGF. However, inflammation performs dynamic effects on these cells during active disease states, to the extent that it can alter the behavior of these cells and prove to be damaging (Wang et al. 2014). Of note, tissueresident MSCs are probably not as effective as infused MSCs in restoring homeostasis in damaged tissue. These cells are location-specific in their properties. On the other hand, contrary to the immunomodulatory effect of mesenchymal stem cells, research has shown that infused MSCs wouldn't last in damaged tissues for so long (von Bahr et al. 2012). Also, several strategies have been proposed to improve the engraftment of MSCs for poor survival, which are genetic modification, CXCR4 overexpression via the viral vector, activation of the E-prostanoid 2 (EP2) receptor by PGE2 (Xu et al. 2019).

\section{Immune cells}

$\mathrm{T}$ cells are of stem cell-derived progenitors in the thymus (Livák et al. 1999), activated by two signals; T receptor signaling and costimulatory signaling (DL 1989). CD $4^{+}$T cells, also known as Th cells, are the key cells of the acquired immune system that differentiate into Th1, Th2, Th9, Th17, or Treg $\left(\mathrm{CD}^{+-}\right.$ CD45RO) subsets based on the severity of stimulation and the milieu of cytokines (Pejman and Taylor 2009). MSCs can alter the activation, proliferation, differentiation, as well as cytotoxic activity of T cells through several mechanisms (Angoulvant et al. 2004) both indirectly or directly, through cell-cell contact (Renner et al. 2009), with the cellular ratio of notice (Krampera et al. 2003), so that the low cell ratio leads to $\mathrm{T}$ cell proliferation stimulation (Le Blanc et al. 2003). It is noted that MSCs could suppress the T-cells at high cell ratio. (Song et al. 2018) To stop the T cell cycle in the G1 phase, MSCs release TGF- $\beta$ and HGF (Glennie et al.), and to modulate and regulate the $\mathrm{T}$ cell-mediated inflammatory response (Crop et al. 2010), MSCs further express soluble immunoregulatory molecules, adhesion molecules (Ren et al. 2010), chemokines and immunosuppressive molecules, such as IDO, PGE2, leukemia inhibitory factor (LIF), NO, IL-6, PD-L1, and HLAG5 (Cho et al. 2017; Su et al. 2014a) in the presence of specific inflammatory cytokines, including IFN- $\gamma$, as well as at least another prestimulated cytokine, such as TNF- $\alpha$, interleukin 1 
alpha (IL-1 $\alpha$ ), or IL-1 $\beta$ (Ren et al. 2010). Tryptophan deficiency is another mechanism of MSCs to generate Treg and drive T cells towards apoptosis (Benvenuto et al. 2007; Plumas et al. 2005). Thus, T cells are kept in the quiescent state and balance of $\mathrm{T}$ cell subtypes is regulated (Djouad et al. 2007).

B cells are also of the acquired immune system, B lymphocytes develop in the bone marrow (BM) from hematopoietic precursor cells (Pieper et al. 2013). In fact, MSCs differentiate into adipocytes and the secreted B-cell activating factor (BAFF) promote the proliferation of activated B-cells in a dose-dependent manner (Wang et al. 2011). Following the stimulation of cell surface receptors by specific antigens, B cells proliferate, and further differentiation gives rise to antibody-producing cells and memory cells, leading to mediation and sustained protection against foreign pathogens. MSCs can prevent the activation, proliferation, differentiation, antibody production, and cytotoxicity of B cells, both indirectly and directly, through cell-cell contact (Franquesa et al. 2012). Through the paracrine activity, MSCs stop cell cycle in G0/ G1 phase (Corcione et al. 2006). Furthermore, IFN- $\gamma$-induced MSCs would suppress B cell differentiation into plasma cells (Schena et al. 2010) and also promote non-activated B cell formation (naive, transitional and memory subsets) (Rafei et al. 2008) by secreting molecules such as IL-1Ra (Luz-Crawford et al. 2013) and EVs at precise doses (Asari et al. 2009; Di Trapani et al. 2016). Also, IL-10-induced Bregs would express high levels of IL-10, which results in the regulation of B cell response (Park et al. 2015) and suppression of immune response (Franquesa et al. 2015). However, in some cases, MSCs can stimulate B cells to secrete antibodies (Asari et al. 2009).

Dendritic cells (DCs) are known as the most potent antigen-presenting cells (APCs) in the body (Vickers 2017), which play an essential role in the acquisition, processing, transportation, and presentation of various antigens. DCs are also involved in activating antigenspecific $\mathrm{T}$ cell response, as well as the direct interaction between $\mathrm{B}$ cells and natural killer cells (Pende et al. 1999), so the presence of DCs is vital in directing the acquired immune system responses (Kingsley 1994). The proximity of these cells to MSCs leads to the induction of Th2 and Treg, and suppression of the pro-inflammatory T cells, which are the Th1 and Th17 (Spaggiari et al. 2009). MSCs can prevent differentiation of monocytes or $\mathrm{CD} 34^{+}$cells into DCs and inhibit the functioning of the $\mathrm{CD} 34^{+}$hematopoietic progenitor cell-derived DCs ( $\mathrm{Li}$ et al. 2008), which leads to immature DC production and immune suppression (Nauta et al. 2006). MSCs also release IL-6 (Spaggiari et al. 2009), PGE2 (Zhang et al. 2014), and EVs, and further downregulate $\mathrm{C}-\mathrm{C}$ motif chemokine ligand 7 (CCR7) and CD49d $\beta 1$ to prevent mature DC migration, which results in the lower expression of inflammatory factors and antigen-presenting potential in these cells (Consentius et al. 2015), thus less induction of $T$ cells (Chiesa et al. 2011). MSCs can even shift DCs into an antiinflammatory phenotype by downregulating pro-inflammatory factors such as TNF- $\alpha$ and IL-12 along with upregulating anti-inflammatory factors, such as IL-10 and PGE2, and as a result, these altered cells inhibit $\mathrm{T}$ cell activity through the secretion of IL-10 (Favaro et al. 2016).

Macrophages are of the innate immune system, which can be tissue-resident, derived from yolk-sac, or circulating, derived from bone marrow monocytes (Perdiguero and Geissmann 2016). Depending on the microenvironment, these cells can further be polarized into activated M1 or activated M2 with proinflammatory and immunomodulatory properties, respectively. Macrophage M1 can exhibit antimicrobial properties through secretion of inflammatory cytokines and chemokines. In contrast, macrophage M2 eliminates trophic factors of inflammation by secreting immunosuppressive factors, such as IL-10, accelerates tissue repair (Koch and Radtke 2011), and secrete immune activators such as IL-6, IL-12, TNF $\alpha$, IL-1 $\beta$, IL-23, CD86, and MHCII in quite a limited level (Abumaree et al. 2013). Accordingly, MSCs can polarize macrophages of classically activated pro-inflammatory phenotype into alternatively activated anti-inflammatory phenotype, following the detection of inflammatory factors (Melief et al. 2013a), and through producing immunosuppressive molecules and metabolites, such as PGE2, TSG6, lactate, and kynurenic acid (Vasandan et al. 2016). The mentioned shift further results in disruption of $\mathrm{T}$ cell response, as well as the induction of Treg (Bernardo and Fibbe 2013).

Natural killer cells are the effective key cells of the innate immune system, derived from a common lymphoid progenitor, and give rise to the lymphocyte subtypes, inside or outside the bone marrow (Fathman et al. 2011). These cells can control various microbial infections and tumors by directly stimulating 
cytotoxicity against target cells, as well as producing proinflammatory cytokines (Childs and Carlsten 2015). They can also lyse cells lacking MHC class I molecules, and because MSCs express less of these molecules, they are subject to the cytolytic activity of these cells (Le Blanc and Mougiakakos 2012). According to research, allogeneic MSCs can gradually undergo the effects of natural killers. At the same time, activation of these cells with TLR3 ligand and stimulating their anti-inflammatory phenotype (MSC2 phenotype) protects them from this effect (Giuliani et al. 2014). Studies have also shown that MSCs would affect NKs directly and through cell-cell contact (Lu et al. 2015), or indirectly interfere with proliferation, cytolytic activity (CYT), and cytokine production of these cells (Noone et al. 2013). In the presence of IDO and PGE2 and the higher ratio of MSCs to NK cells (Spaggiari et al. 2008), proliferation, activation, cytokine production, and cytotoxicity is suppressed. Therefore, the low ratio of MSCs to natural killers leads to the proliferation of NK cells and lysis of MSCs, as well as cytokine production in natural killer cells (Götherström et al. 2011). The interaction between MSCs and NK cells can be twoway, performing suppressive or inductive effects on each other. In other words, IFN- $\gamma$ secretion from NK cells can lead to the synthesis of CCL2 in MSCs, with the launch of positive feedback on NK cell production (Cui et al. 2016).

Neutrophils are polymorphonuclear leukocytes playing an essential role in acute inflammations (Kolaczkowska and Kubes 2013). They circulate freely in the bloodstream and move to the site of injury through chemotaxis, and bring down pathogens through phagocytosis and secretion of bactericidal molecules (Brinkmann et al. 2004). MSCs can prevent recruitment and activation of neutrophils, formation of extracellular traps, and the secretion of proteases by neutrophils (Munir et al. 2016). Of course, the modulation of neutrophils by MSCs can also depend on the proinflammatory/ anti-inflammatory phenotype of MSCs, as MSCs may lead to apoptosis of resting/ IL-8 activated neutrophils by secreting IL-6 or may prevent apoptosis of these cells and promote their activity (Cassatella et al. 2011). Besides, they can be effective in retaining neutrophil resources in the bone marrow and facilitate neutrophil migration toward the inflammation site, thus helping to attenuate inflammation (Brandau et al. 2014). MSCs also perform an anti-inflammatory activity and recruit neutrophils in the early stages through expression of ligands and many binding molecules, such as C-X-C motif chemokine receptor 3 (CXCR3) ligands, CCR5 ligand, intercellular adhesion molecule 1 (ICAM-1), and vascular cell adhesion protein 1 (VCAM-1) (Ren et al. 2008).

By the release of histamine, mast cells are known to be the key cells of the innate immune system in allergic anaphylaxis, and are also stimulated during inflammation by non-allergic agents (Theoharides et al. 2015), in a way that the released histamine affects IL-6 expression in MSCs, prevents the apoptosis of neutrophils and promotes phagocytic cells (Nemeth et al. 2012). IgE-stimulated mast cells can also activate MSCs and secrete factors, such as thymic stromal lymphopoietin and hematopoietic growth factor (Allakhverdi et al. 2013). According to studies, MSCs have a suppressive effect on cytotoxic activity, secretion of inflammatory cytokine, and degranulation of mast cells (Brown et al. 2011).

\section{Stem cell therapy approaches}

Cell-based therapy is recognized as a promising therapeutic field in recent years, which performs treating effects through stopping degeneration and starting regeneration of the somatic and progenitor cells, thus activating the endogenous repair system, or performs injury preventive effects through slowing/ stopping pathophysiologic processes, naturally repairing, restoring, and/or regenerating damaged or diseased tissues and organs, such as diabetes, neurodegenerative diseases, cardiovascular diseases, muscular degenerative disorders, cancers, liver injuries, hematopoietic and immune system disorders, metabolic disorders, GvHD, Crohn's disease, inflammatory bowel disease, rheumatoid arthritis (RA), sepsis, and ARDS, burn, wound and excisional injuries (Abbasi-Malati et al. 2018; Alijani-Ghazyani et al. 2020a, 2020b; Gentile et al. 2014a, 2017a, 2020c; Rad et al. 2019; Roushandeh et al. 2017; Sabzevari et al. 2020). MSCs therapy demonstrates protection and possible efficacy in patients with ARDS, like the BMMSCs which effectively reduce pulmonary inflammation and edema through the release of therapeutic factors, however the same behavior in respiratory virus-caused ARDS is yet to be thoroughly established 
(Rawat et al. 2019; Sleem and Saleh 2020; Zhang et al. 2020b). The BM, UC and adipose tissue are the main sources in stem cell therapy. The UC, a neonatal tissue with plentiful supply of easily expandable and accessible MSCs, is composed of two arteries and a vein, supported within a mucoid connective tissue, called Wharton's jelly (WJ) between the amniotic epithelium and the umbilical vessels within the UC, and provides protection, cushion, and structural support to the umbilical vessels. WJ is rather recognized multipotent than pluripotent, and is the most common source of MSCs to harvest for the lack of severe adverse effects, superiority over the other biologics, containing the highest concentration of primitive MSCs per milliliter than any other allogeneic tissue, as well as secreting large quantities of anti-inflammatory CKs, GFs, and EVs. While, Autologous bone marrow requires the patient to undergo an invasive procedure associated with pain and morbidity to harvest the MSCs (G Jeschke et al. 2011; Mohamed-Ahmed et al. 2018).

Adipose tissue is the proper source for cell therapy. There are many subcutaneous fat tissue that is extremely easy to isolate the stem cells from the adipose tissue via minimal manipulation or enzymatic digestion of fat. The mixed cell population referred to as stromal vascular fraction (SVF), also known as adipose-derived regenerative cells (ADRCs), is a plentiful source of heterogeneous mesenchymal cell set in the subcutaneous human adipose tissue (HAT), including the hematopoietic cells, adipose-derived stem cells (ASCs), preadipocytes, fibroblasts, pericytes, vascular smooth muscle cells, endothelial cells, resident monocytes/ macrophages and lymphocytes. The SVF of the adipose tissue has come more and more into the focus of stem cell research because this tissue compartment provides a rich source of multipotent adipose tissue derived stromal cells. Each $\mathrm{mL}$ of acquired HAT from minimal invasive liposuction in the abdominal region, lumbar region, hump, arms flanks, thighs, or knees and minimal manipulation through enzymatic digestion with collagenase or mechanical digestion equals $1000-9000 / \mathrm{mL}$ of ASCs (Gentile et al. 2020e). ASCs have been infused for treating complex perianal fistulas, alopecia and hair loss, wound healing, facial reconstruction, diabetic foot ulcers, knee osteoarthritis, ARDS, refractory rheumatoid arthritis, pediatrics disease, fecal incontinence, allogeneic flap, breast augmentation, calvarial defects, Crohn's fistulas, damaged skeletal muscle, ischemic heart disease, autoimmune encephalomyelitis, lateral epicondylitis, and soft tissue defects with no severe adverse events being reported, owing to their anti-inflammatory, immunomodulatory, and tissue regenerative properties, regarding an increase in peripheral lymphocytes amount, decline in the CRP and over-activated cytokine-secreting immune cells, expressing a large amount of anti-inflammatory factors, such as TGF-1, HGF, and IFN- $\gamma$ (Gentile et al. 2019a), osteogenesis, secreting proangiogenic, various growth factors that induce proliferation of vascular endothelial cell and angiogenesis, including PDGF and VEGF, and anti-apoptotic factors, secreting vasculogenesis, differentiation into skeletal muscle, pancreatic cells, hepatocytes, neurons, tendons, and cardiomyocytes (Strem et al. 2005), as well as, providing ECM composed of collagen, elastin, glycoproteins, polysaccharides, glycosaminoglycans and water, thus ASCs can light up a way to treating COVID-19 (Gentile and Sterodimas 2020b) and compared to BM-MSCs, easy access using a minimally invasive procedure (Fraser et al. 2006), and easy to use with local anesthesia and with higher quantity (roughly tenfolds), higher proliferative capacity, longer life-span, and shorter doubling time, greater suppression of IgG production, stronger differentiation inhibition of monocytes into DCs, and more genetically and morphologically stability in long-term culture (Kern et al. 2006) gives ASCs a significant edge over BM-MSCs. Further, the administration of BM-MSCs for therapeutic aims of COVID-19 is obstructed by safety issues, cell survivability, scalability, and regulatory issues (Liang et al. 2020). However, evidence point to variation in the growing and differentiation ability of adipose precursors among different fat depots and changes with age, in a way that the growth rate of ASCs decreases through aging (Gentile and Garcovich 2019a). In addition, embryonic stem cells (ESCs), is a non-tumorigenic afterbirth extensive source of stem cells, considered medical waste which unlike BM and AD stem cells, have faster doubling times, more plasticity and possibly more potency (Nagamura-Inoue and $\mathrm{He}$ 2014). In short, Application of MSCs is promising and challenging in several diseases. However, its application in COVID-19 patients is to be considered for accumulating within the lung microvasculature when intravenously administered and performing antiinflammatory and immunomodulatory effects, 
protecting alveolar epithelial cells, promoting endogenous repair of local cells and tissue regeneration, and lowering lung fibrosis. Here, some clinical trials that registered in www.clinicaltrials.gov were summarized (Table 1). Despite the fact that administration of autologous MSCs usually requires an invasive procedure, it is the method of choice for COVID-19 patients, as the infection occurred in the blood cells and several other organs may impact the quality and sufficiency of the autologous MSCs (Al-Khawaga and Abdelalim 2020). High doses of MSCs to treat organ failure is administered via IV route, followed by intraarterial (IA) to increase engrafting of the cells (Sairam Atluri et al. 2020). IV MSCs delivery is the most common route, during which a large share of MSCs are entrapped in the lung's microvasculature for relatively large size and expression of various adhesion molecules and exhibit immunomodulatory properties, improve the pulmonary microenvironment, protect alveolar epithelial cells, prevent pulmonary fibrosis and improve lung function (Cruz and Rocco 2020), while a small fraction engraft in the target organs (Götherström et al. 2004). However, IV applications of MSCs has contraindication for many of the critically ill patients for their systemic procoagulant state, as tissue factor (TF)/CD142-expressing. MSC products could increase the coagulation activation markers thrombin-antithrombin-complex (TAT) and D-dimer, aggravate the pro-thrombotic state, and promote the risk of thrombosis, embolism, disseminated intravascular coagulation (DIC), and thrombotic multi-organ failure (Moll et al. 2019). Of note, different sources of MSCs stand in stark contrast regarding the expression of highly procoagulant TF/CD142, such as AD-MSCs which are known to be of highly TF/CD142-expressing cells (Moll et al. 2020). Alternative routes to IV cell administration and avoiding blood contact may solve the dose-limiting toxicity, such as intramuscular (IM) and intratracheal (IT). Further, IM administration is characterized by longer in vivo survival of the cells, improved functionality, and a lack of hemocompatibility issues (Braid et al. 2018). Also, intratracheal administration of MSCs unlike the systemic administration directly delivers the cells and increases the accessibility of MSCs to both the alveolar epithelium and the pulmonary endothelium, where MSCs demonstrate reduction in endotoxin-induced injury to explanted human lungs (Lee et al. 2009). In below, some of them described in detail.
An experimental human placenta-derived stem cell therapy, also known as natural killer cells, will be conducted on 86 patients with confirmed symptoms of COVID-19 in early stages of the disease by Cellularity, Inc., a clinical-stage cell therapeutics company. The experiment is however conducted with a hope to prevent the disease course as well as to evaluate the efficacy issues. As it would take some time for the immune system to recognize the virus, the study aims to prevent the out of control replication of the virus by transforming placental stem cells into one-size-fits-all "Natural Killer" cells, which would function as sentinels. Once the patients will be infused with their doze for 30-60 days, the experiment is ready to move to a placebo-controlled study. Still the company is waiting for the FDA to give a green light, and the experiment is good to be conducted. The experiment, CYNK-001, is said to have been tested on cancer patients formerly and proved effective. Although controversies concerning what the application of these cells could possibly lead into is also highlighted, as would result in destruction of respiratory cells and exacerbation of most severe cases, if the natural killer cells are to go in the other direction.

In another attempt to treat COVID-19 patients, as well as to evaluate the potential effects of WJ-MSCs, a phase I intervention is being conducted in Jordan, which is planning to enroll 5 patients who have tested positive for COVID-19. The study is going to provide $1 \times 10^{6} / \mathrm{kg}$ doses of newborns' cord tissue-derived WJ-MSCs to the patients intravenously, in 3 separate days. The newly isolated cells will first be screened for HIV1/2, HBV, HCV, CMV, and Mycoplasma, and cultured to enrich for MSCs. WJ-MSCs will be counted and suspended in $25 \mathrm{~mL}$ of Saline solution containing $0.5 \%$ human serum Albumin. There will be a three weeks long follow up to assess the severity of the condition and monitor the improvement of clinical symptoms including fever, respiratory distress, pneumonia, cough, sneezing, and diarrhea. In this period the RT-PCR has to report negative and CT findings will be used for observing any side effects.

In order to treat intubated-ventilated patients suffering from SARS-CoV-2-related acute respiratory distress syndrome (ARDS), a phase I/II study has been conducted by Assistance Publique-Hôpitaux de Paris, registered in March 29, 2020. 60 patients over 18 years old will be included, 20 as treatment group and the rest for the control group. The control group 


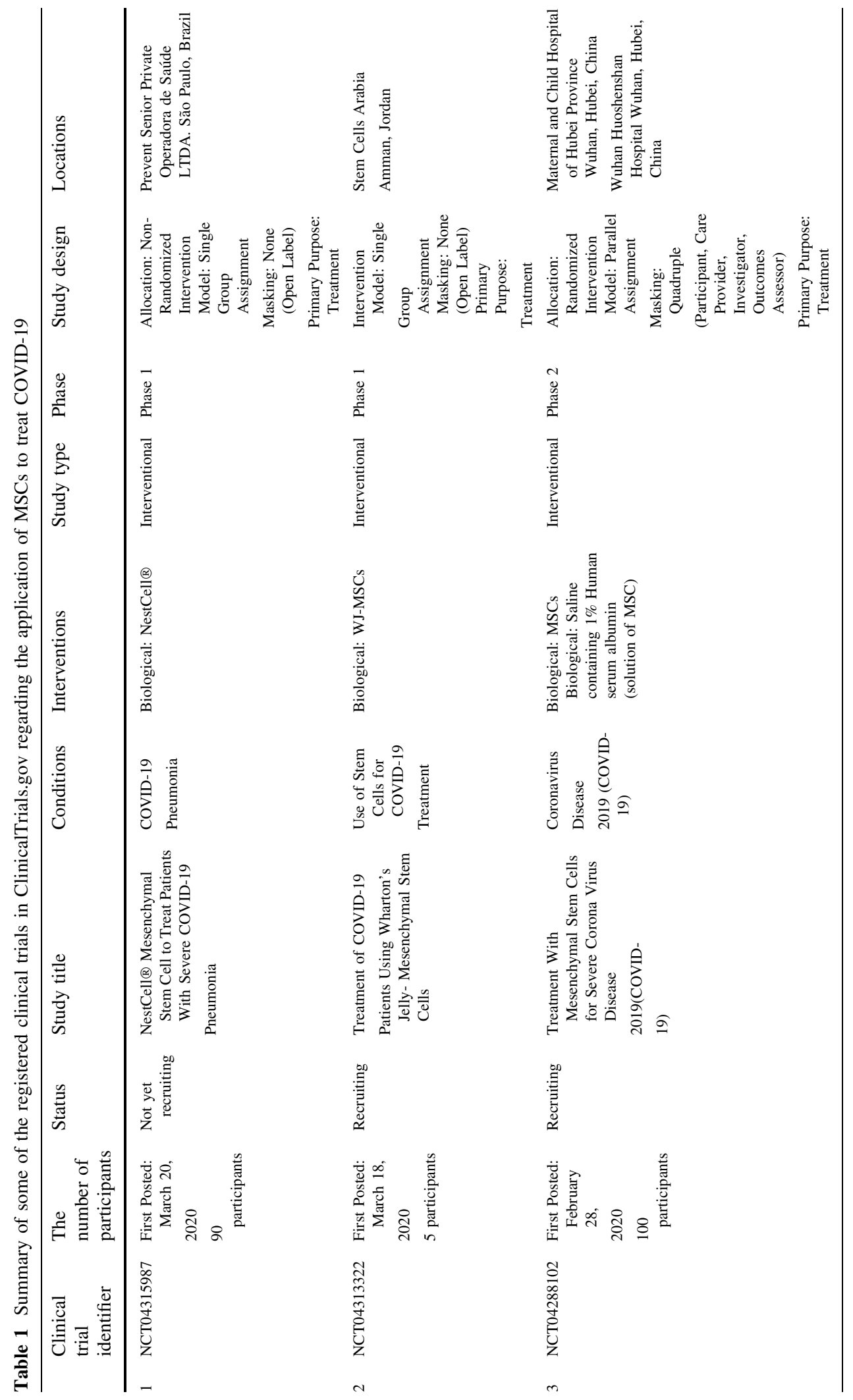




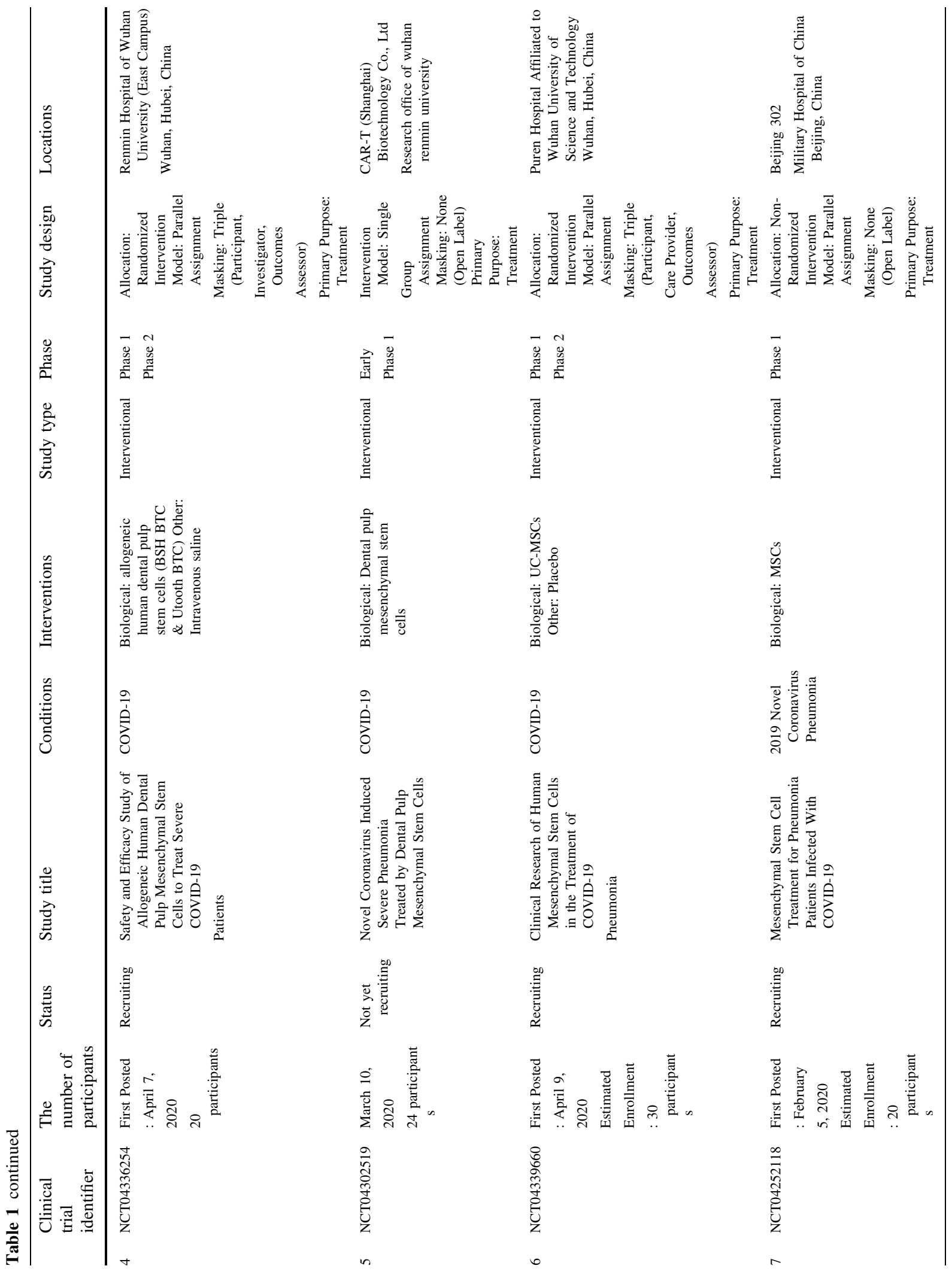




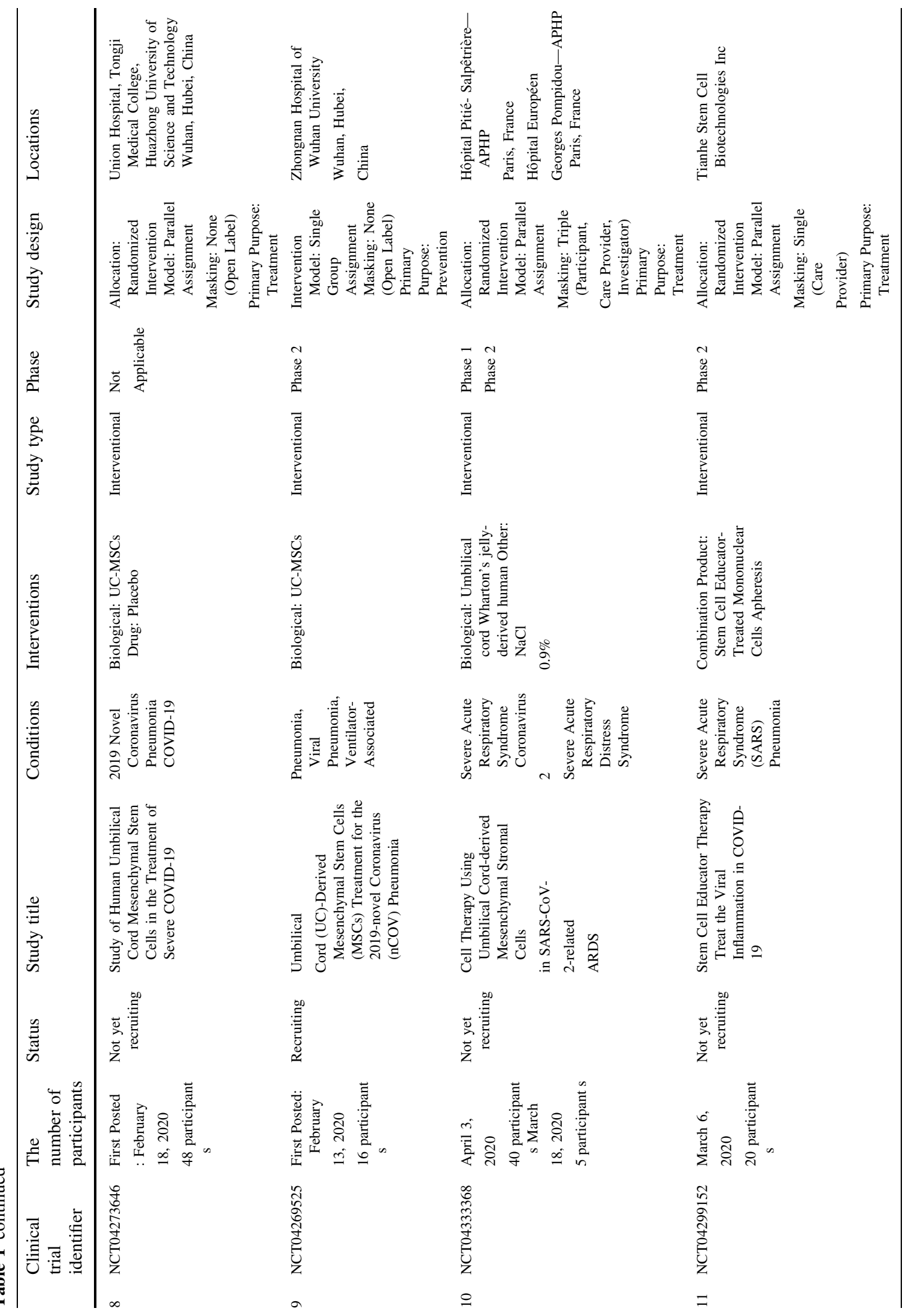




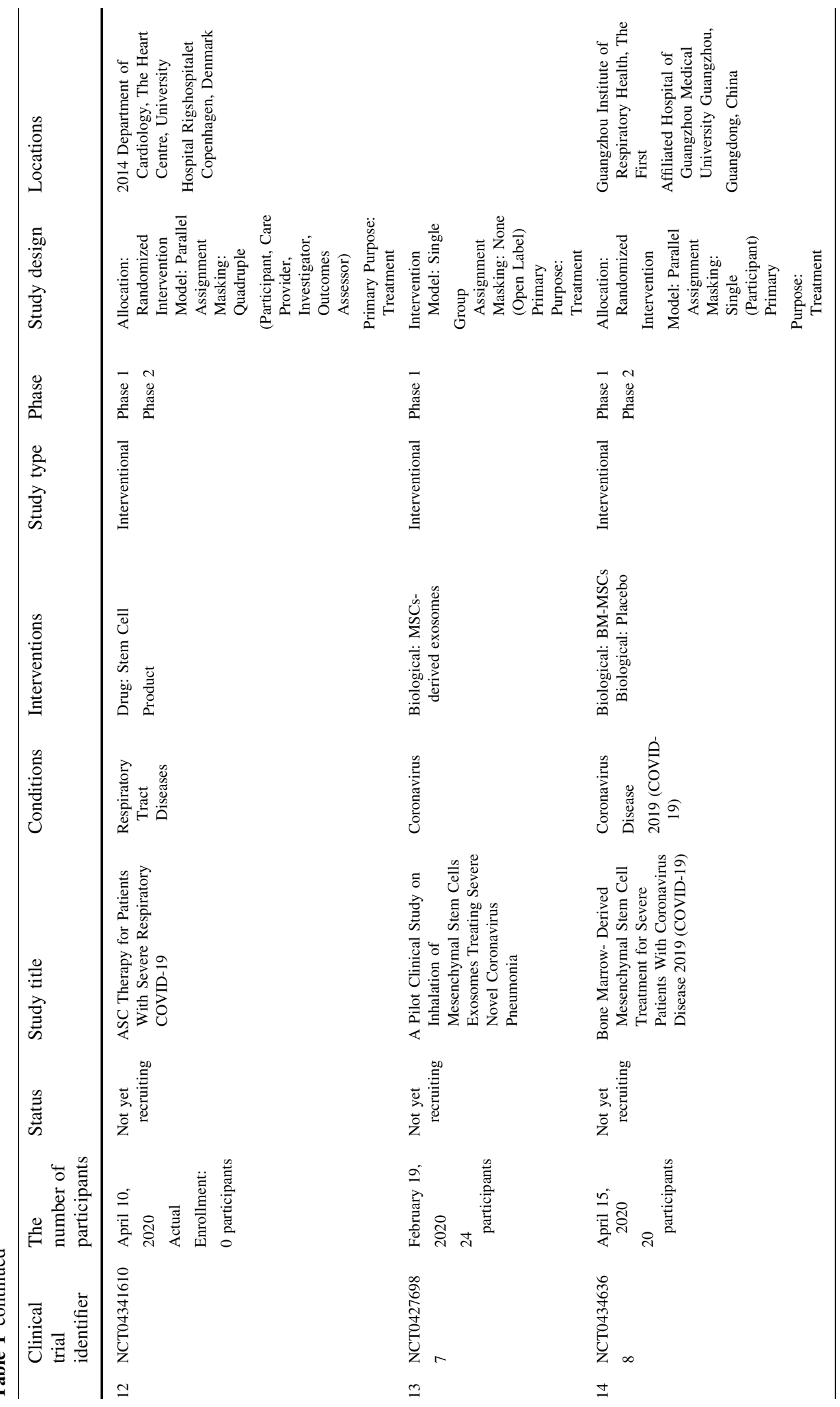




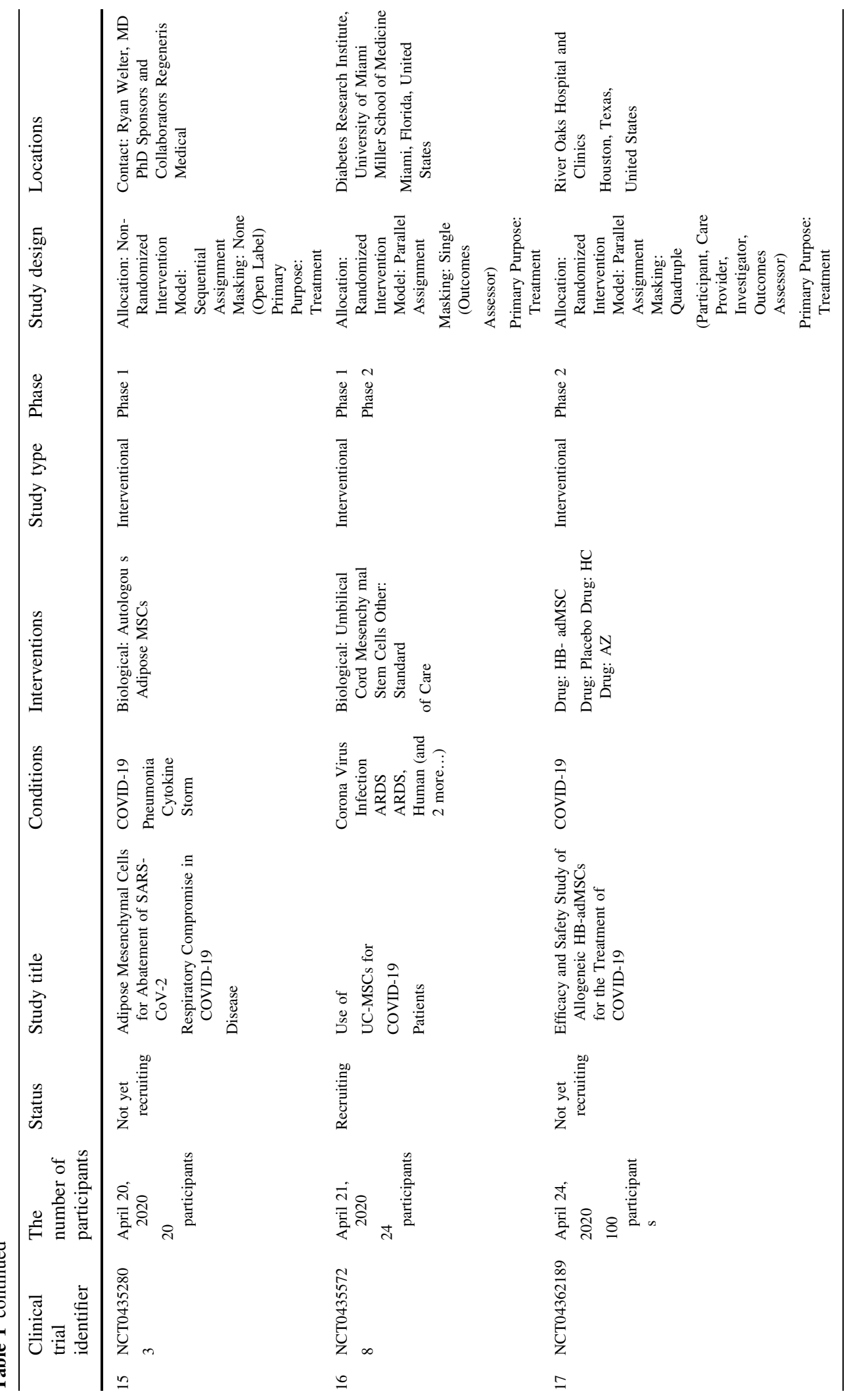




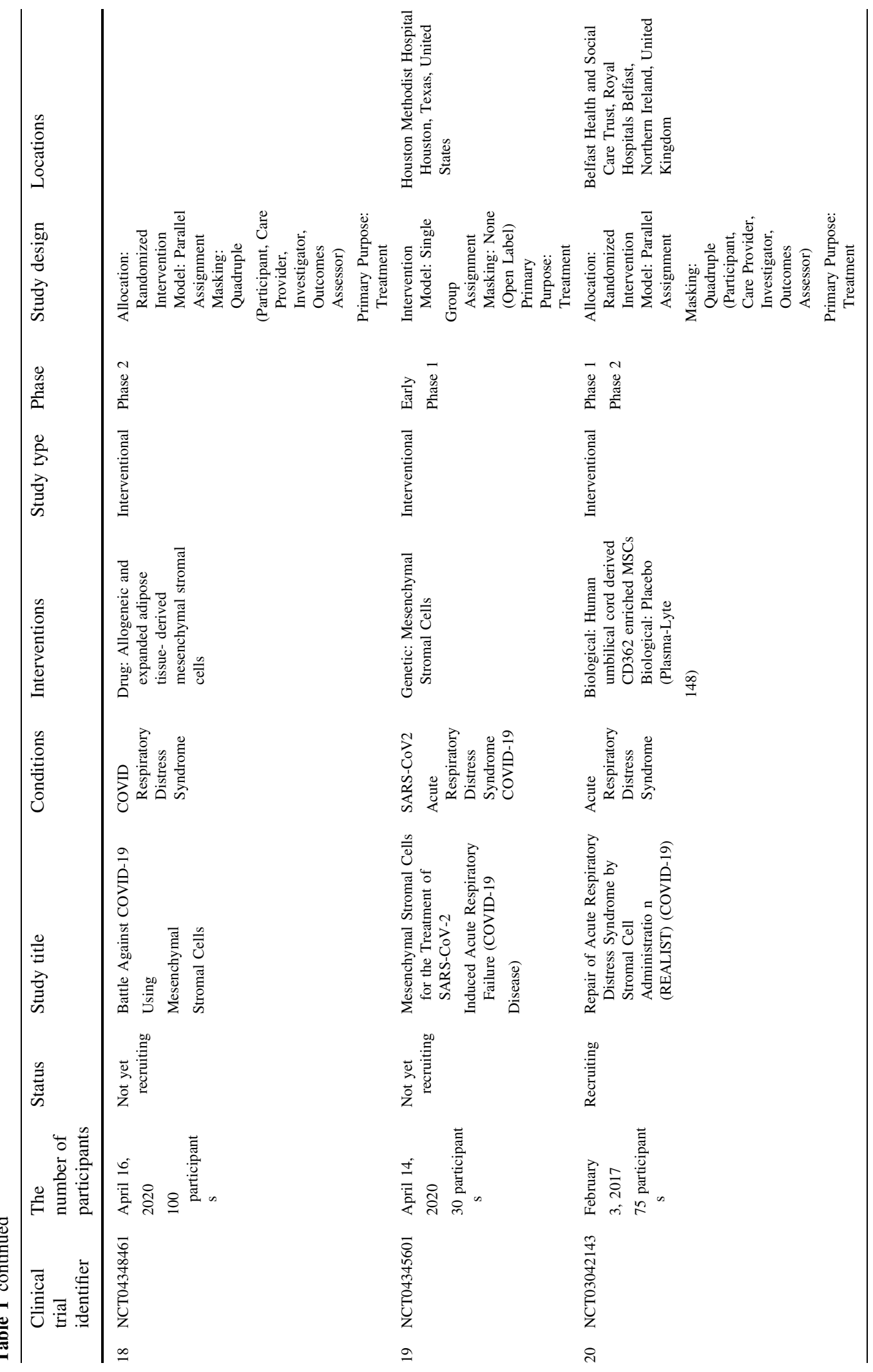




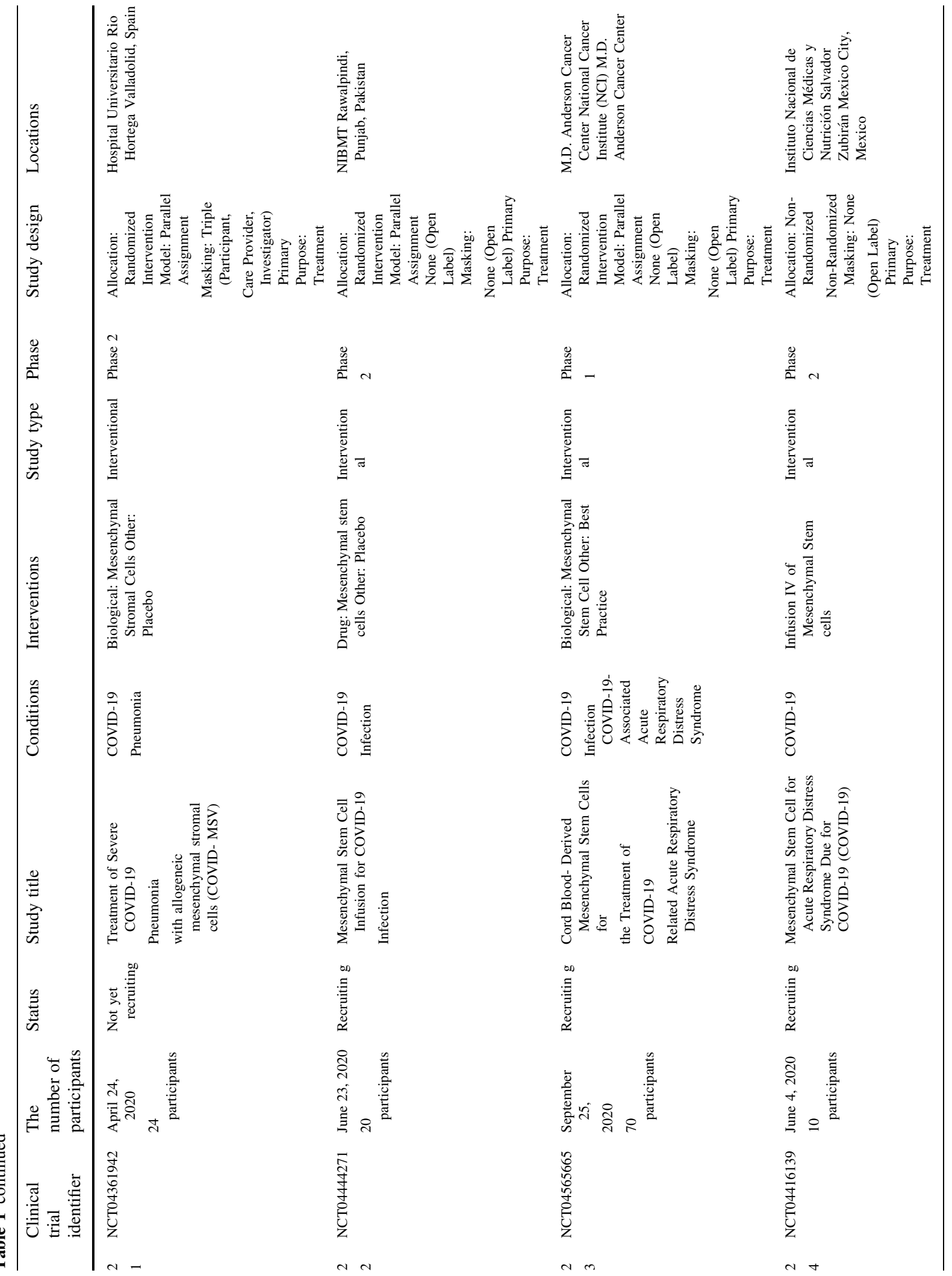




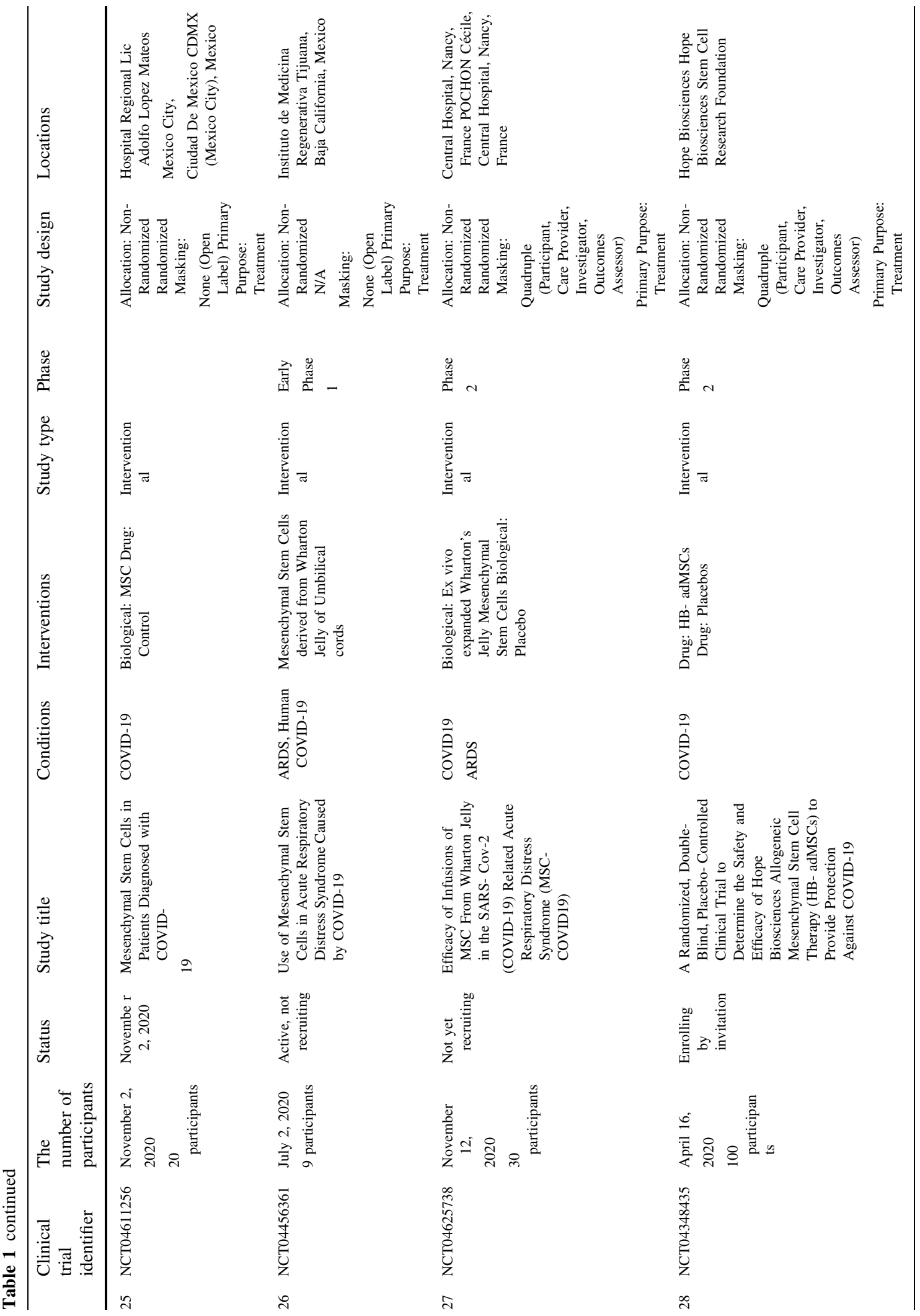




\begin{tabular}{|c|c|c|c|}
\hline & 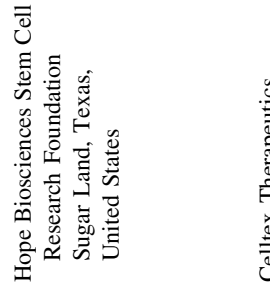 & $x^{2}$ & 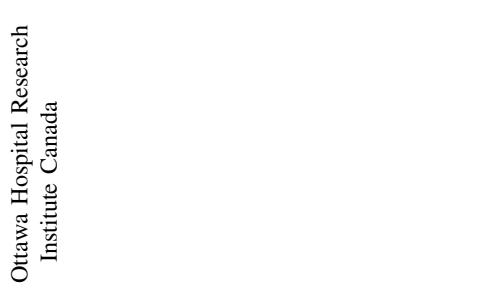 \\
\hline 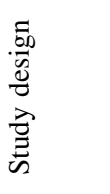 & 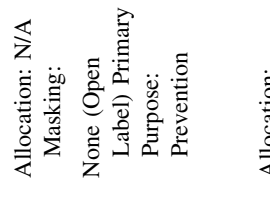 & 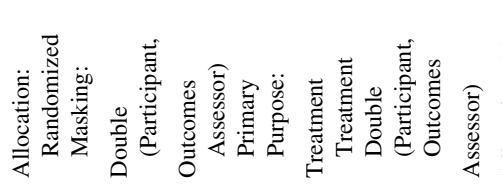 & 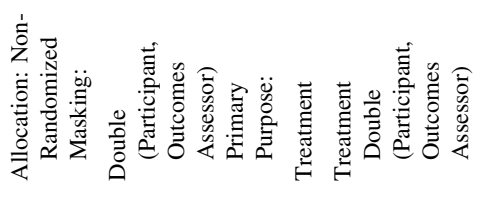 \\
\hline $\begin{array}{c}0 \\
\text { 怘 } \\
\frac{\Xi}{2}\end{array}$ & 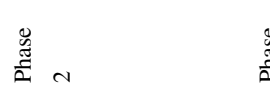 & $\begin{array}{l}\mathscr{\mathscr { D }} \\
\frac{\mathscr{E}}{2} \\
\mathbb{E}\end{array}$ & 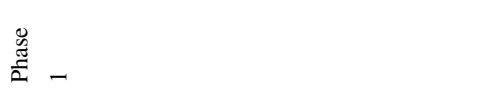 \\
\hline 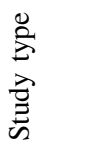 & 竞 & 总 & : \\
\hline & 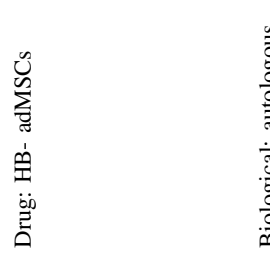 & 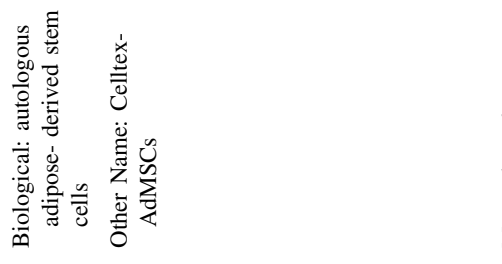 & 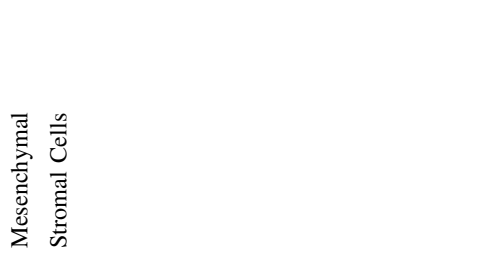 \\
\hline & 官 & $\frac{2}{\partial}$ & 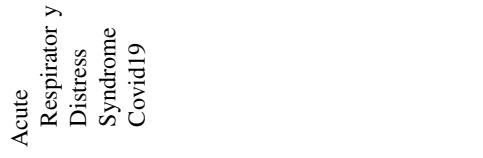 \\
\hline & 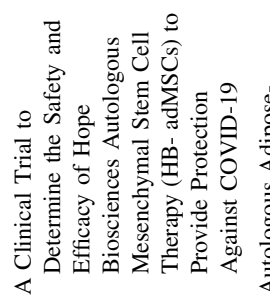 & 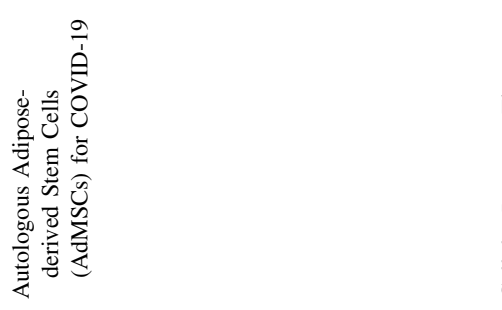 & 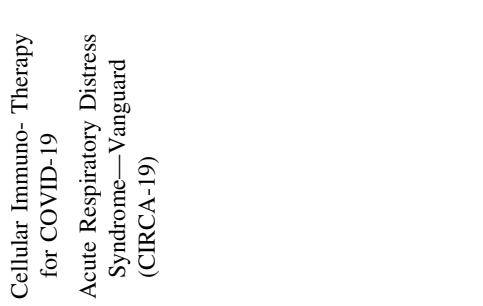 \\
\hline 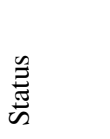 & 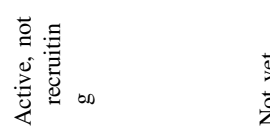 & 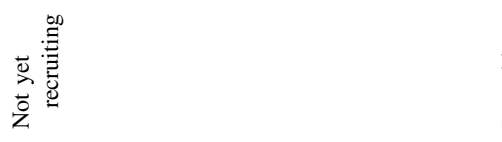 & 量 \\
\hline 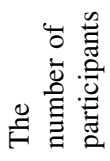 & 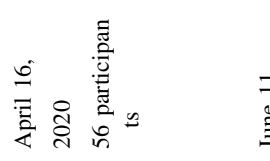 & 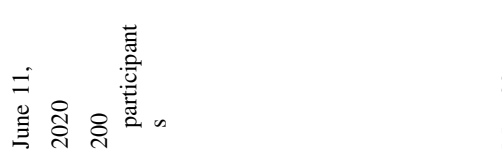 & 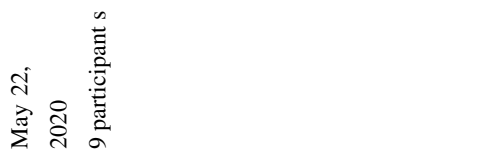 \\
\hline 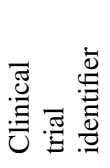 & 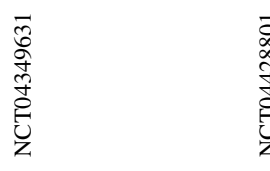 & 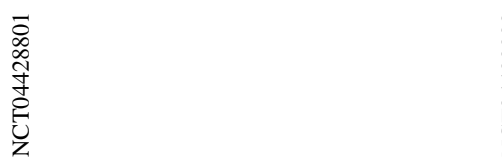 & 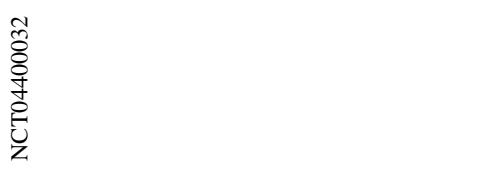 \\
\hline & ते & i & $\bar{m}$ \\
\hline
\end{tabular}




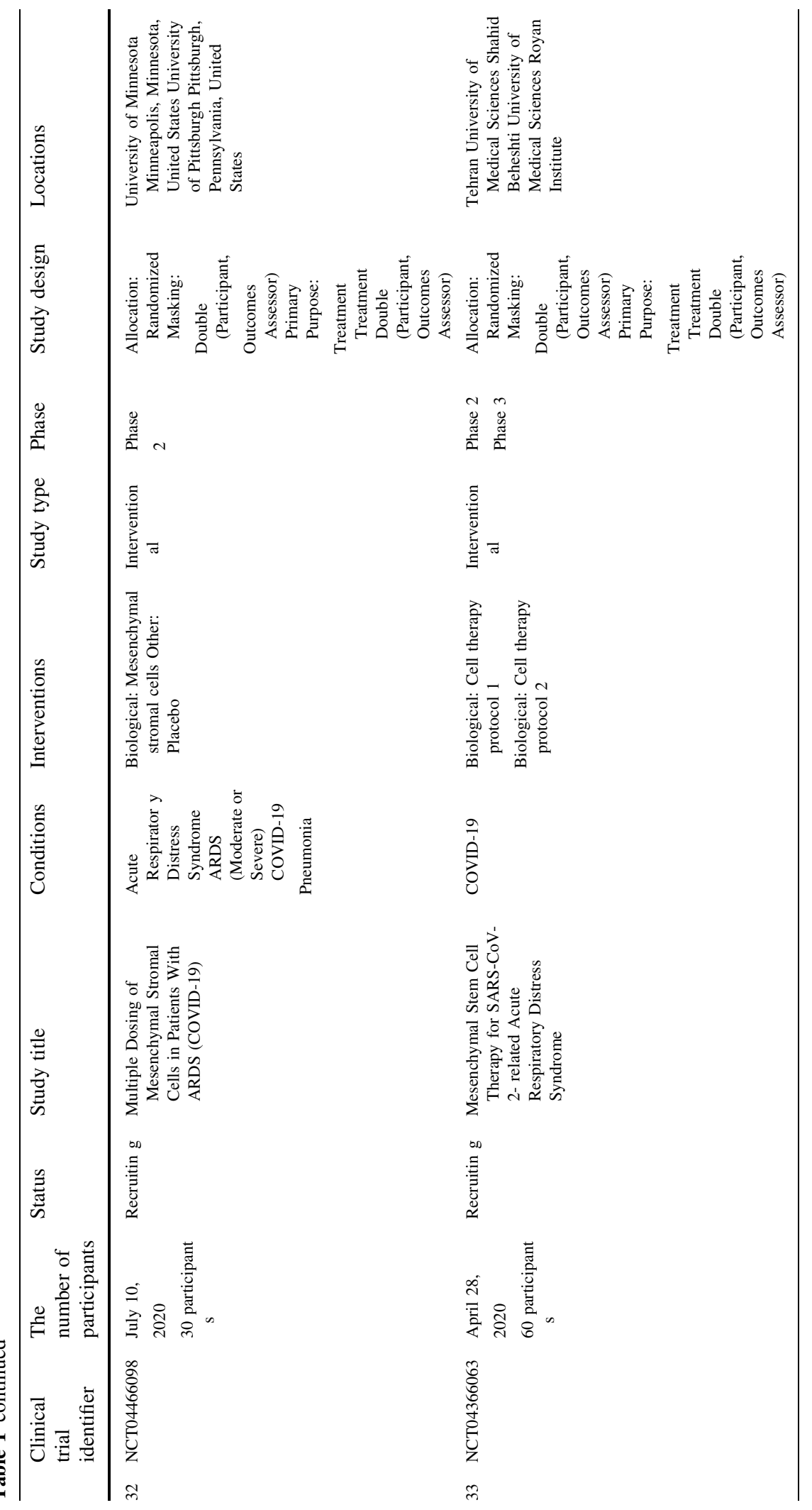




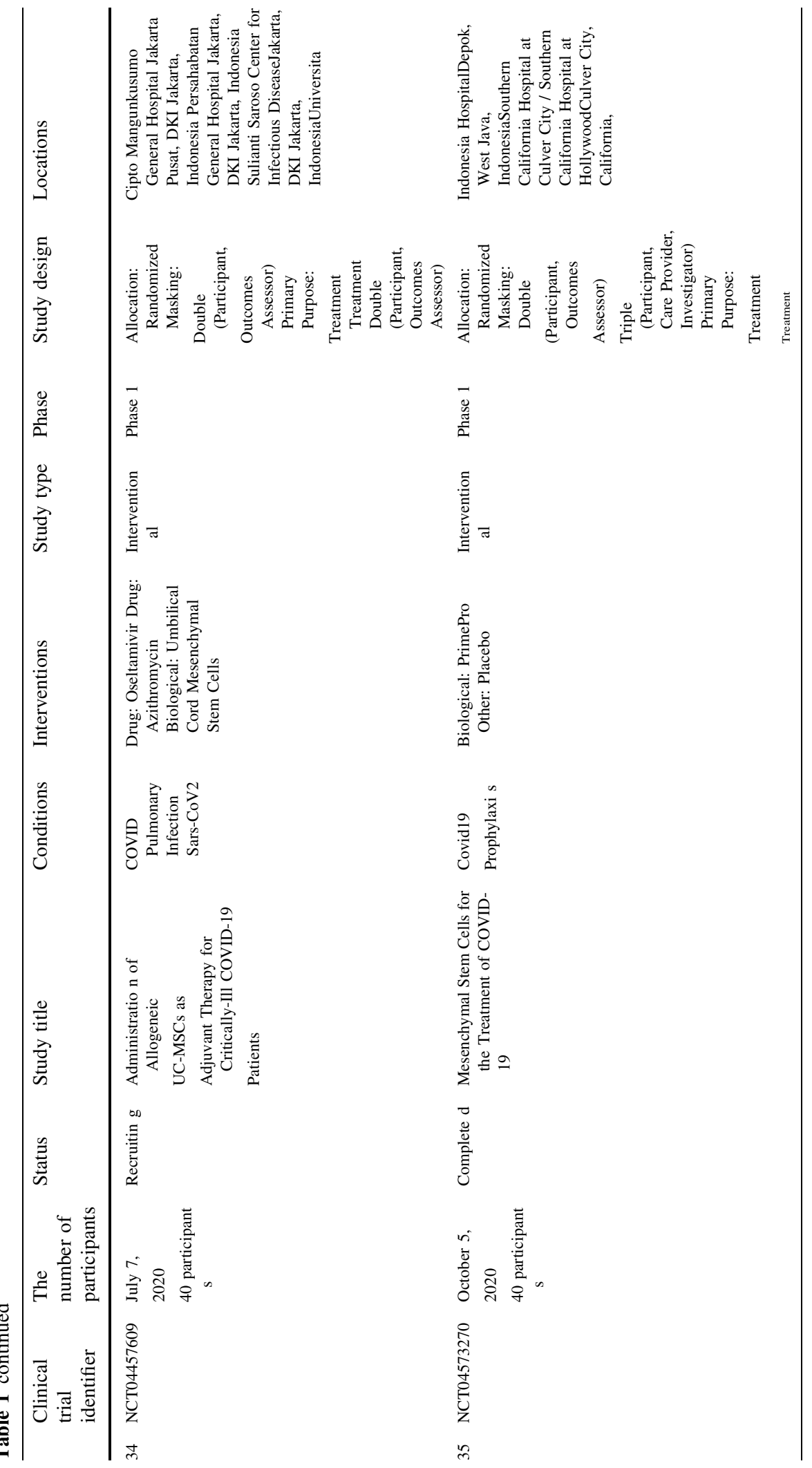




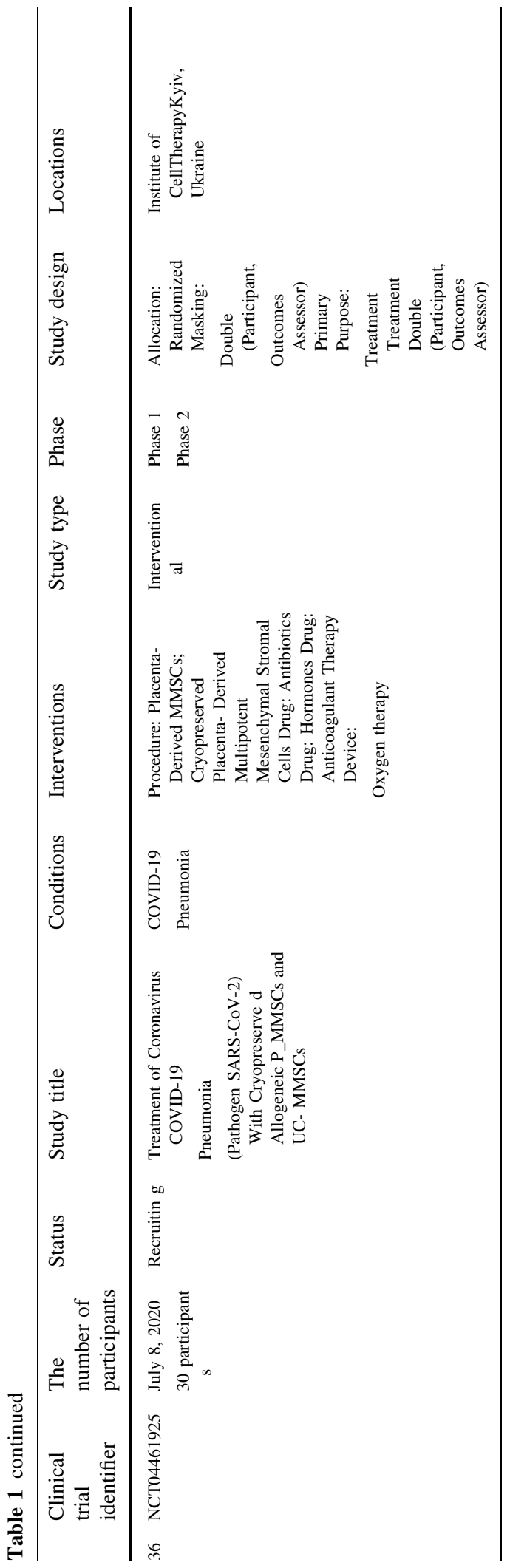

will receive $150 \mathrm{~mL}$ of $\mathrm{NaCl} 0.9 \%$ as a placebo. The other 20 patients will receive $1 \times 10^{6}$ of umbilical cord Wharton's jelly-derived human MSCs/Kg, via a peripheral or central venous over 30-45 min. The injections will be on day 1, 3, and 5. Several inflammatory markers, such as $\mathrm{T}$ regulatory lymphocytes and donor-specific antibodies will also be monitored during follow up.

A Phase II intervention in ZhiYong Peng, Zhongnan Hospital has been registered on February 7, 2020, involving 10 patients aged between 18 and 75 years to assess the availability and safety of UC-MSCs treatment in serious and critical types of COVID-19 patients. Patients of serious and critical groups will be under treatment in a 28 days' time, and each subject will be infused with $3.3 \times 10^{7}$ of UC-MSCs per $50 \mathrm{~mL}$ per bag every other day intravenously, 3 bags each time. In the follow up, participants will be assessed for the efficacy and safety of the treatment, and the adverse reactions. Every 7th day, patients will be tested for the virus nucleic acid for 3 times. Also lung imaging, WBC count, Lymphocyte count, Lymphocyte percentage, procalcitonin, and IL-2/4/6/8/10 will be evaluated on the same days.

Yang Jin, Wuhan Union Hospital in China is also conducting an experiment, administering human umbilical cord mesenchymal stem cells to treat COIVD-19 in severe stages of the disease, as well as to investigate efficiency and safety of UC-MSCs. The study is registered in February 14, 2020, planning to recruit 48 patients, with an age limit between 18 and 65 years. 24 patients will be the treatment group and another 24 patients acting control group. The treatment group will be administered $5.0 \times 10^{6}$ of UC$\mathrm{MSCs} / \mathrm{kg}$ every $3^{\text {rd }}$ day on four rounds. In addition, both groups will receive conventional treatment and during the 90 days to 96 weeks of follow up, patients will be monitored for the respiratory function, pulmonary inflammation, clinical symptoms, pulmonary imaging, side effects, and immunological characteristics (immune cells, inflammatory factors, etc.).

On April 2, 2020, a phase I/II study will be conducted to explore the therapeutic potential of UCMSCs for COVID-19 patients in Puren Hospital Affiliated to Wuhan University of Science and Technology. 30 participants aged $18-75$ will participate in the two control and treatment groups. The treatment group will receive $1 \times 10^{6}$ of $\mathrm{UC}-\mathrm{MSC} / \mathrm{Kg}$, suspended in $100 \mathrm{~mL}$ of normal saline, as well as the 
conventional treatment. If there is a necessity in infusion of another dose, it will be administrated during one week. Control group will receive conventional treatments and, as well as the placebo intravenously. Patients will be monitored within 4 weeks of time frame for the immune indices, such as TNF- $\alpha$, IL-1 $\beta$, IL-6, TGF- $\beta$, IL-8, PCT, and CRP, as well as the improvement and recovery time of inflammatory and immune factors. In addition, blood oxygen saturation will be evaluated.

A phase II, prospective, two-arm, partially masked, single center clinical study in an attempt to assess the safety, feasibility, and efficacy of SCE therapy, mediate the overreaction of the immune system, and treat the patients utilizing stem cell educator (SCE) therapy, produced by Tianhe Stem Cell Biotechnologies Inc., has been conducted. According to the responsible party, SCE therapy uses human multipotent cord blood stem cells (CB-SC), derived from human cord blood. 20 adult patients aged 18-60 years old are estimated to enroll, who will receive SCEtreated MNCs intravenously, which have been collected by apheresis of blood, and subjects will be under monitor within 4 weeks of follow up, including evaluation of the percentage of activated $\mathrm{T}$ cells, and Th17 cells by flow cytometry, chest imaging every, which is performed 3-5 days for 4 weeks, as well as determining the viral load by real time RT-PCR using the samples of blood, sputum, and nose/ throat swab.

An elder female aged 65 years old suffering from critical COVID-19 pneumonia, representing fatigue and fever of $38.2{ }^{\circ} \mathrm{C}$, cough, as well as small amount of white bubble sputum, was received in the Longling People's Hospital, China. After she was tested positive for the novel coronavirus, IFN $\alpha$ inhalation was performed and was sent to the infectious disease department of the Baoshan People's Hospital for better treatment. Antiviral therapy of lopinavir/ritonavir, IFN- $\alpha$ inhalation and oseltamivir was administered to the patient, as well as IV moxifloxacin, Xuebijing, methylprednisolone, and immunoglobulin. She was also under ventilator. After worsening of the status, she was sent to the ICU, followed by performing invasive tracheal cannula to decrease the respiratory distress. Thymosin $\alpha 1$ was administered to the patient, due to the inflammation hemolysis-related anemia, which didn't turn out to be effective. On day 12, the hUCMSCs adoptive transfer therapy was proposed, following withdrawal of the glucocorticoid and antiviral therapy, by which time she was confirmed to be a critical COVID-19 patient, with severe pneumonia, acute respiratory distress, multiple organ injury, moderate anemia, hypertension, type II diabetes, electrolyte disturbance, immunosuppression, acute gastrointestinal bleeding, etc. 2 days after the withdrawn antiviral therapy, $5 \times 10^{7}$ of allogeneic hUCMSCs produced under GMP condition was infused intravenously every 3 days. She was receiving thymosin $\alpha 1$ and antibiotics as well. After 8 days, she recovered most of vital signs to normal level and was good to be out of ICU again (Liang et al. 2020).

Camillo Ricordi from the University of Miami, the USA, is also recruiting an interventional phase I/ II experiment, regarding the safety and efficacy of human umbilical cord-derived mesenchymal stem cells in treating the patients suffering from severe complications of acute lung injury or ARDS. 24 participants will be involved in this study, according to their CT findings, need for ventilation, and age over 18 years old. The patients of the experimental group will receive two infusions of $100 \times 10^{6} \mathrm{UC}-\mathrm{MSCs} /$ intravenously, as well as the routine treatment. The first infusion will be within the $24 \mathrm{~h}$ of study enrollment, and the following infusion will be within the following $48 \mathrm{~h}$. The participants of the active comparator will only be given standard of care treatment. The current primary outcome measures will be looking into the incidence of severe adverse events, as well as the incidence of pre-specified infusion-associated adverse events during the 90 days of follow up.

An open label dose escalation phase 1 pilot study, followed by a randomized, double-blind, allocation concealed placebo-controlled study is to be conducted by Belfast Health and Social Care Trust, the UK. The study aims to assess the safety of realist orbcel-C in COVID-19 patients with ARDS. 75 subjects of moderate to severe type over 16 years old. In the phase I trial, subjects receive $100 \times 10^{6}, 200 \times 10^{6}$, and $400 \times 10^{6}$ of realist orbcel-C cells in three infusions within 7 days. In the phase II trial, $400 \times 10^{6}$ cell dose of realist orbcel-C will be administered to the patients. Oxygenation index will be checked during the 7 days of follow-up, as well as the adverse events during the 28 days.

Another clinical trial which is approved by FDA on April 06, 2020, is being conducted by Hope Biosciences, a clinical stage biotechnology company, in 
an attempt to pretreat patients with confirmed symptoms of early stage COVID-19, determine the efficacy of autologous, adipose-derived mesenchymal stem cells (HB-adMSCs), and increase the immune system capability against the virus. The trial involves 75 participants in a Phase II, single arm, and nonrandomized study, who will be given five IV infusions of the adMSCs in a fourteen weeks' time and will be followed up for a 6 months' time. Meanwhile, they'll be monitored for the health status, including immune cell levels, inflammatory markers, and requirements for supplementary care or hospitalization. If the study goes well, the progression and severity of COVID-19 will be limited, resulting in less hospitalization of patients, as well as less need for ventilation. However, the study has been designed for patients with banked stem cells, but in the next step, donor cell source will be utilized as well.

A phase I non-randomized trial is to be conducted by Regeneris Medical, a company with stem cell therapy specialty. The study aims to assess the effect of autologous adipose-derived mesenchymal cells on sever type patients, or those suffering from ARDS. 20 patients will be given $5 \times 10^{5} / \mathrm{kg}$ body weight of autologous adipose derived MSCs intravenously. Patients will then be monitored for adverse effects and any changes in length of mechanical ventilation during the 28 days of follow-up.

Hope Biosciences is to recruit a randomized, placebo-controlled, double-blind, single center phase II trial to investigate the safety and efficacy of allogeneic adipose-derived mesenchymal stem cells on COVID-19 patients. Of the 110 involved patients, experimental group is going to receive hydroxychloroquine and azithromycin, as well as $100 \times 10^{6}$ of HBadMSCs/dose at day $0,3,7$, and 10. Participants of the placebo comparator will also receive hydroxychloroquine and azithromycin, and saline solution as a placebo on the same days. During the 28 days of follow up, participants will be monitored for any mortality and invasive mechanical ventilation.

Another two-treatment, randomized, controlled, multicenter clinical trial to investigate the safety and efficacy of expanded allogeneic adipose tissue adult mesenchymal stromal cells on patients on patients of critical type, will be recruiting by Instituto de Investigación Sanitaria de la Fundación Jiménez Díaz, Spain. 100 patients over 18 years old are estimated to enroll, out of whom, the treatments group will be receiving $1.5 \times 10^{6}$ of allogeneic and expanded adipose tissue-derived mesenchymal stromal cells/dose in two series, whereas regular respiratory distress treatment will be administered to the control group patients. Efficacy of the infusion will be monitored during the 28 days of follow up, and in a 6 months long time, safety will be checked.

A phase II, multicenter, randomized, double-blind, placebo-controlled intervention in Fu-Sheng Wang, Beijing 302 Hospital is recruiting 90 patients between 18 and 75 years old, suffering from severe COVID-19 to inspect the safety and efficiency of mesenchymal stem cells (MSCs) therapy. The preliminary data of parallel assignment study (NCT04252118) has shown that three doses of MSCs were safe in patients with COVID-19. $4.0 \times 10^{7}$ of MSCs per time will be administered intravenously to 60 of the patients every 3rd day, as well as the conventional treatment. The remaining 30 patients in the control group and will receive placebo, and conventional treatment. 90 days of follow up will be in progress and patients will be monitored for size of lesion area and severity of pulmonary fibrosis by chest CT, mMRC, dyspnea scale, 6-min walk test, VCmax, DLCO, oxygen saturation, oxygenation index, duration of oxygen therapy, side effects, and immunological characteristics (immune cells, inflammatory factors, etc.)

Before the conduction of the previous study, a phase I intervention was conducted in Fu-Sheng Wang, Beijing 302 Hospital to investigate the safety and efficiency of MSCs in treating patients infected with 2019-nCoV. 10 out of 20 of the involved patients were allocated in the treatment group and were given three $3.0 \times 10^{7}$ doses of MSCs intravenously every 3rd day, as well as the conventional treatment. The remaining 10 patients were in control group. During the 180 days' time long follow up, the patients were assessed for clinical symptoms, pulmonary imaging, side effects, and immunological characteristics (immune cells, inflammatory factors, etc.)

In another study to treat severe pneumonia of COVID-19, utilizing allogeneic human dental pulp mesenchymal stem cells has been registered on March 28, 2020, by Ye Qingsong, Renmin Hospital of Wuhan University. This phase I/II study aims to evaluate the safety and efficacy of allogeneic human dental pulp mesenchymal stem cells in the treatment of patients of severe type and explores the effects of these cells regarding the mortality rate, as well as the disease 
progression course. 20 patients with severe stages of COVID-19 aged 18-65 years will be enrolled and $3.0 \times 10^{7}$ of human dental pulp stem cells solution (30 mL) will be infused intravenously, along with the routine treatment. Control group however, will be administered with $3 \mathrm{~mL}$ of $0.9 \%$ saline as placebo every 3rd day and will also receive the routine treatment. In 28 days' time follow up, patients will be monitored for lung lesions according to CT findings, C-reactive protein levels, Th1 cytokines, Th2 cytokines, immunoglobulins, lymphocyte counts, etc.

A similar early phase I study to treat patients suffering from the severe COVID-19 pneumonia utilizing dental pulp mesenchymal stem cells has been registered on February 27, 2020, by CAR-T (Shanghai) Biotechnology Co., Ltd., involving 24 participants with age limit of 18 to 75 years old. Subjects will receive conventional treatment with administration of dental pulp mesenchymal stem cells. On days 1, 3, and $7,50 \mathrm{~mL}$ of saline gradually will be given to the patients, during $60 \mathrm{~min}$, then $1.0 \times 10^{6}$ of dental pulp mesenchymal stem cells $/ \mathrm{kg}$ will be infused, and finally another $50 \mathrm{~mL}$ of saline will be administered. Kaplanmeier method will be used to calculate the median glassy shadow time in all subjects during the 14 days' time frame.

A phase I study to assess the efficacy of NestCell ${ }^{\circledR}$ mesenchymal stem cell to treat patients with severe COVID-19 pneumonia has been registered as of March 18, 2020, by Azidus Brasil. The experiment will be conducted in 2 phases, as in phase I, 6 patients with a minimum age of 18 will be involved with positive report of RT-PCR. The patients will receive conventional therapy, as well as $1 \times 10^{6}$ of NestCell ${ }^{\circledR}$ mesenchymal stem cells/kg weight on days 1,3 and 7 . In the follow up period, the monitoring board will see if the study needs any change regarding the dose or posology before moving to the next phase. In phase II, more than 60 patients will be involved and study will be conducted under the recommendation of the monitoring board. In the 28 days' time frame, Kaplan-meier method will be used to calculate the median glassy shadow time in all subjects for evaluating pneumonia change. Also factors like rate of mortality, course of changes in clinical symptoms, $\mathrm{CD}^{+}{ }^{+}$and $\mathrm{CD}^{+}{ }^{+} \mathrm{T}$ cell count, blood oxygen level, as well as the side effects in the treatment group will be observed during the 28 days of time frame.
A phase I, single-arm design, open label, combined interventional clinical trial is also being conducted by Ruijin Hospital, Medical School of Shanghai Jiaotong University Shanghai, China, registered as of February 16,2020 , to treat patients of sever type via aerosol inhalation of the allogeneic adipose mesenchymal stem cells-derived exosomes (MSCs-Exo), as well as to explore the safety and efficiency of the study. 30 patients will be included, administered with conventional therapy, in addition to $2.0 \times 10^{8}$ of nano vesicles $/ 3 \mathrm{~mL}$ in 5 consecutive days. During the 28 days of time frame, subject will be taken under control regarding the $\mathrm{AE}, \mathrm{SAE}$, and clinical improvement.

A pilot study was conducted from January 23, 2020, to February 16, 2020 to transplant MSCs to COVID19 patients. 10 participants were received the routine treatment but the therapies were ineffective. $1 \times 10^{6}$ of $\mathrm{MSCs} / \mathrm{Kg}$ were transplanted intravenously into 7 patients including 1 critically sever type, 4 severe type, and 2 common types during $40 \mathrm{~min}$ long. The other patients as control received placebo and were be observed during 14 days of follow up. Patients recovered with improvement in primary and secondary outcomes, after 2-4 days of transplantation. Additionally, no secondary infection or delayed hypersensitivity was reported after the treatment. According to the CyTOF findings, Treg cells and DCs increased in the treatment group, except the common type patients. In addition, high levels of overactivated T cells and NK cells was back to normal, following 6 days of transplantation. Furthermore, ratio of serum TNF $\alpha$ decreased, despite the ratio of IL-10 (Leng et al. 2020).

A phase 1/2 randomized controlled trial to look into the safety and efficacy of intravenous infusion of mesenchymal stem cells COVID-19 patients of severe type is being conducted by Guangzhou Institute of Respiratory Health, Guangdong, China. 20 patients are estimated to enroll, varying from 18 to 75 years. The treatment group will be given $1 \times 10^{6} / \mathrm{kg}$ body weight of BM-MSCs intravenously for once, as well as the conventional treatments, whereas the control group will receive conventional treatment and placebo. The patients of treatment group will then be monitored for changes of oxygenation index and side effects as the current primary outcome measures. Patients suffering from other types of pneumonia, and 


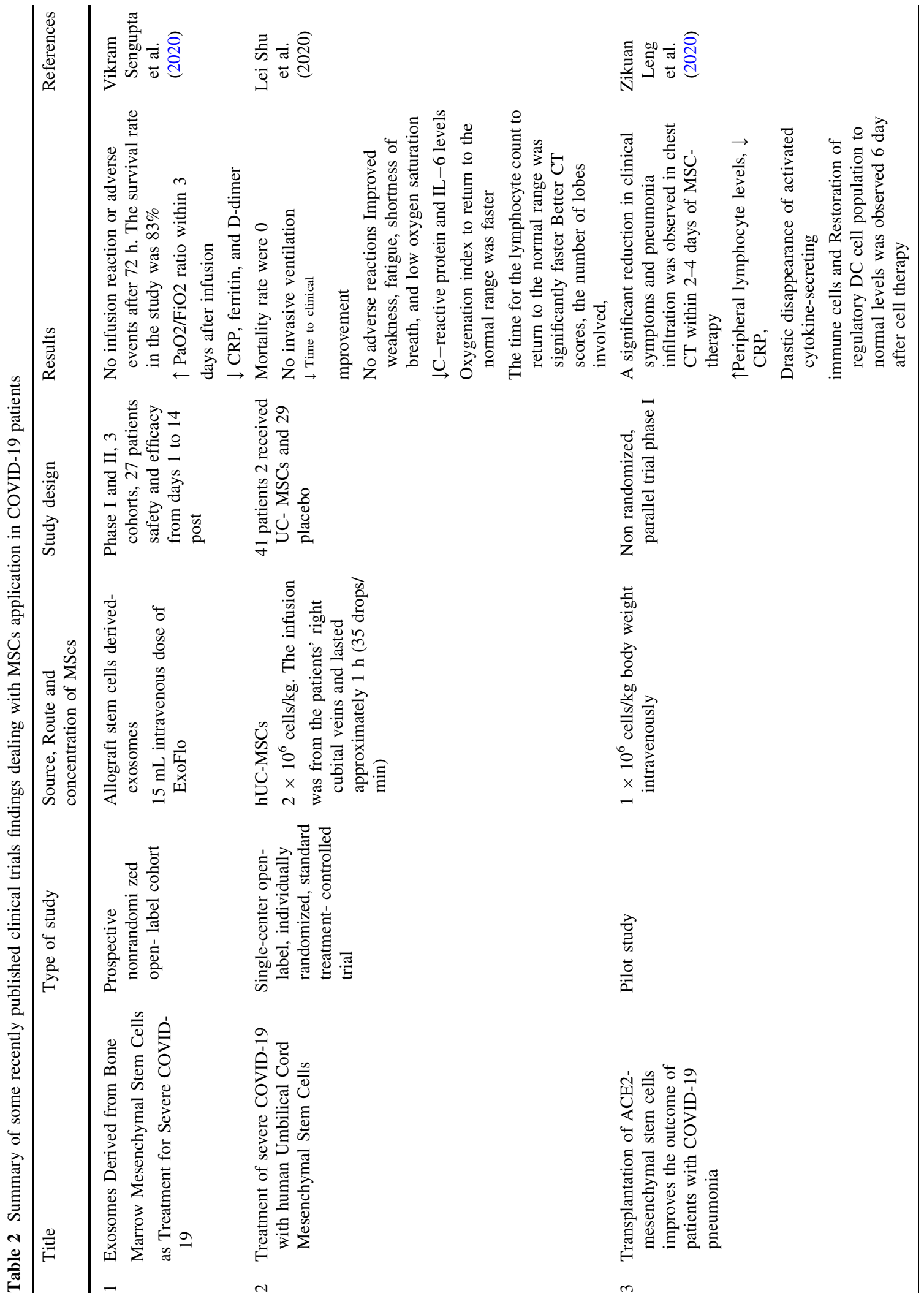




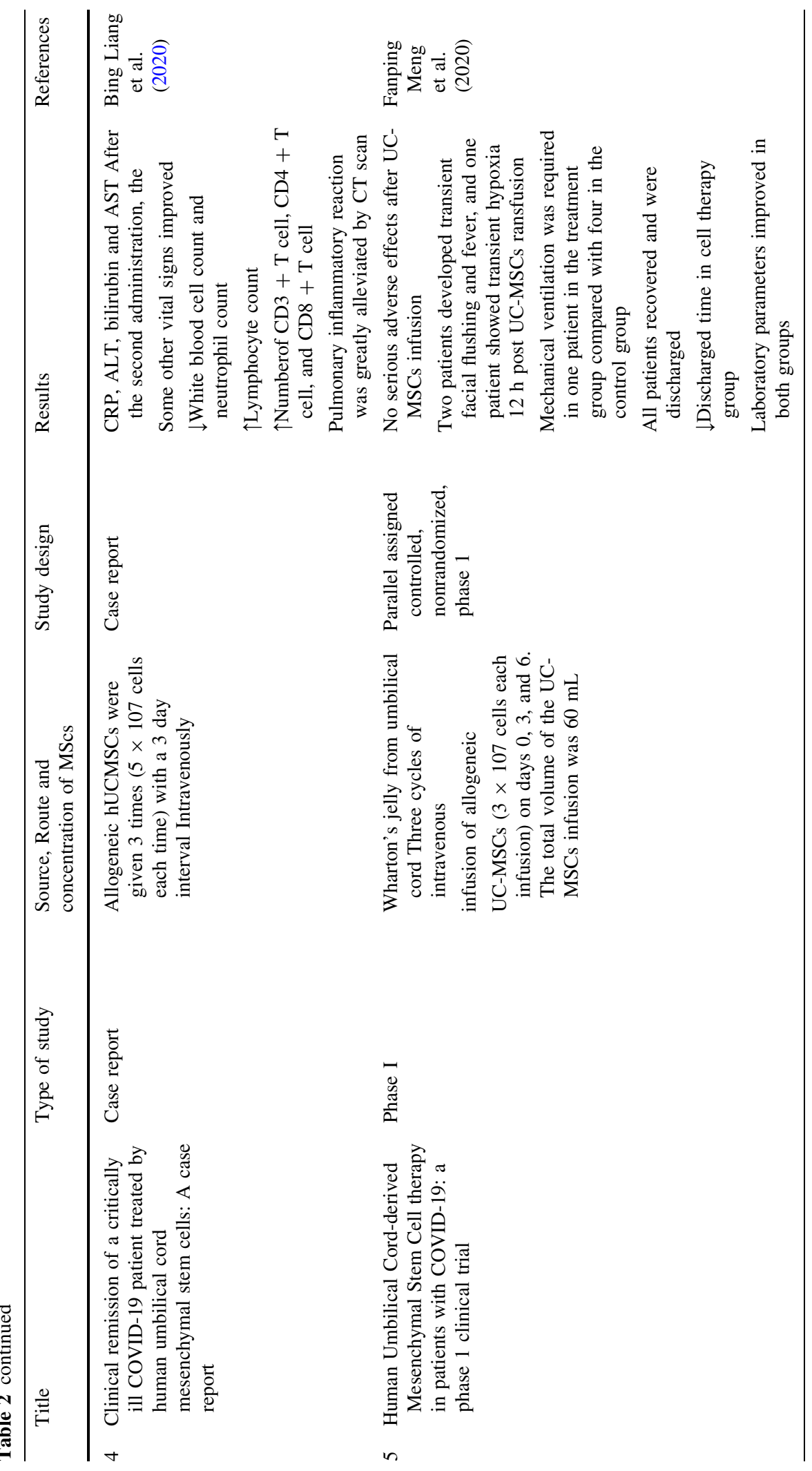




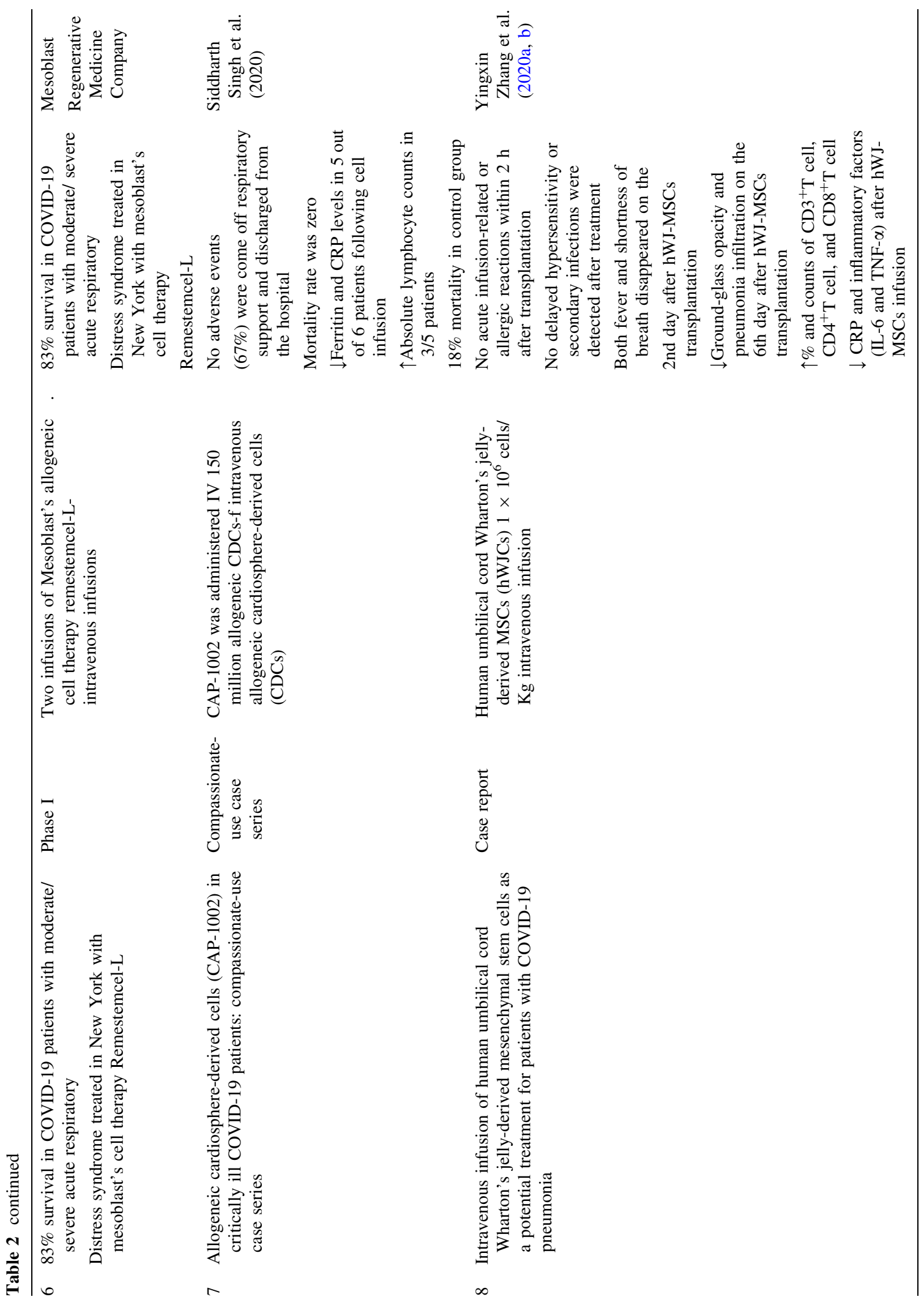



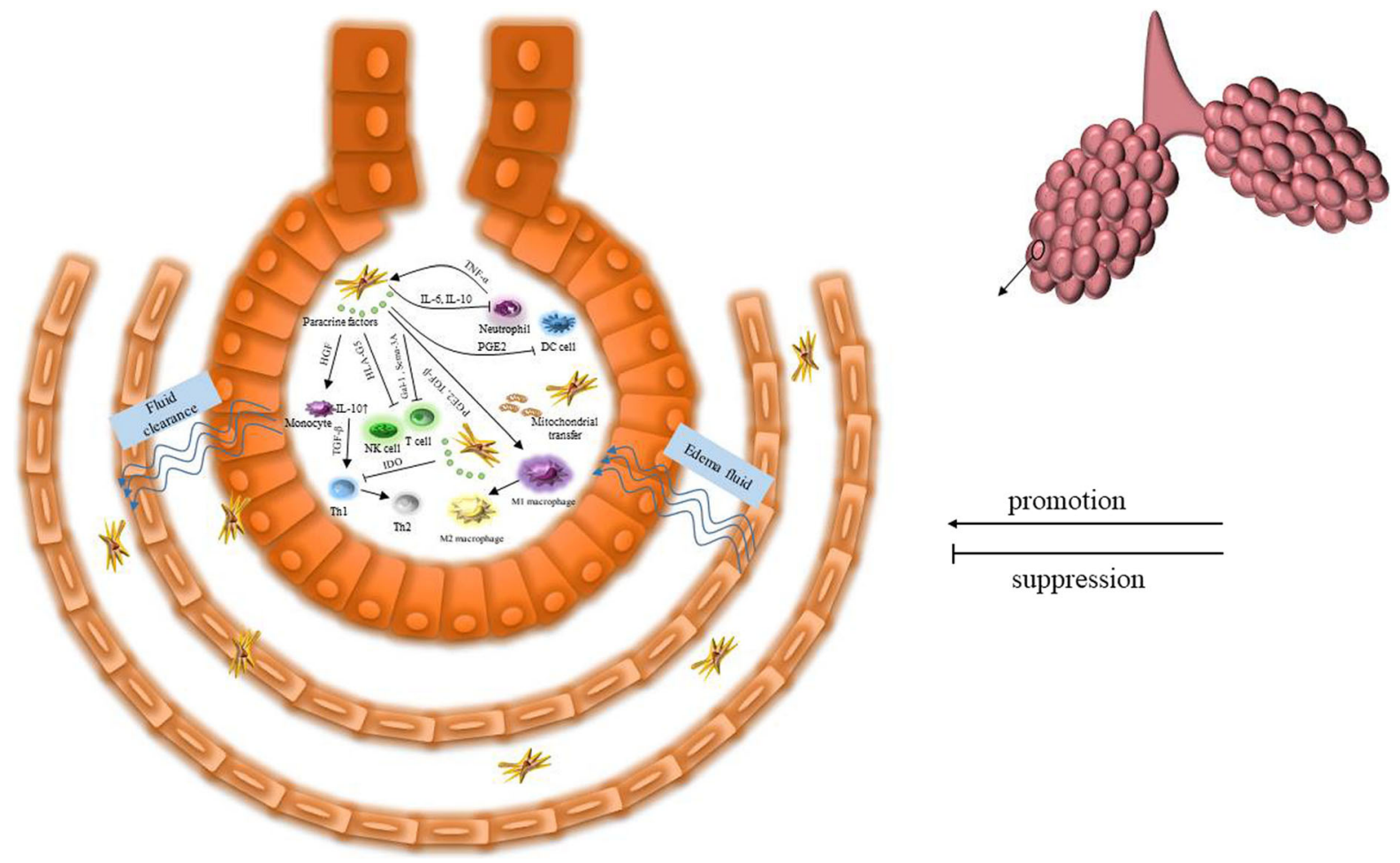

patients of mild, moderate or critical will be excluded from the study.

An early phase I, single-arm, pilot study, conducted by the Baylor College of Medicine, Houston, Texas. 30 patients of sever type of COVID-19 pneumonia, over 18 years old are to be involved in this study. $1 \times 10^{8}$ of MSCs will be infused to the subjects intravenously, and then will be checked for any adverse effects during the 28 days of follow up, as well as the oxygen saturations in 7 days' time after cell infusion. The study aims to look into the efficacy of MSCs in treating COVID-19 pneumonia.

Red de Terapia Celular, Spain is to conduct a double blind, placebo-controlled, phase II trial, with 24 subjects in experimental and control groups. Experimental group intravenous injection of $1 \times 10^{6}$ of MSV cells $/ \mathrm{Kg}$ in $100 \mathrm{~mL}$ of saline, whereas the control group will be infused with $100 \mathrm{~mL}$ of saline containing no cells intravenously. The study aims to investigate the safety and efficacy of allogeneic mesenchymal stromal cells MSV. The subjects will then be monitored for withdrawal of invasive mechanical ventilation following 7 days of infusion, and rate of mortality within the 28 days of follow up.
10-Application of MSCs showed their potential therapeutic effects on COVID-19 patients

As it was described earlier, the cytokines storm and disturbance of immune system are the main pathogenesis of the COVID-19. It has been revealed that MSCs modulate immume system and improve the patients conditions in several diseases including autoimmune diseases ( $\mathrm{Rad}$ et al. 2019). Therefore, following the current epidemiologic pandemic, MSCs therapy was prioritized in some hospitals. The many clinical trials were performed worldwide but the results of some of them were released. It is noted that the main sources of these cells are BM-MSCs, ASC, UC-MSCs, Wharton Gelly and oral cavity derived stem cells such pulp derived MSCs. The details of some clinical trials that their results have been released, have been summarized in Table 2. As it was mentioned in Table 2, all of these studies revealed the safety of application of MSCs in these patients. It is a good news and reduce the worries about using this strategy. In all of the studies, the cells were infused intravenously, therefore many number of cells were used. The cells number that used in these studies varies from $10^{6}$ to $150 \times 10^{6} / \mathrm{Kg}$ that infused through one or 
4Fig. 3 The immunomodulating potential of MSCs in lung. HGFs are involved in inflammatory damage reduction, autophagy promotion, fibrosis attenuation, enhance alveolar epithelium repair, as well as the modulation of IL-10 production in monocytes via the ERK1/2 pathway. TNF- $\alpha$ is involved in further activation of MSCs by IL-10, which is responsible for decreasing the neutrophil inflow and aggregation into the lungs, and reduce the production of TNF- $\alpha$. Also, HLA-G5 secretion of which is dependent on IL-10, which functions as T cell and NK cell suppressor, as well as Treg activator. In fact, a shift from Th1 to Th2 phenotype is accomplished through secretion of IL-10 and TGF- $\beta$, growth factors, soluble factors like and the inhibition of pro-inflammatory cytokines. In addition, T cell suppression may be accomplished by the secretion of Gal-1 and Sema-3A by MSCs. Gal-1 is involved in regulating the release of TNF$\alpha$, IFN- $\gamma$, IL-2, and IL-10. PGE2 inhibits the antigen presentation by DCs and proliferations of T-effector cells and together with TGF- $\beta$ functions to repolarize the macrophages from the proinflammatory M1-phenotype towards the anti-inflammatory M2-phenotype in an LPS-dependent manner, which is further accompanied by decrease inflammatory reactions, enhance phagocytic activity through the Akt/FoxO1 pathway, and progress tissue repair. TGF- $\beta$ also triggers the proliferation of Tregs, induces IL- 6 , and stimulates PGE2. IL-6 is also recognized as an inhibitor of neutrophil proliferation. MSCs-secreted IDO is involved in the enhancement of pulmonary antimicrobial activity, differentiation of $\mathrm{CD} 14^{+} / \mathrm{CD} 206^{+}$monocytes into IL-10-secreting immunosuppressive M2 macrophages, as well as the inhibition of IFN-secreting Th1 cells expansion, along with PGE2, to stop NK cell activity. To increase the exposure of MSCs to immunosuppressive effect inducing IL-1 $\beta$, TNF- $\alpha$, and IFN- $\gamma$, MSCs secrete IL-1Ra and PDL1, which are involved in inhibiting Th17 polarization and supporting the cell-cell contact through MSC-mediated inhibition of Th17, respectively. Induction of MSCs by IL-1 $\beta$, TNF- $\alpha$, and NO in the alveolar endothelial cells further leads to enhanced paracrine potential and increased secretion of regenerative, immunomodulatory, and trafficking molecules, including the IGF-1, HO-1, FGF-10, and KGF-2. HO-1 is a stressresponse protein overexpression which further leads to increase production of trophic molecules, such as FGF2, IGF-1, and VEGF, as well as promote anti-inflammatory, anti-apoptotic, anti-oxidative, and vascular remodeling properties. Regulation of the epithelialmesenchyme interactions and lung development is accomplished by FGF-10 and KGF-2, as FGF-10 inhibits viral replication and exerts a role in lung resident MSC propagation, mobilization, and the protective effects against acute lung injury, whereas KGF2 promotes AFC, restores sodium dependent alveolar fluid transport, reduces injury, promotes proliferation and repair of alveolar epithelial cells by increasing surface-active substances, such as matrix metalloprotein MMP-9, IL-1Ra, and GM-CSF, facilitates phagocytosis together with PGE2, GM-CSF, IL-6, and IL-13, protects the alveolar cells along with VEGF and HGF, and reduces apoptosis of the alveolar epithelial cells and endothelial cell in collaboration with Ang-1 and HGF. FGF-7 is thought to regulate the function of membrane channels and transporters to improve the AFC. Of note, VEGF, IGF, HGF, neurotrophin-3, and nerve growth factor are the MSCssecreted bioactive factors to exert an anti-apoptotic effect. In addition, VEGF together with HGF restores pulmonary capillary permeability to stabilize the endothelial barrier function, and together with PDGF induce proliferation of vascular endothelial cells and angiogenesis. Overexpression of anti-inflammatory and anti-oxidative molecules, including SST2, Del-1, and manganese superoxide dismutase, enhances the regenerative ability of lung injury. AFC alveolar fluid clearance, Ang-1 angiopoietin-1, DC dendritic cell, Del-1 developmental endothelial locus-1, FGF fibroblast growth factor, Gal-1 Galectin-1, GM-CSF granulocyte-macrophage colonystimulating factor, $H G F$ hepatocyte growth factor, $H L A-G 5$ human leukocyte antigen class I molecule G5, $H O-1$ haem oxygenase 1 , $I D O$ indoleamine 2,3-dioxygenase, $I F N$ - $\gamma$ interferon gamma, $I G F$ insulin-like growth factor $1, I L-10$ interleukin $10, I L-13$ interleukin $13, I L-1 R a$ interleukin-1 receptor antagonist, $I L-1 \beta$ interleukin 1 beta, $I L-2$ interleukin $2, I L-6$ interleukin $6, K G F 2$ keratinocyte growth factor 2, LPS lipopolysaccharide, MMP-9 metalloprotein, $M S C$ mesenchymal stem cell, $N K$ natural killer, $N O$ nitric oxide, $P D G F$ platelet-derived growth factor, $P D L 1$ programmed cell death ligands 1, PGE2 prostaglandin E2, Sema-3A Semaphorin-3A, sST2 soluble IL-1 receptor-like-1, TGF- $\beta$ transforming growth factor-beta, Th1 T helper type $1, T N F-\alpha$ tumor necrosis factor alpha, Treg regulatory $\mathrm{T}$ cell, $V E G F$ vascular endothelial growth factor

three injections. It seems that in this situation, the allograft transplantation is inevitable. Autologous transplantation needs more times for preparation and expansion of the cells, so it is not possible to use it for COVID-19 patients. As it has been represented in Table 2, the time of hospitalization were decreased after infusion of the cells. In addition, the need for ventilator decreased as reported in these studies. More importantly, the rate of mortality decreased in most of them that highlights the efficiency of MSCs therapy. As it has been represented in Table 2, the symptoms of patients including fever, weakness and fatigue, shortness of breath, abnormal lung CT score, and low oxygen saturation improved as the most of the patients left the hospitals earlier. The level of CRP, IL-6 and
TNF- $\alpha$ as inflammatory factors and neutrophils decreased, however, the number of lymphocytes increased after the cells infusion.

It is noteworthy that stem cells products such as exosomes, microvesicle and extracellular vesicles have therapeutic potential on several disaeses (Abbasi-Malati et al. 2018; Gentile et al. 2020d). In a study conducted by Vikram Sengupta, the (ExoFlo) an exosomes derived from allogeneic bone marrow mesenchymal stem cells was infused for COVID-19 patients. The results were promising and the survival rate was $83 \%$. Laboratory values revealed significant improvements in absolute neutrophil count [mean reduction $32 \%$ ( $\mathrm{P}$ value $<0.001)$ ] and lymphopenia with average $\mathrm{CD}^{+}, \mathrm{CD}^{+}$, and $\mathrm{CD} 8^{+}$lymphocyte 
counts increasing by $46 \% \quad(\mathrm{P}<0.05), \quad 45 \%$ $(\mathrm{P}<0.05)$, and $46 \%(\mathrm{P}<0.001)$, respectively. In addition, the early inflammation molecules such as CRP, ferritin, and D-dimer decreased. Overall, application of exosome showed beneficial effects on cytokine storm inhibition and improved the patient's condition. It seems that it could be consider as a valuable candidate for COVID-19 treatment in future.

The early outcomes of application of MSCs on COVID-19 patients are promising; however, it had several limitations and challenges including absence of randomization, blinding, and the limited sample size. Therefore, it is difficult to conclude with certainly its efficacy. In addition, relevant mechanisms by which MSCs therapy exerts its therapeutic properties should be investigated in future. However, some aspects and pathways in which MSCs represent their immunomodulatory effects on lung tissue after covid19 has been shown in Fig. 3.

\section{Conclusion}

To prevent and better control the spread of these diseases in the future, preventing the transmission of zoonotic diseases should be a research priority ( $\mathrm{Li}$ et al. 2020b). The first step of the HCoV-19 pathogenesis is the virus to recognize the ACE2 using its spike. Studies on human and animals show that once the coronavirus infects the cell, an inflammatory response will be performed, followed by the rapid replication of the virus, resulting in damage to the alveolar epithelial cells and capillary endothelial cells, as well as interstitial and alveolar edema, and impaired lungs, leading to acute hypoxic respiratory insufficiency. Although the cure of COVID-19 is essentially dependent on the patient's own immune system, it's speculated that the inhibition of the inflammatory immune response-related cytokine storms is the key to treating the patients of severe type, as the virusinduced cytokine storms can be the primary reason for the organ damage. Administration of MSCs is recommended, as MSCs feature special properties, such as high proliferation potential, migration to the site of inflammation, anti-inflammatory, pro-inflammatory, immunoregulatory, immunomodulatory, and tissueregenerating capabilities. Thus, the damage of alveolar epithelial cells and capillary endothelial cells would be recovered. In other words, following activation of TLR receptor in MSCs, these cells secrete cytokines through paracrine secretion, as well as direct interactions, may lead to modulating the immune response and attenuating the cytokine storms. Moreover, MSCs are negative for ACE2 or TMPRSS2, which means the SARS-CoV-2, would fail in infecting these cells.

Despite the fact that stem cell therapy is not a method to eradicate or cure SARS-CoV-2, it is recommended that MSCs be used in developing regenerative medicine and diseases associated with autoimmune disorders, as these cells can be easily isolated, own self-renewal abilities, and are characterized by multi-potent differentiation. Also, according to studies, these cells can be used for tissue regeneration, including liver (Cho et al. 2009), kidney (Qian et al. 2008), and pancreas (Han et al. 2012), which will probably be affected during the viral infection. The primary mechanisms of these cells, as well as application in treatment in pre-clinical and clinical studies, are made through a paracrine mechanism. Immune system components, including immune molecules and immune cells, protect the host against exogenous pathogens and also, progression of endogenous cancer, so the understimulated immune system will fail to defend the host. At the same time, overstimulation leads the immune system to attack healthy cells and tissues, resulting in autoimmune diseases. Accordingly, regulation of the immune system with different mechanisms is inevitable.

Acknowledgements Part of this review study was supported by research deputy of Guilan University of Medical Sciences (Gran Number: IR.GUMS.REC.1396.343).

Author contributions NN: performed the literature search and data analysis and prepared the manuscript draft. MHR: critically revised and edited the manuscript. HZL: revised and left the comments. AMR: had the idea for the article, critically read and revised and edited the manuscript.

\section{Declarations}

Conflict of interest The authors declare that they have no conflict of interest.

Ethical approval The all processes and protocols were accordance with ethical standards. 


\section{References}

Abbasi-Malati Z, Roushandeh AM, Kuwahara Y, Roudkenar MH (2018) Mesenchymal stem cells on horizon: a new arsenal of therapeutic agents. Stem Cell Rev Rep 14:484-499

Abraham A, Krasnodembskaya A (2020) Mesenchymal stem cell-derived extracellular vesicles for the treatment of acute respiratory distress syndrome. Stem Cells Transl Med 9:28-38

Abumaree M et al (2013) Human placental mesenchymal stem cells (pMSCs) play a role as immune suppressive cells by shifting macrophage differentiation from inflammatory M1 to anti-inflammatory M2 macrophages. Stem Cell Rev Rep 9:620-641

Aggarwal S, Pittenger MF (2005) Human mesenchymal stem cells modulate allogeneic immune cell responses. Blood 105:1815-1822. https://doi.org/10.1182/blood-2004-041559

Alhazzani W et al (2020) Surviving Sepsis Campaign: guidelines on the management of critically ill adults with Coronavirus Disease 2019 (COVID-19). Intens Care Med. https://doi.org/10.1007/s00134-020-06022-5

Alijani-Ghazyani Z, Roushandeh AM, Sabzevari R, Salari A, Razavi Toosi MT, Jahanian-Najafabadi A, Roudkenar MH (2020a) Conditioned medium harvested from Hif1 $\alpha$ engineered mesenchymal stem cells ameliorates LAD-occlusion -induced injury in rat acute myocardial ischemia model. Int J Biochem Cell Biol 130:105897. https://doi. org/10.1016/j.biocel.2020.105897

Alijani-Ghazyani Z, Sabzevari R, Roushandeh AM, JahanianNajafabadi A, Amiri F, Roudkenar MH (2020b) Transplantation of umbilical cord-derived mesenchymal stem cells overexpressing lipocalin 2 ameliorates ischemia-induced injury and reduces apoptotic death in a rat acute myocardial infarction model. Stem Cell Rev Rep 16:968-978

Al-Khawaga S, Abdelalim EM (2020) Potential application of mesenchymal stem cells and their exosomes in lung injury: an emerging therapeutic option for COVID-19 patients. Stem Cell Res Ther 11:1-33

Allakhverdi $\mathrm{Z}$ et al (2013) Mast cell-activated bone marrow mesenchymal stromal cells regulate proliferation and lineage commitment of $\mathrm{CD} 34+$ progenitor cells. Front Immunol 4:461

Angoulvant D, Clerc A, Benchalal S, Galambrun C, Farre A, Bertrand Y, Eljaafari A (2004) Human mesenchymal stem cells suppress induction of cytotoxic response to alloantigens. Biorheology 41:469-476

Asari S, Itakura S, Ferreri K, Liu C-P, Kuroda Y, Kandeel F, Mullen Y (2009) Mesenchymal stem cells suppress B-cell terminal differentiation. Exp Hematol 37:604-615

Backer JA, Klinkenberg D, Wallinga J (2020) Incubation period of 2019 novel coronavirus (2019-nCoV) infections among travellers from Wuhan, China. Eurosurveillance 25:2000062

Baglio SR, Pegtel DM, Baldini N (2012) Mesenchymal stem cell secreted vesicles provide novel opportunities in (stem) cell-free therapy. Front Physiol 3:359
Bari E, Ferrarotti I, Saracino L, Perteghella S, Torre ML, Corsico AG (2020) Mesenchymal stromal cell secretome for severe COVID-19 infections: premises for the therapeutic use. Cells 9:924

Baruah V, Bose S (2020) Immunoinformatics-aided identification of $\mathrm{T}$ cell and $\mathrm{B}$ cell epitopes in the surface glycoprotein of 2019-nCoV. J Med Virol 92:495-500

Bashiri H et al (2018) Dual preconditioning: a novel strategy to withstand mesenchymal stem cells against harsh microenvironments. Adv Pharm Bull 8:465

Bastola A et al (2020) The first 2019 novel coronavirus case in Nepal. Lancet Infect Dis 20:279-280. https://doi.org/10. 1016/s1473-3099(20)30067-0

Belouzard S, Millet JK, Licitra BN, Whittaker GR (2012) Mechanisms of coronavirus cell entry mediated by the viral spike protein. Viruses 4:1011-1033

Benvenuto $\mathrm{F}$ et al (2007) Human mesenchymal stem cells promote survival of T cells in a quiescent state. Stem Cells (Dayton, Ohio) 25:1753-1760

Bernardo ME, Fibbe WE (2013) Mesenchymal stromal cells: sensors and switchers of inflammation. Cell Stem Cell 13:392-402. https://doi.org/10.1016/j.stem.2013.09.006

Bianco P (2014) "Mesenchymal" stem cells. Annu Rev Cell Dev Biol 30:677-704. https://doi.org/10.1146/annurevcellbio-100913-013132

Braid LR, Wood CA, Wiese DM, Ford BN (2018) Intramuscular administration potentiates extended dwell time of mesenchymal stromal cells compared to other routes. Cytotherapy 20:232-244. https://doi.org/10.1016/j.jcyt. 2017.09.013

Brandau S et al (2014) Mesenchymal stem cells augment the anti-bacterial activity of neutrophil granulocytes. PLoS ONE 9:e106903

Brinkmann V et al (2004) Neutrophil extracellular traps kill bacteria. Science (New York, NY) 303:1532-1535

Brown JM, Nemeth K, Kushnir-Sukhov NM, Metcalfe DD, Mezey E (2011) Bone marrow stromal cells inhibit mast cell function via a COX2-dependent mechanism. Clin Exp Allergy 41:526-534

Cassatella MA et al (2011) Toll-like receptor-3-activated human mesenchymal stromal cells significantly prolong the survival and function of neutrophils. Stem Cells (Dayton, $\mathrm{OH}$ ) 29:1001-1011

Cervelli V et al (2013) PRL platelet rich lipotransfert: our experience and current state of art in the combined use of fat and PRP. BioMed Res Int 2013:434191

Chamseddine RS, Wahbeh F, Chervenak F, Salomon LJ, Ahmed B, Rafii A (2020) Pregnancy and neonatal outcomes in SARS-CoV-2 infection: a systematic review medRxiv

Chan JF et al (2020) A familial cluster of pneumonia associated with the 2019 novel coronavirus indicating person-to-person transmission: a study of a family cluster. Lancet (London, England) 395:514-523. https://doi.org/10.1016/ s0140-6736(20)30154-9

Che N, Li X, Zhou S, Liu R, Shi D, Lu L, Sun L (2012) Umbilical cord mesenchymal stem cells suppress B-cell proliferation and differentiation. Cell Immunol 274:46-53. https://doi.org/10.1016/j.cellimm.2012.02.004

Chen $\mathrm{H}$ et al (2020a) Clinical characteristics and intrauterine vertical transmission potential of COVID-19 infection in nine pregnant women: a retrospective review of medical 
records. Lancet (London, England) 395:809-815. https:// doi.org/10.1016/s0140-6736(20)30360-3

Chen N et al (2020b) Epidemiological and clinical characteristics of 99 cases of 2019 novel coronavirus pneumonia in Wuhan, China: a descriptive study. Lancet (London, England) 395:507-513. https://doi.org/10.1016/s01406736(20)30211-7

Chiesa $S$ et al (2011) Mesenchymal stem cells impair in vivo T-cell priming by dendritic cells. Proc Natl Acad Sci 108:17384-17389

Childs RW, Carlsten M (2015) Therapeutic approaches to enhance natural killer cell cytotoxicity against cancer: the force awakens. Nat Rev Drug Discov 14:487-498

Cho KA et al (2009) Mesenchymal stem cells showed the highest potential for the regeneration of injured liver tissue compared with other subpopulations of the bone marrow. Cell Biol Int 33:772-777. https://doi.org/10.1016/j.cellbi. 2009.04.023

Cho K-A, Lee J-K, Kim Y-H, Park M, Woo S-Y, Ryu K-H (2017) Mesenchymal stem cells ameliorate B-cell-mediated immune responses and increase IL-10-expressing regulatory B cells in an EBI3-dependent manner. Cell Mol Immunol 14:895-908

Consentius C et al (2015) Mesenchymal stromal cells prevent allostimulation in vivo and control checkpoints of Th1 priming: migration of human DC to lymph nodes and NK cell activation. Stem Cells (Dayton, Ohio) 33:3087-3099

Corcione A et al (2006) Human mesenchymal stem cells modulate B-cell functions. Blood 107:367-372

Crop $M$ et al (2010) Inflammatory conditions affect gene expression and function of human adipose tissue-derived mesenchymal stem cells. Clin Exp Immunol 162:474-486

Cruz FF, Rocco PRM (2020) The potential of mesenchymal stem cell therapy for chronic lung disease. Expert Rev Respir Med 14:31-39

Cui R et al (2016) Human mesenchymal stromal/stem cells acquire immunostimulatory capacity upon cross-talk with natural killer cells and might improve the NK cell function of immunocompromised patients. Stem Cell Res Ther 7:88

Cui J, Li F, Shi ZL (2019) Origin and evolution of pathogenic coronaviruses. Front Immunol 17:181-192. https://doi.org/ 10.1038/s41579-018-0118-9

da Silva ML, Chagastelles PC, Nardi NB (2006) Mesenchymal stem cells reside in virtually all post-natal organs and tissues. J Cell Sci 119:2204-2213. https://doi.org/10.1242/ jes.02932

Dawood FS et al (2020) Interim Estimates of 2019-20 Seasonal Influenza Vaccine Effectiveness - United States, February 2020. MMWR Morb Mortal Wkly Rep 69:177-182. https://doi.org/10.15585/mmwr.mm6907a1

de Wit E, van Doremalen N, Falzarano D, Munster VJ (2016) SARS and MERS: recent insights into emerging coronaviruses. Nat Rev Microbiol 14:523-534. https://doi.org/ 10.1038/nrmicro.2016.81

Del Rio C, Malani PN (2020) 2019 novel coronavirus-important information for clinicians. JAMA. https://doi.org/10.1001/ jama.2020.1490

Di Trapani M et al (2016) Differential and transferable modulatory effects of mesenchymal stromal cell-derived extracellular vesicles on T B and NK cell functions. Sci Rep $6: 24120$
Djouad F et al (2007) Mesenchymal stem cells inhibit the differentiation of dendritic cells through an interleukin-6dependent mechanism. Stem Cells (Dayton, Ohio) 25:2025-2032

Drexler JF et al (2010) Genomic characterization of severe acute respiratory syndrome-related coronavirus in European bats and classification of coronaviruses based on partial RNAdependent RNA polymerase gene sequences. J Virol 84:11336-11349. https://doi.org/10.1128/jvi.00650-10

Dubey AK, Singh A, Prakash S, Kumar M, Singh AK (2020) Race to arsenal COVID-19 therapeutics: current alarming status and future directions. Chem-Biol Interact 332:109298. https://doi.org/10.1016/j.cbi.2020.109298

Fan E, Brodie D, Slutsky AS (2018) Acute respiratory distress syndrome: advances in diagnosis and treatment. JAMA 319:698-710

Fathman JW, Bhattacharya D, Inlay MA, Seita J, Karsunky H, Weissman IL (2011) Identification of the earliest natural killer cell-committed progenitor in murine bone marrow. Blood 118:5439-5447

Favaro E et al (2016) Human mesenchymal stem cells and derived extracellular vesicles induce regulatory dendritic cells in type 1 diabetic patients. Diabetologia 59:325-333

Fehr AR, Perlman S (2015) Coronaviruses: an overview of their replication and pathogenesis. Coronaviruses. Springer, New York, pp 1-23

Force ADT, Ranieri V, Rubenfeld G, Thompson B, Ferguson N, Caldwell E (2012) Acute respiratory distress syndrome. JAMA 307:2526-2533

Franquesa M, Hoogduijn MJ, Bestard O, Grinyó JM (2012) Immunomodulatory effect of mesenchymal stem cells on B cells. Front Immunol 3:212

Franquesa $\mathrm{M}$ et al (2015) Human adipose tissue-derived mesenchymal stem cells abrogate plasmablast formation and induce regulatory B cells independently of T helper cells. Stem Cells (Dayton, Ohio) 33:880-891

Fraser JK, Wulur I, Alfonso Z, Hedrick MH (2006) Fat tissue: an underappreciated source of stem cells for biotechnology. Trends Biotechnol 24:150-154

Gattinoni L, Coppola S, Cressoni M, Busana M, Rossi S, Chiumello D (2020) Covid-19 does not lead to a "typical" acute respiratory distress syndrome. Am J Respir Crit Care Med 201:1299-1300

Gentile P (2019) Autologous cellular method using micrografts of human adipose tissue derived follicle stem cells in androgenic alopecia. Int J Mol Sci 14:3446. https://doi.org/ 10.3390/ijms20143446

Gentile P, Garcovich S (2019a) Advances in regenerative stem cell therapy in androgenic alopecia and hair loss: Wnt pathway growth-factor, and mesenchymal stem cell signaling impact analysis on cell growth and hair follicle development. Cells. https://doi.org/10.3390/cells8050466

Gentile P, Garcovich S (2019b) Concise review: adiposederived stem cells (ASCs) and adipocyte-secreted exosomal microRNA (A-SE-miR) modulate cancer growth and promote wound repair. J Clin Med. https://doi.org/10.3390/ jcm8060855

Gentile P, Sterodimas A (2020a) Adipose-derived stromal stem cells (ASCs) as a new regenerative immediate therapy combating coronavirus (COVID-19)-induced pneumonia. 
Expert Opin Biol Ther 20:711-716. https://doi.org/10. 1080/14712598.2020.1761322

Gentile P, Sterodimas A (2020b) Adipose stem cells (ASCs) and stromal vascular fraction (SVF) as a potential therapy in combating (COVID-19)-disease. Aging Dis 11:465-469. https://doi.org/10.14336/ad.2020.0422

Gentile P et al (2014a) Adipose-derived stromal vascular fraction cells and platelet-rich plasma: basic and clinical evaluation for cell-based therapies in patients with scars on the face. J Craniofac Surg 25:267-272

Gentile P, Scioli MG, Bielli A, Orlandi A, Cervelli V (2017a) Comparing different nanofat procedures on scars: role of the stromal vascular fraction and its clinical implications. Regen Med 12:939-952. https://doi.org/10.2217/rme2017-0076

Gentile P, Scioli MG, Bielli A, Orlandi A, Cervelli V (2017b) Stem cells from human hair follicles: first mechanical isolation for immediate autologous clinical use in androgenetic alopecia and hair loss. Stem Cell Investig 4:58. https://doi.org/10.21037/sci.2017.06.04

Gentile P, Calabrese C, De Angelis B, Pizzicannella J, Kothari A, Garcovich S (2019a) Impact of the different preparation methods to obtain human adipose-derived stromal vascular fraction cells (AD-SVFs) and human adipose-derived mesenchymal stem cells (AD-MSCs): enzymatic digestion versus mechanical centrifugation. Int J Mol Sci 20:5471. https://doi.org/10.3390/ijms20215471

Gentile P, Casella D, Palma E, Calabrese C (2019b) Engineered fat graft enhanced with adipose-derived stromal vascular fraction cells for regenerative medicine: clinical histological and instrumental evaluation in breast reconstruction. J Clin Med. https://doi.org/10.3390/jcm8040504

Gentile P, Piccinno MS, Calabrese C (2019c) Characteristics and potentiality of human adipose-derived stem cells (hASCs) obtained from enzymatic digestion of fat graft. Cells 8:232. https://doi.org/10.3390/cells8030282

Gentile P et al (2019d) Platelet-rich plasma and micrografts enriched with autologous human follicle mesenchymal stem cells improve hair re-growth in androgenetic alopecia biomolecular pathway analysis and clinical evaluation. Biomedicines. biomedicines 7020027

Gentile P, Kothari A, Casella D, Calabrese C (2020a) Fat graft enhanced with adipose-derived stem cells in aesthetic breast augmentation: clinical histological, and instrumental evaluation. Aesthet Surg J 40:962-977. https://doi.org/10. 1093/asj/sjz292

Gentile P, Scioli MG, Cervelli V, Orlandi A, Garcovich S (2020b) Autologous micrografts from scalp tissue: trichoscopic and long-term clinical evaluation in male and female androgenetic alopecia. BioMed Res Int 2020:1-10

Gentile P, Sterodimas A, Pizzicannella J, Calabrese C, Garcovich S (2020c) Research progress on mesenchymal stem cells (MSCs), adipose-derived mesenchymal stem cells (AD-MSCs), drugs, and vaccines in inhibiting COVID-19 disease. Aging Dis 11:1191-1201. https://doi.org/10. 14336/ad.2020.0711

Gentile P, Sterodimas A, Pizzicannella J, Dionisi L, De Fazio D, Calabrese C, Garcovich S (2020d) Systematic review: allogenic use of stromal vascular fraction (SVF) and decellularized extracellular matrices (ECM) as advanced therapy medicinal products (ATMP) in tissue regeneration. Int J Mol Sci 21:4982

Giuliani M et al (2014) TLR ligands stimulation protects MSC from NK killing. Stem Cells (Dayton, Ohio) 32:290-300

Glennie S, Soeiro I, Dyson PJ, Lam EW, Dazzi F (2005) Bone marrow mesenchymal stem cells induce division arrest anergy of activated T cells. Blood 105:2821

Götherström C, Ringdén O, Tammik C, Zetterberg E, Westgren M, Le Blanc K (2004) Immunologic properties of human fetal mesenchymal stem cells. Am J Obstet Gynecol 190:239-245

Götherström C, Lundqvist A, Duprez IR, Childs R, Berg L, le Blanc K (2011) Fetal and adult multipotent mesenchymal stromal cells are killed by different pathways. Cytotherapy 13:269-278

Guan WJ et al (2020) Clinical characteristics of coronavirus disease 2019 in China. N Engl J Med. https://doi.org/10. 1056/NEJMoa2002032

Gupta A, Kashte S, Gupta M, Rodriguez HC, Gautam SS, Kadam S (2020) Mesenchymal stem cells and exosome therapy for COVID-19: current status and future perspective. Hum Cell 33:1-12

Hamming I, Timens W, Bulthuis M, Lely A, Navis G, van Goor $\mathrm{H}$ (2004) Tissue distribution of ACE2 protein, the functional receptor for SARS coronavirus A first step in understanding SARS pathogenesis. J Pathol 203:631-637

Han F, Wang CY, Yang L, Zhan SD, Zhang M, Tian K (2012) Contribution of murine bone marrow mesenchymal stem cells to pancreas regeneration after partial pancreatectomy in mice. Cell Biol Int 36:823-831

Hao Q et al (2019) Mesenchymal stem cell-derived extracellular vesicles decrease lung injury in mice. J Immunol 203:1961-1972

Hoffmann M, Kleine-Weber H, Krüger N, Mueller MA, Drosten C, Pöhlmann S (2020) The novel coronavirus 2019 (2019$\mathrm{nCoV}$ ) uses the SARS-coronavirus receptor ACE2 and the cellular protease TMPRSS2 for entry into target cells. BioRxiv

Holshue ML et al (2020) First case of novel coronavirus in the United States. N Engl J Med 382:929-936. https://doi.org/ 10.1056/NEJMoa2001191

Hosseini A, Amiri F, Khalighi F, Mohammadi Roushandeh A, Kuwahara Y, Bashiri H, Habibi Roudkenar M (2019) Cell survival effects of autophagy regulation on umbilical cordderived mesenchymal stem cells following exposure to oxidative stress. Iran J Med Sci 44:493-500. https://doi. org/10.30476/ijms.2019.44947

Hu S, Park J, Liu A, Lee J, Zhang X, Hao Q, Lee JW (2018) Mesenchymal stem cell microvesicles restore protein permeability across primary cultures of injured human lung microvascular endothelial cells. Stem Cells Transl Med $7: 615-624$

Huang $\mathrm{C}$ et al (2020a) Clinical features of patients infected with 2019 novel coronavirus in Wuhan, China. Lancet 395:497-506

Huang C et al (2020b) Clinical features of patients infected with 2019 novel coronavirus in Wuhan, China. Lancet (London, England) 395:497-506. https://doi.org/10.1016/s01406736(20)30183-5

IM DL, Jenkins MK, Schwartz RH (1989) Clonal expansion versus functional clonal inactivation: a 
costimulatorl'signalling pathway determines the outcome of $\mathrm{T}$ cell antigen receptor occupancy. Annu Rev Immunol 7:445-480

Jeschke MG, Gauglitz GG, Herndon DN, Phan TT, Kita K (2011) Umbilical cord lining membrane and wharton's jelly-derived mesenchymal stem cells: the similarities and differences. Open Tissue Eng Regen Med J 4:21-27

Ji W, Wang W, Zhao X, Zai J, Li X (2020) Cross-species transmission of the newly identified coronavirus 2019-nCoV. J Med Virol 92:433-440. https://doi.org/10. $1002 / j m v .25682$

Jiang W, Xu J (2020) Immune modulation by mesenchymal stem cells. Cell Prolif 53:e12712. https://doi.org/10.1111/ cpr.12712

Jones E, Yang X (2011) Mesenchymal stem cells and bone regeneration: current status. Injury 42:562-568. https://doi. org/10.1016/j.injury.2011.03.030

Kamen DL, Nietert PJ, Wang H, Duke T, Cloud C, Robinson A, Gilkeson GS (2018) CT-04 Safety and efficacy of allogeneic umbilical cord-derived mesenchymal stem cells (MSCs) in patients with systemic lupus erythematosus: results of an open-label phase I study. Archives of Disease in childhood

Kanne J (2020) Chest CT findings in 2019-nCoV infections from Wuhan, China: what is currently known radiology

Keating A (2012) Mesenchymal stromal cells: new directions. Cell Stem Cell 10:709-716. https://doi.org/10.1016/j.stem. 2012.05.015

Kern S, Eichler H, Stoeve J, Klüter H, Bieback K (2006) Comparative analysis of mesenchymal stem cells from bone marrow, umbilical cord blood, or adipose tissue. Stem Cells (Dayton, Ohio) 24:1294-1301

Kfoury Y, Scadden DT (2015) Mesenchymal cell contributions to the stem cell niche. Cell Stem Cell 16:239-253. https:// doi.org/10.1016/j.stem.2015.02.019

Khatri M, Richardson LA, Meulia T (2018) Mesenchymal stem cell-derived extracellular vesicles attenuate influenza virus-induced acute lung injury in a pig model. Stem Cell Res Ther 9:1-13

Kingsley DM (1994) The TGF-beta superfamily: new members, new receptors, and new genetic tests of function in different organisms. Genes Dev 8:133-146

Kirchdoerfer RN et al (2016) Pre-fusion structure of a human coronavirus spike protein. Nature 531:118-121. https://doi. org/10.1038/nature 17200

Koch U, Radtke F (2011) Mechanisms of T cell development and transformation. Annu Rev Cell Dev Biol 27:539-562

Kolaczkowska E, Kubes P (2013) Neutrophil recruitment and function in health and inflammation. Nat Rev Immunol 13:159-175

Kowal J, Tkach M, Théry C (2014) Biogenesis and secretion of exosomes. Curr Opin Cell Biol 29:116-125

Krampera M, Glennie S, Dyson J, Scott D, Laylor R, Simpson E, Dazzi F (2003) Bone marrow mesenchymal stem cells inhibit the response of naive and memory antigen-specific T cells to their cognate peptide. Blood 101:3722-3729

Lam TT-Y, et al (2020) Identification of 2019-nCoV related coronaviruses in Malayan pangolins in southern China. BioRxiv

Lambeir AM, Durinx C, Scharpé S, De Meester I (2003) Dipeptidyl-peptidase IV from bench to bedside: an update on structural properties, functions, and clinical aspects of the enzyme DPP IV. Crit Rev Clin Lab Sci 40:209-294. https://doi.org/10.1080/713609354

Lauring AS, Andino R (2010) Quasispecies theory and the behavior of RNA viruses. PLoS Pathog 6:e1001005. https://doi.org/10.1371/journal.ppat.1001005

Le Blanc K, Mougiakakos D (2012) Multipotent mesenchymal stromal cells and the innate immune system. Nat Rev Immunol 12:383-396

Le Blanc K, Tammik L, Sundberg B, Haynesworth S, Ringden O (2003) Mesenchymal stem cells inhibit and stimulate mixed lymphocyte cultures and mitogenic responses independently of the major histocompatibility complex. Scand J Immunol 57:11-20

Le Blanc K, Rasmusson I, Sundberg B, Götherström C, Hassan M, Uzunel M, Ringdén O (2004) Treatment of severe acute graft-versus-host disease with third party haploidentical mesenchymal stem cells. Lancet 363:1439-1441. https:// doi.org/10.1016/s0140-6736(04)16104-7

Lee JW, Fang X, Gupta N, Serikov V, Matthay MA (2009) Allogeneic human mesenchymal stem cells for treatment of E. coli endotoxin-induced acute lung injury in the ex vivo perfused human lung. Proc Natl Acad Sci USA 106:16357-16362. https://doi.org/10.1073/pnas. 0907996106

Leng $\mathrm{Z}$ et al (2020) Transplantation of ACE2-mesenchymal stem cells improves the outcome of patients with COVID19 pneumonia. Aging Dis 11:216

Leung C (2020) The difference in the incubation period of 2019 novel coronavirus (SARS-CoV-2) infection between travelers to Hubei and non-travelers: the need of a longer quarantine period. Infect Control Hosp Epidemiol 41:1-8. https://doi.org/10.1017/ice.2020.81

Li Y-P et al (2008) Human mesenchymal stem cells license adult CD34+ hemopoietic progenitor cells to differentiate into regulatory dendritic cells through activation of the Notch pathway. J Immunol 180:1598-1608

Li W et al (2012) Mesenchymal stem cells: a double-edged sword in regulating immune responses. Cell Death Differ 19:1505-1513. https://doi.org/10.1038/cdd.2012.26

Li Q et al (2020a) Early transmission dynamics in Wuhan, China, of novel coronavirus-infected pneumonia. N Engl J Med 382:1199-1207. https://doi.org/10.1056/ NEJMoa2001316

Li X, Zai J, Zhao Q, Nie Q, Li Y, Foley BT, Chaillon A (2020b) Evolutionary history, potential intermediate animal host, and cross-species analyses of SARS-CoV-2. J Med Virol. https://doi.org/10.1002/jmv.25731

Liang B et al (2020) Clinical remission of a critically ill COVID19 patient treated by human umbilical cord mesenchymal stem cells. ChinaXiv

Lin X, Gong Z (2020) Novel coronavirus pneumonia outbreak in 2019: computed tomographic findings in two cases. Korean J Radiol 21:365-368. https://doi.org/10.3348/kjr.2020. 0078

Lipsitch M, Swerdlow DL, Finelli L (2020) Defining the epidemiology of covid-19 - studies needed. N Engl J Med 382:1194-1196. https://doi.org/10.1056/NEJMp2002125

Livák F, Tourigny M, Schatz DG, Petrie HT (1999) Characterization of TCR gene rearrangements during adult murine T cell development. J Immunol 162:2575-2580 
Lu Y, Liu J, Liu Y, Qin Y, Luo Q, Wang Q, Duan H (2015) TLR4 plays a crucial role in MSC-induced inhibition of NK cell function. Biochem Biophys Res Commun 464:541-547

Lu R et al (2020) Genomic characterisation and epidemiology of 2019 novel coronavirus: implications for virus origins and receptor binding. Lancet (London, England) 395:565-574. https://doi.org/10.1016/s0140-6736(20)30251-8

Luk HKH, Li X, Fung J, Lau SKP, Woo PCY (2019) Molecular epidemiology, evolution and phylogeny of SARS coronavirus. Infect Genet Evol 71:21-30. https://doi.org/10. 1016/j.meegid.2019.03.001

Luz-Crawford P et al (2013) Mesenchymal stem cells generate a CD4+ CD25+ Foxp3+ regulatory T cell population during the differentiation process of Th1 and Th17 cells. Stem Cell Res Ther 4:65

Maffioli E et al (2017) Proteomic analysis of the secretome of human bone marrow-derived mesenchymal stem cells primed by pro-inflammatory cytokines. J Proteomics 166:115-126. https://doi.org/10.1016/j.jprot.2017.07.012

Malainou C, Herold S (2019) [Influenza] Der Internist 60:1127-1135. https://doi.org/10.1007/s00108-01900670-6

McVey M, Tabuchi A, Kuebler WM (2012) Microparticles and acute lung injury. Am J Physiology 303:L364-L381

Melief SM, Schrama E, Brugman MH, Tiemessen MM, Hoogduijn MJ, Fibbe WE, Roelofs H (2013a) Multipotent stromal cells induce human regulatory $\mathrm{T}$ cells through a novel pathway involving skewing of monocytes toward anti-inflammatory macrophages. Stem Cells (Dayton, Ohio) 31:1980-1991

Melief SM, Zwaginga JJ, Fibbe WE, Roelofs H (2013b) Adipose tissue-derived multipotent stromal cells have a higher immunomodulatory capacity than their bone marrowderived counterparts. Stem Cells Transl Med 2:455-463. https://doi.org/10.5966/sctm.2012-0184

Mohamed-Ahmed S, Fristad I, Lie SA, Suliman S, Mustafa K, Vindenes H, Idris SB (2018) Adipose-derived and bone marrow mesenchymal stem cells: a donor-matched comparison. Stem Cell Res Ther 9:168

Moll G et al (2019) Intravascular mesenchymal stromal/stem cell therapy product diversification: time for new clinical guidelines. Trends Mol Med 25:149-163

Moll G, Drzeniek N, Kamhieh-Milz J, Geissler S, Volk H-D, Reinke P (2020) MSC therapies for COVID-19: importance of patient coagulopathy, thromboprophylaxis, cell product quality and mode of delivery for treatment safety and efficacy. Front Immunol 11:1091

Monsel A et al (2015) Therapeutic effects of human mesenchymal stem cell-derived microvesicles in severe pneumonia in mice. Am J Respir Crit Care Med 192:324-336

Munir H, Luu N-T, Clarke LS, Nash GB, McGettrick HM (2016) Comparative ability of mesenchymal stromal cells from different tissues to limit neutrophil recruitment to inflamed endothelium. PLoS ONE 11:e0155161

Murdoch DR, French NP (2020) COVID-19: another infectious disease emerging at the animal-human interface. N Z Med J 133:12-15
Nagamura-Inoue T, He H (2014) Umbilical cord-derived mesenchymal stem cells: their advantages and potential clinical utility. World Journal Stem Cells 6:195

Najar M, Raicevic G, Fayyad-Kazan H, Bron D, Toungouz M, Lagneaux L (2016) Mesenchymal stromal cells and immunomodulation: a gathering of regulatory immune cells. Cytotherapy 18:160-171. https://doi.org/10.1016/j. jcyt.2015.10.011

Nauta AJ, Fibbe WE (2007) Immunomodulatory properties of mesenchymal stromal cells. Blood 110:3499-3506. https:// doi.org/10.1182/blood-2007-02-069716

Nauta AJ, Kruisselbrink AB, Lurvink E, Willemze R, Fibbe WE (2006) Mesenchymal stem cells inhibit generation and function of both CD34+-derived and monocyte-derived dendritic cells. J Immunol 177:2080-2087

Nemeth K et al (2012) Characterization and function of histamine receptors in human bone marrow stromal cells. Stem Cells (Dayton, Ohio) 30:222-231

Noone C, Kihm A, English K, O'Dea S, Mahon BP (2013) IFN$\gamma$ stimulated human umbilical-tissue-derived cells potently suppress NK activation and resist NK-mediated cytotoxicity in vitro. Stem Cells Dev 22:3003-3014

Novel CPERE (2020) The epidemiological characteristics of an outbreak of 2019 novel coronavirus diseases (COVID-19) in China. Zhonghua liu xing bing xue za zhi = Zhonghua liuxingbingxue zazhi 41:145

Pan F, Ye T (2020) Time course of lung changes on chest ct during recovery from 2019 novel coronavirus (COVID-19) pneumonia. Radiology. https://doi.org/10.1148/radiol. 2020200370

Park M-J, Kwok S-K, Lee S-H, Kim E-K, Park S-H, Cho M-L (2015) Adipose tissue-derived mesenchymal stem cells induce expansion of interleukin-10-producing regulatory B cells and ameliorate autoimmunity in a murine model of systemic lupus erythematosus. Cell Transplant 24:2367-2377

Paules CI, Marston HD, Fauci AS (2020) Coronavirus infections-more than just the common cold. JAMA. https://doi. org/10.1001/jama.2020.0757

Pejman S, Taylor A (2009) The and allergic disease. Immunology 127:450-458

Pende D et al (1999) Identification and molecular characterization of NKp30, a novel triggering receptor involved in natural cytotoxicity mediated by human natural killer cells. J Exp Med 190:1505-1516

Perdiguero EG, Geissmann F (2016) The development and maintenance of resident macrophages. Nat Immunol 17:2

Perlman S, Netland J (2009) Coronaviruses post-SARS: update on replication and pathogenesis. Nat Rev Microbiol 7:439-450. https://doi.org/10.1038/nrmicro2147

Phan T (2020) Genetic diversity and evolution of SARS-CoV-2. Infect Genet Evol 81:104260. https://doi.org/10.1016/j. meegid.2020.104260

Pieper K, Grimbacher B, Eibel H (2013) B-cell biology and development. J Allergy Clin Immunol 131:959-971

Pittenger MF et al (1999) Multilineage potential of adult human mesenchymal stem cells. Science (New York, NY) 284:143-147. https://doi.org/10.1126/science.284.5411. 143 
Plumas J, Chaperot L, Richard M-J, Molens J-P, Bensa J-C, Favrot M-C (2005) Mesenchymal stem cells induce apoptosis of activated T cells. Leukemia 19:1597-1604

Pollard JW (2004) Tumour-educated macrophages promote tumour progression and metastasis. Nat Rev Cancer 4:71-78. https://doi.org/10.1038/nrc1256

Pourgholaminejad A, Aghdami N, Baharvand H, Moazzeni SM (2016) The effect of pro-inflammatory cytokines on immunophenotype, differentiation capacity and immunomodulatory functions of human mesenchymal stem cells. Cytokine 85:51-60. https://doi.org/10.1016/j. cyto.2016.06.003

Qian H et al (2008) Bone marrow mesenchymal stem cells ameliorate rat acute renal failure by differentiation into renal tubular epithelial-like cells. Int $\mathbf{J}$ Mol Med 22:325-332

Qin C et al (2020) Dysregulation of immune response in patients with COVID-19 in Wuhan, China Clinical Infectious Diseases

Qualls N et al (2017) Community Mitigation Guidelines to Prevent Pandemic Influenza - United States, 2017. MMWR Recomm Rep 66:1-34. https://doi.org/10.15585/mmwr. rr6601a1

Rad F, Ghorbani M, Roushandeh AM, Roudkenar MH (2019) Mesenchymal stem cell-based therapy for autoimmune diseases: emerging roles of extracellular vesicles. Mol Biol Rep 46:1533-1549

Rafei M et al (2008) Mesenchymal stromal cell-derived CCL2 suppresses plasma cell immunoglobulin production via STAT3 inactivation and PAX5 induction. Blood 112:4991-4998

Rasmussen SA, Smulian JC, Lednicky JA, Wen TS, Jamieson DJ (2020) Coronavirus disease 2019 (COVID-19) and pregnancy: what obstetricians need to know. Am J Obstetr Gynecol. https://doi.org/10.1016/j.ajog.2020.02.017

Rawat S, Gupta S, Mohanty S (2019) Mesenchymal stem cells modulate the immune system in developing therapeutic interventions. In: Tyagi R, Bisen PS (eds) Immune response activation and immunomodulation. IntechOpen, London

Ren G et al (2008) Mesenchymal stem cell-mediated immunosuppression occurs via concerted action of chemokines and nitric oxide. Cell Stem Cell 2:141-150

Ren $\mathrm{G}$ et al (2010) Inflammatory cytokine-induced intercellular adhesion molecule-1 and vascular cell adhesion molecule1 in mesenchymal stem cells are critical for immunosuppression. J Immunol (Baltimore, Md: 1950) 184:2321-2328. https://doi.org/10.4049/jimmunol. 0902023

Renner P et al (2009) Mesenchymal stem cells require a sufficient, ongoing immune response to exert their immunosuppressive function. In: Transplantation proceedings, vol 6. Elsevier, pp 2607-2611

Rodriguez HC, Gupta M, Cavazos-Escobar E, El-Amin SF, Gupta A (2020) Umbilical cord: an allogenic tissue for potential treatment of COVID-19. Hum Cell 34:1-13

Rogers CJ et al (2020) Rationale for the clinical use of adiposederived mesenchymal stem cells for COVID-19 patients. J Transl Med 18:1-19

Romieu-Mourez R, François M, Boivin MN, Bouchentouf M, Spaner DE, Galipeau J (2009) Cytokine modulation of
TLR expression and activation in mesenchymal stromal cells leads to a proinflammatory phenotype. J Immunol (Baltimore, Md: 1950) 182:7963-7973. https://doi.org/10. 4049/jimmunol.0803864

Rothe C et al (2020) Transmission of 2019-nCoV infection from an asymptomatic contact in Germany. N Engl J Med 382:970-971. https://doi.org/10.1056/NEJMc2001468

Roudkenar MH et al (2018) Lipocalin 2 enhances mesenchymal stem cell-based cell therapy in acute kidney injury rat model. Cytotechnology 70:103-117. https://doi.org/10. 1007/s10616-017-0107-2

Roushandeh AM, Bahadori M, Roudkenar MH (2017) Mesenchymal stem cell-based therapy as a new horizon for kidney injuries. Arch Med Res 48:133-146. https://doi.org/ 10.1016/j.arcmed.2017.03.007

Sabzevari R, Roushandeh AM, Mehdipour A, Alini M, Roudkenar MH (2020) SA/G hydrogel containing hCAP-18/LL37-engineered WJ-MSCs-derived conditioned medium promoted wound healing in rat model of excision injury. Life Sci 261:118381. https://doi.org/10.1016/j.lfs.2020. 118381

Sahin AR et al (2020) 2019 novel coronavirus (COVID-19) outbreak: a review of the current literature. EJMO 4:1-7

Sairam Atluri M, Vivek Manocha M, Navneet Boddu M, Syed Z, Sudhir Diwan M, Laxmaiah Manchikanti M (2020) Safety and effectiveness of intravascular mesenchymal stem cells to treat organ failure and possible application in covid-19 complications. Pain Phys 23:S391-S420

Schena $F$ et al (2010) Interferon- $\gamma$-dependent inhibition of B cell activation by bone marrow-derived mesenchymal stem cells in a murine model of systemic lupus erythematosus. Arthritis Rheum 62:2776-2786

Schraufstatter IU, Discipio RG, Zhao M, Khaldoyanidi SK (2009) C3a and C5a are chemotactic factors for human mesenchymal stem cells, which cause prolonged ERK1/2 phosphorylation. J Immunol (Baltimore, Md: 1950) 182:3827-3836. https://doi.org/10.4049/jimmunol. 0803055

Scioli MG, Bielli A, Gentile P, Cervelli V, Orlandi A (2017) Combined treatment with platelet-rich plasma and insulin favours chondrogenic and osteogenic differentiation of human adipose-derived stem cells in three-dimensional collagen scaffolds. J Tissue Eng Regen Med 11:2398-2410. https://doi.org/10.1002/term.2139

Sengupta V, Sengupta S, Lazo A, Woods P, Nolan A, Bremer N (2020) Exosomes derived from bone marrow mesenchymal stem cells as treatment for severe COVID-19. Stem Cells Dev 29:747-754

Simon-Loriere E, Holmes EC (2011) Why do RNA viruses recombine? Nat Rev Microbiol 9:617-626. https://doi.org/ 10.1038/nrmicro2614

Sindrilaru A et al (2011) An unrestrained proinflammatory M1 macrophage population induced by iron impairs wound healing in humans and mice. J Clin Investig 121:985-997

Sioud M, Mobergslien A, Boudabous A, Fløisand Y (2010) Evidence for the involvement of galectin-3 in mesenchymal stem cell suppression of allogeneic T-cell proliferation. Scand J Immunol 71:267-274. https://doi.org/10. 1111/j.1365-3083.2010.02378.x 
Sleem A, Saleh F (2020) Mesenchymal stem cells in the fight against viruses: face to face with the invisible enemy. Curr Res Transl Med 68:105

Smith JD, MacDougall CC, Johnstone J, Copes RA, Schwartz B, Garber GE (2016) Effectiveness of N95 respirators versus surgical masks in protecting health care workers from acute respiratory infection: a systematic review and meta-analysis. CMAJ 188:567-574. https://doi.org/10.1503/cmaj. 150835

Son BR et al (2006) Migration of bone marrow and cord blood mesenchymal stem cells in vitro is regulated by stromalderived factor-1-CXCR4 and hepatocyte growth factor-cmet axes and involves matrix metalloproteinases. Stem Cells (Dayton, Ohio) 24:1254-1264

Song HB et al (2018) Mesenchymal stromal cells inhibit inflammatory lymphangiogenesis in the cornea by suppressing macrophage in a TSG-6-dependent manner. Mol Ther 26:162-172

South AM, Shaltout HA, Washburn LK, Hendricks AS (2019) Fetal programming and the angiotensin-(1-7) axis: a review of the experimental and clinical data. Clin Sci 133:55-74. https://doi.org/10.1042/cs20171550

Spaggiari GM, Capobianco A, Abdelrazik H, Becchetti F, Mingari MC, Moretta L (2008) Mesenchymal stem cells inhibit natural killer-cell proliferation, cytotoxicity, and cytokine production: role of indoleamine 2, 3-dioxygenase and prostaglandin E2. Blood 111:1327-1333

Spaggiari GM, Abdelrazik H, Becchetti F, Moretta L (2009) MSCs inhibit monocyte-derived DC maturation and function by selectively interfering with the generation of immature DCs: central role of MSC-derived prostaglandin E2. Blood 113:6576-6583

Sparks MA, Crowley SD, Gurley SB, Mirotsou M, Coffman TM (2014) Classical Renin-Angiotensin system in kidney physiology. Comp Physiol 4:1201-1228. https://doi.org/ 10.1002/cphy.c130040

Strem BM et al (2005) Expression of cardiomyocytic markers on adipose tissue-derived cells in a murine model of acute myocardial injury. Cytotherapy 7:282-291

$\mathrm{Su} \mathrm{J}$ et al (2014a) Phylogenetic distinction of iNOS and IDO function in mesenchymal stem cell-mediated immunosuppression in mammalian species. Cell Death Differ 21:388-396

Su S et al (2016) Epidemiology, Genetic Recombination, and Pathogenesis of Coronaviruses. Trends Microbiol 24:490-502. https://doi.org/10.1016/j.tim.2016.03.003

Sutton MT et al (2016) Antimicrobial properties of mesenchymal stem cells: therapeutic potential for cystic fibrosis infection, and treatment. Stem Cells Int 2016:5303048

Taghavi-farahabadi M, Mahmoudi M, Soudi S, Hashemi SM (2020) Hypothesis for the management and treatment of the COVID-19-induced acute respiratory distress syndrome and lung injury using mesenchymal stem cellderived exosomes. Med Hypotheses 144:109865

Tan JT, Dudl E, Le Roy E, Murray R, Sprent J, Weinberg KI, Surh CD (2001) IL-7 is critical for homeostatic proliferation and survival of naive T cells. Proc Natl Acad Sci USA 98:8732-8737. https://doi.org/10.1073/pnas.161126098

Tay JY et al (2020) De-isolating COVID-19 suspect cases: a continuing challenge. Clin Infect. https://doi.org/10.1093/ $\mathrm{cid} / \mathrm{ciaa} 179$
Taylor CT, Colgan SP (2017) Regulation of immunity and inflammation by hypoxia in immunological niches. Nat Rev Immunol 17:774-785. https://doi.org/10.1038/nri. 2017.103

Theoharides TC, Valent P, Akin C (2015) Mast cells, mastocytosis, and related disorders. N Engl J Med 373:163-172

Thompson BT, Chambers RC, Liu KD (2017) Acute respiratory distress syndrome. N Engl J Med 377:562-572

To KK et al (2020) Consistent detection of 2019 novel coronavirus in saliva. Clin Infect Dis 71:841. https://doi.org/10. 1093/cid/ciaa149

Tran K, Cimon K, Severn M, Pessoa-Silva CL, Conly J (2012) Aerosol generating procedures and risk of transmission of acute respiratory infections to healthcare workers: a systematic review. PLoS ONE 7:e35797. https://doi.org/10. 1371/journal.pone.0035797

Tsukamoto A et al (2016) Challenging regeneration to transform medicine. Stem Cells Transl Med 5:1-7. https://doi.org/10. 5966/sctm.2015-0180

Van Cuong L et al (2020) The first Vietnamese case of COVID19 acquired from China. Lancet Infect Dis 20:408-409. https://doi.org/10.1016/s1473-3099(20)30111-0

Vasandan AB, Jahnavi S, Shashank C, Prasad P, Kumar A, Prasanna SJ (2016) Human mesenchymal stem cells program macrophage plasticity by altering their metabolic status via a PGE 2-dependent mechanism. Sci Rep 6:38308

Vickers NJ (2017) Animal communication: when i'm calling you, will you answer too? Curr Biol 27:R713-R715

von Bahr L et al (2012) Analysis of tissues following mesenchymal stromal cell therapy in humans indicates limited long-term engraftment and no ectopic tissue formation. Stem Cells (Dayton, Ohio) 30:1575-1578. https://doi.org/ 10.1002/stem.1118

Wang H, Chen T, Ding T, Zhu P, Xu X, Yu L, Xie Y (2011) Adipogenic differentiation alters the immunoregulatory property of mesenchymal stem cells through BAFF secretion. Hematology (Amsterdam, Netherlands) 16:313-323. $102453311 \times 13085644679944$

Wang Y, Chen X, Cao W, Shi Y (2014) Plasticity of mesenchymal stem cells in immunomodulation: pathological and therapeutic implications. Nat Immunol 15:1009-1016. https://doi.org/10.1038/ni.3002

Wang D et al (2020) Clinical characteristics of 138 hospitalized patients with 2019 novel coronavirus-infected pneumonia in Wuhan, China. JAMA. https://doi.org/10.1001/jama. 2020.1585

Ware LB, Matthay MA (2001) Alveolar fluid clearance is impaired in the majority of patients with acute lung injury and the acute respiratory distress syndrome. Am J Respir Crit Care Med 163:1376-1383

Wenjie T (2019) A novel coronavirus genome identified in a cluster of pneumonia cases-wuhan China. China CDC Wkly 2020:61-62

Wong CK et al (2004) Plasma inflammatory cytokines and chemokines in severe acute respiratory syndrome. Clin Exp Immunol 136:95-103. https://doi.org/10.1111/j.13652249.2004.02415.x

Wong JEL, Leo YS, Tan CC (2020) COVID-19 in Singaporecurrent experience: critical global issues that require 
attention and action. JAMA. https://doi.org/10.1001/jama. 2020.2467

Wu Z, McGoogan JM (2020) Characteristics of and important lessons from the coronavirus disease 2019 (COVID-19) outbreak in China: summary of a report of 72314 cases from the chinese center for disease control and prevention. JAMA. https://doi.org/10.1001/jama.2020.2648

Xiao K, Hou F, Huang X, Li B, Qian ZR, Xie L (2020) Mesenchymal stem cells: current clinical progress in ARDS and COVID-19. Stem Cell Res Ther 11:1-7

Xu N, Shao Y, Ye K, Qu Y, Memet O, He D, Shen J (2019) Mesenchymal stem cell-derived exosomes attenuate phosgene-induced acute lung injury in rats. Inhal Toxicol 31:52-60

Xu Z et al (2020) Pathological findings of COVID-19 associated with acute respiratory distress syndrome. Lancet Respir Med. https://doi.org/10.1016/s2213-2600(20)30076-x

$\mathrm{Xu} \mathrm{X}$ et al (2020) Evolution of the novel coronavirus from the ongoing Wuhan outbreak and modeling of its spike protein for risk of human transmission Science China. Life Sci 63:457-460. https://doi.org/10.1007/s11427-020-1637-5

Yao X et al (2020) In vitro antiviral activity and projection of optimized dosing design of hydroxychloroquine for the treatment of severe acute respiratory syndrome coronavirus 2 (SARS-CoV-2). Clin Infect Dis. https://doi.org/10.1093/ $\mathrm{cid} / \mathrm{ciaa} 237$

Yu F, Du L, Ojcius DM, Pan C, Jiang S (2020) Measures for diagnosing and treating infections by a novel coronavirus responsible for a pneumonia outbreak originating in Wuhan, China. Microbes Infect 22:74-79. https://doi.org/ 10.1016/j.micinf.2020.01.003
Zhang Y et al (2014) Mesenchymal stem cells alleviate bacteriainduced liver injury in mice by inducing regulatory dendritic cells. Hepatology 59:671-682

Zhang L, Li Q, Liu W, Liu Z, Shen H, Zhao M (2019) Mesenchymal stem cells alleviate acute lung injury and inflammatory responses induced by paraquat poisoning. Med Sci Monit 25:2623

Zhang T, Wu Q, Zhang Z (2020) Probable pangolin origin of SARS-CoV-2 associated with the COVID-19 outbreak. Curr Biol. https://doi.org/10.1016/j.cub.2020.03.022

Zhang J, Xie B, Hashimoto K (2020a) Current status of potential therapeutic candidates for the COVID-19 crisis. Brain Behav Immunity

Zhou P et al (2020a) Discovery of a novel coronavirus associated with the recent pneumonia outbreak in humans and its potential bat origin. BioRxiv

Zhou P et al (2020) A pneumonia outbreak associated with a new coronavirus of probable bat origin. Nature 579:270-273. https://doi.org/10.1038/s41586-020-2012-7

Zhu Y et al (2014) Human mesenchymal stem cell microvesicles for treatment of Escherichia coli endotoxin-induced acute lung injury in mice. Stem Cells (Dayton, Ohio) 32:116-125

Zhu N et al(2020) A Novel Coronavirus from Patients with Pneumonia in China, 2019. N Engl J Med 382:727-733. https://doi.org/10.1056/NEJMoa2001017

Publisher's Note Springer Nature remains neutral with regard to jurisdictional claims in published maps and institutional affiliations. 